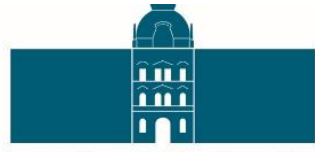

University of Maribor Press

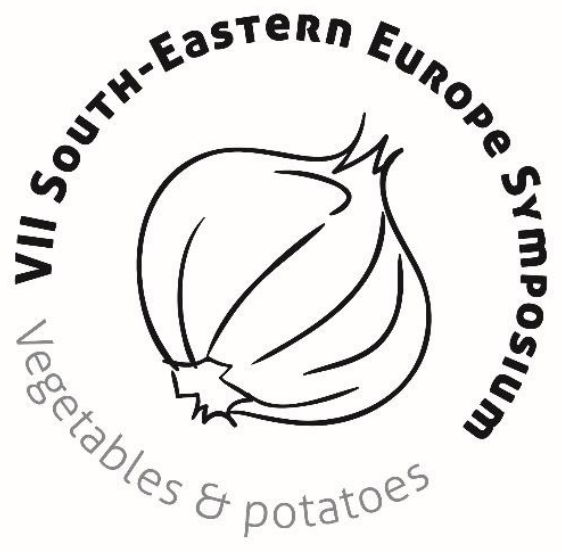





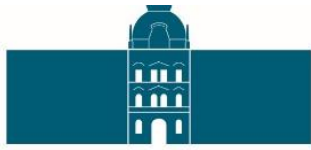

University of Maribor Press

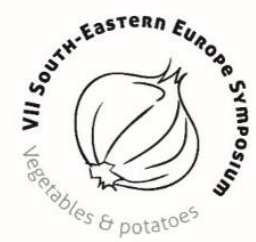

\title{
Book Of Abstracts
}

\section{South-Eastern Europe Syposium on Vegetables \& Potatoes}

\author{
June 20 - 23, 2017, Maribor, Slovenia
}

\section{Editors:}

dr. Martina Bavec

dr. Franc Bavec

dr. Silva Grobelnik Mlakar 
Title: Book Of Abstracts VII South-Eastern Europe Syposium on Vegetables \& Potatoes (June 20 23, 2017, Maribor, Slovenia)

Editors: full prof. Martina Bavec, Ph.D. (University of Maribor, Faculty of Agriculture and Life Sciences), full prof. Franc Bavec, Ph.D. (University of Maribor, Faculty of Agriculture and Life Sciences), assist. prof. Silva Grobelnik Mlakar, Ph.D. (University of Maribor, Faculty of Agriculture and Life Sciences).

Layout: Tjaša Vukmanič and Urška Lisec

Design and layout: Dinocolor d.o.o.

First published in 2017 by:

University of Maribor Press

Slomškov trg 15, 2000 Maribor, Slovenia

tel. +38622504242, faks +38622523245

http://press.um.si, zalozba@um.si

\section{Co-published by}

Faculty of Agriculture and Life Sciences

Pivola 10, 2311 Hoče, Slovenia

tel. +386232090 00, faks +38626161158

http://www.fkbv.um.si, fkbv@um.si

Print by: PIK-REPNIK, STORITVE D.O.O.

Number of copies: 149

Published: $\quad$ 16. june 2017

\section{(๑) University of Maribor Press}

All rights reserved. No part of this book may be reprinted or reproduced or utilized in any form or by any electronic, mechanical, or other means, now known or hereafter invented, including photocopying and recording, or in any information storage or retrieval system, without permission in writing from the publisher.

Book of Abstracts is made in accordance with the rules of ISHS.

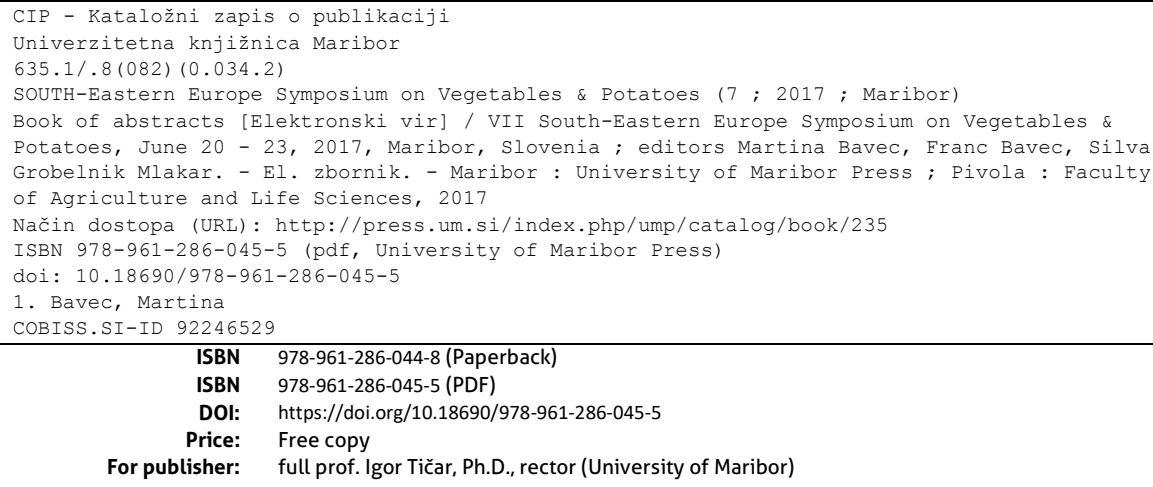


International Society for Horticultural Science (ISHS)

And

University of Maribor, Faculty of Agriculture and Life Sciences
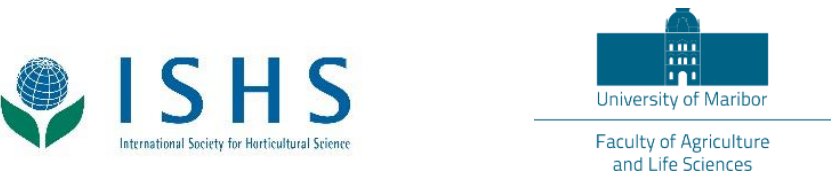

In collaboration with:

Food and Agriculture Organization of the United Nations (FAO)

Slovenian Ministry of Agriculture, Forestry and Food

Slovenian Association for the integrated vegetable production

RURAL

DEVELOPMENT

PROGRAMME
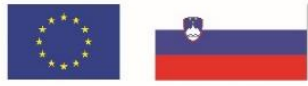

The European Agricultural furd for Rual Development: Europe investirg in rural arces

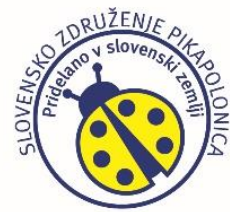

REPUBLIKA SLOVENIJA

MINISTRSTVO ZA KMETIJSTVO, GOZDARSTVO IN PREHRANO 


\section{Honorary committee}

Mr. Dejan Židan, M. Sc., Minister of Ministry of Agriculture, Forestry and Food Republic of Slovenia

Mrs. Tanja Strniša, M. Sc., State Secretary of Ministry of Agriculture, Forestry and Food, Republic of Slovenia

Mrs. Silvana Nicola, Ph.D., Prof., Vice Chairperson of International Society for Horticultural Science (ISHS), University of Torino, Italy

Mr. Avetik Nersisyan, Food and Agriculture Organization of the United Nations (FAO) Plant Production and Protection Division, Roma, Italy

Mr. Stanko Volk, Chairperson of Slovene Association for Integrated Production of Vegetables,

Mr. Andrej Fištravec, Ph.D., Major of City of Maribor

Mr. Branko Kramberger, Ph.D., Prof., Dean of the Faculty of Agriculture and Life Sciences 


\section{Convener}

Prof. Dr. Martina Bavec, Slovenia

\section{Scientific committee}

President of Scientific Committee

Prof. Dr. Franc Bavec, Slovenia

\section{Members of Scientific Committee}

Prof. Dr. Martina Bavec, Slovenia

Mag. Martina Robačer, Slovenia

Assist. Prof. Dr. Silva Groblenik Mlakar, Slovenia

Dr. Wilfried Baudoin, Italy

Assist. Prof. Dr. Božidar Benko, Croatia

Dr. Peter Dolničar, Slovenia

Prof. Dr. Zoran Ilić, Serbia

Prof. Dr. Žarko M. Ilin, Serbia

Prof. Dr. Maja Manojlović, Serbia

Assist. Prof. Dr. Nina Kacjan Maršić, Slovenia

Prof. Dr. Nataša Mirecki, Montenegro

Prof. Dr. Ewa Rembiałkowska, Poland

Dr. Zdravko Matotan, Croatia

Assist. Prof. Dr. Ana Slatnar, Slovenia

Dr. Kristina Ugrinović, Slovenia

Dr. Nazim Gruda, Germany

Prof. Dr. Dimitrios Savvas, Greece

Dr. Georgia Ntatsi, Greece

Dr. Astrit Balliu, Albania

Assist. Prof. Dr. Johannes Balas, Austria

Prof. Dr. Yüksel Tuzel, Turkey 


\title{
Organizing Committee
}

From University of Maribor Faculty of Agriculture and Life Sciences Chair of Organic Agriculture, Field Crops, Vegetable and Ornamental Plants Pivola 10, 2311 Hoče/Maribor, Slovenia:

\author{
Prof. Dr. Martina Bavec \\ Tjaša Vukmanič \\ Mag. Martina Robačer \\ Doc. Dr. Silva Groblenik Mlakar \\ Mag. Manfred Jakop \\ Prof. Dr. Franc Bavec \\ Urška Lisec
}

From Congress organizing company Galileo 3000

Tomaž Eisenhut 


\section{CONTENTS}

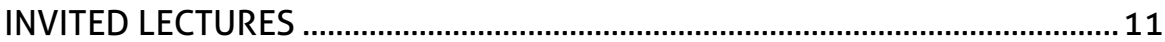

PRODUCTION SYSTEMS AND OUALITY OF VEGETABLES \& POTATOES ........17

ORGANIC VEGETABLES \& POTATOES PRODUCTION........................................31

SHORT SUPPLY CHAINS AND OTHER CONCEPTS OF VEGETABLES \& POTATOES MARKETING ……………………………………………………... 41

PROTECTED CULTIVATION AND GAP OF GREENHOUSE PRODUCTION ON SMALL FARMS

IRRIGATION AND PLANT-WATER RELATIONS …………………………….......59

GENETIC RESOURCES AND BREEDING …………………………………….....73

POTATO

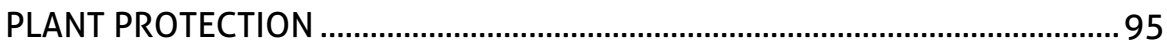

GENERAL AND OTHER TOPICS ………………………………………..... 101

AUTHOR INDEX ............................................................................................... 107 
Dear participants of 7th SEE Symposium on Vegetables and Potatoes (Maribor, 20-23 June 2017),

University of Maribor Faculty of Agriculture and Life Science and the International Society of Horticulture Sciences (ISHS) with the support of Food and Agriculture Organization (FAO) and Slovene Ministry of Agriculture, Food and Forestry (MAFF) have the honor to welcome all engaged in research, development, producers, teaching, extension and public services, suppliers of horticulture materials, cooperatives, private sector and stakeholders related to vegetable and potatoes production to attend the 7th South East European (former Balkan) Symposium on vegetables and potatoes.

The Symposium is held in Maribor (university city and in 2012 European culture capital) in the north East of Slovenia from where comes the majority of agriculture products including vegetables as along the river Drava several irrigation systems were established. Long tradition of vegetable production for processing industry in the past and for fresh market in the last period, encouraged Slovene Association for integrated vegetable production established in the year 2000, to prepare all procedures for the first vegetable crop with the origin of denomination "Ptujski lük" which was approved on the European level on 2011.

Two days of symposium from 20th to 23rd of June 2017 have scientific programme with additional FAO workshop on GAP for Greenhouse Production on small farms in SEE with the presentation of a new manual printed by FAO in 2017, ISHS meeting and special session about possibilities for networking among researchers in the future. Scientific programme is covering topics: Production systems and quality of V\&P, Organic V\&P production, Short supply chains and other concepts of V\&P marketing, Protected cultivation and GAP of greenhouse production on small farms, Biodiversity, Irrigation and plant water relations, Genetic resources and breeding, Potato, Plant protection, General and other topics.

On the 22 nd of June 2017 a side event for vegetable and potatoes growers, advisors, technical workers and other professional public titled "Some important facts for improving greenhouse vegetable production" will take place. Under support of FAO and MAFF ten distinguished professionalists will present the most important topics for successful greenhouse vegetable production with the goal to give also Slovene growers and professional public insights in novel research findings and recommendations for improvements.

Last day is field trip to growers where different production methods (from biodynamic organic to integrated and soilless, Global GAP) and different marketing strategies (direct selling, CSA, protected origin products, establishing non formal cooperation's and supplying to big chains) are presented with the aim to exchange ideas and knowledge among participants and growers from Podravje region.

We hope that you will have a nice time in Slovenia and enjoy your stay with us - a team from Chair of Organic Agriculture, Field Crops, Vegetable and Ornamental Plants University of Maribor Faculty of Agriculture and Life Science.

Prof. Dr. Martina Bavec, Convener 


\section{INVITED LECTURES}

-11- 


\title{
Quality of Vegetables and Potatoes from the Organic Production
}

\author{
Ewa Rembialkowska1*, Stanislaw Kaniszewski² \\ ${ }^{1}$ Warsaw University of Life Sciences, Faculty of Human Nutrition and Consumer Sciences, \\ Division of Organic Food, Nowoursynowska 166, 02-787 Warsaw, Poland \\ * e-mail: ewa rembialkowska@sggw.pl \\ ${ }^{2}$ Research Institute of Vegetable Crops, ul. Konstytucji 3, Maja 1/3, 96-100 Skierniewice, \\ Poland
}

Keywords: vegetables, potatoes, organic, nutritional value, harmful substances

Organic production evolves quickly across the whole world. According to current data the world organic agricultural land in 2014 was 43.7 million hectares (in 1999 - 11 million hectares). At the end of 2014 in Europe 11.6 million hectares of agricultural land were cultivated organically by almost 340000 producers; 2.,4 percent of the agricultural area was organic, what creates $27 \%$ of the organic land in the world. Organic agriculture in Europe is founded on the legal frame - Council Regulation (EC) No. 834/2007 of 28 June 2007 on organic production and labelling of organic products and repealing Regulation (EEC) No. 2092/91 and Commission Regulation (EC) No. 889/2008 laying down detailed rules for the implementation of Council Regulation (EC) No. 834/2007 on organic production and labelling of organic products with regard to organic production, labelling and control.

According to many studies, vegetables and potatoes produced in the organic way have higher nutritional value compared to the conventional ones. They contain less residues of harmful pesticides and nitrates / nitrites than the conventional crops. The level of mycotoxins and bacteria is similar in the organic and conventional crops. Organic crops contain more bioactive compounds as vitamins and polyphenols than their conventional counterparts, also more nutrients such as copper, boron, zinc, phosphorus, potassium, magnesium and iron. The level of sugars and organic acids is also higher in the organic vs. conventional crops. All these compounds play a key role in human health, providing a protection against many diseases.

The main reason of the above distinction is a different system of fertilization and plant protection in the organic vs. conventional system; especially important is not only a dose but also a form of the nitrogen fertilizer used in the plant production. According to GDBH theory, the plants fertilized with the organic manure direct their metabolism more into differentiation - they produce a wider range of different bio compounds. The plants manured with the synthetic nitrogen fertilizers direct their metabolism more into growth they achieve higher biomass = yield, but they contain lower concentrations of the profitable bio compounds.

To summarize - organic vegetables and potatoes should be promoted among the consumers because of their high nutritional properties. 


\section{Specifics of vegetable production for processing}

\section{Zdravko Matotan*}

Podravka d.d., Ante Starčevića 32, Koprivnica 48000, Croatia

* e-mail: zdravko.matotan@podravka.hr

Keywords: vegetables, processing, trends, market, South East Europe

The production of vegetables for processing in relation to production for fresh consumption is characterized by a series of specifics. One of them is a variety that needs to meet the standards of the processing industry, and need to be highly yielded and suitable for mechanized harvesting. Vegetables for processing are almost exclusively grown outdoors, on acreages large enough to rational use of modern mechanization, especially for harvesting. Also production is organized close to processing facilities in the period of the year in which, with the limited additional investments, it can achieve satisfactory yields of the prescribed quality. Achieved prices of vegetables for processing are significantly lower than those for fresh consumption so agrotechnical measures need to be carried out very rationally for production to be profitable. In the South East Europe, the majority of vegetables is processed by freezing, pasteurization, sterilization and concentration, and a small amount by drying. In the last two decades, the production of vegetables for processing in the South East Europe has undergone significant transformations. Due to the increase of fresh vegetables availability throughout the year distributed by modern chain stores, consumption of most processed vegetables in the region is declining. A lot of processing facilities were closed and the export of processed vegetables from the region was significantly reduced. The production of processing vegetables whose harvesting can not be mechanized is moved from to the regions with the lower cost of human labour and the export of processed vegetables is replaced by the export of raw materials. Regional decreasing in production is evident for vegetables for processing by sterilization and pasteurization, while the production of vegetables processed by drying is very small. The quantities of vegetables for freezing are constant with a slightly increasing trend, while production of vegetable for a higher level of finalization, such as condiments, is growing up. In line with existing trends in the consumption of processed vegetables that will surely continue, in order to improve the production of processing vegetables in the region, it is necessary to align its structure with market needs, modernize processing facilities and improve the agrotechnical measures. 


\title{
Origin and production method traceability of vegetables with stable isotopes - from science to practice
}

\author{
Sonja Lojen ${ }^{1 *}$, Anja Mahne Opatič ${ }^{1}$, Nina Kacjan Maršić ${ }^{2}$, Rajko Vidrih $^{3}$, Marijan Nečemer ${ }^{1}$ \\ 1Jozef Stefan Institute, Jamova cesta 39, 1000 Ljubljana, Slovenia \\ * e-mail: sonja.lojen@ijs.si \\ 2University of Ljubljana, Biotechnical Faculty, Department of Agronomy, Jamnikarjeva 101, \\ 1000 Ljubljana, Slovenia \\ ${ }^{3}$ University of Ljubljana, Biotechnical Faculty, Department of Food Science and Technology, \\ Jamnikarjeva 101, 1000 Ljubljana, Slovenia
}

Keywords: stable isotopes, vegetable, geographic origin, traceability

Since large amounts of food are globally exchanged and transported on a daily basis, increased public attention is paid to the identification and certification of the geographical provenance and the production regime. For many consumers knowing the geographical origin and/or if the product is organically grown, represents an assurance for products' quality and safety. Moreover, it is important for producers to define the authenticity of products in terms of geographical origin and production regime in order to maintain the credibility of food industry. Techniques used for discrimination of foods with respect to their geographical origins have mostly included isotopic compositions of light elements $(\delta 2 \mathrm{H}$, $\delta 13 \mathrm{C}, \delta 180, \delta 34 \mathrm{~S})$ and strontium isotope ratios $(87 \mathrm{Sr} / 86 \mathrm{Sr})$, either independently or in combination with other techniques (e.g. elemental composition analysis). The application of measuring stable isotopes is justified because they are influenced by various region-specific factors, such as climatic and geographical conditions and thus represent a promising tool for the determination of the geographical origin of plant products. Hydrogen and oxygen stable isotopes are fractionated due to climatic conditions and geographical location, namely lower values of $\delta 2 \mathrm{H}$ and $\delta 180$ coincide with colder climate, larger distance from the sea and higher altitude and latitude. $\delta 13 \mathrm{C}$ values are strongly related to the photosynthetic pathway (C3, C4 and CAM), otherwise, they can be also influenced by environmental conditions such as drought, low temperatures, atmospheric pressure and ozone stress. $\delta 34 S$ values are linked to the sea-spray effect, soil geology and pollution. On the other hand, nitrogen isotopic fingerprint $(\delta 15 N)$ in vegetables can be used as a rough marker for differentiating the production regime (conventional vs. organic), reflecting higher $\delta 15 \mathrm{~N}$ values in vegetables grown under organic production system compared to conventional. However, better discrimination among various types of production regimes can be achieved in combination with other parameters (e.g. elemental content, morphological parameters, physicochemical and biochemical parameters etc...). 


\section{Protected Vegetables in South-East Europe}

\section{Nazim Gruda*,}

University of Bonn, Faculty of Agriculture, Meckenheimer Allee 174 D-53115 Bonn, Germany

* e-mail: ngruda@uni-bonn.de

Keywords: greenhouse, SEE, vegetable production, Good Agricultural Practices, sustainable vegetables

In the recent past, the production of protected crops in South East Europe has been continuously increasing. The main reasons are the good Mediterranean climate conditions in coast areas and consumer preferences for a local product in continental areas, even though these products are out of season. These systems allow an early and prolonged production time, which is economically attractive for growers. Vegetable growers use a spectrum of structures, depending on the crop, climatic region, anticipated benefit and investment potential. This contribution outlines the current situation of protected cultivation in South-Eastern-European countries. Based on an over spanning regional survey, we present the development of protected system facilities and vegetable technology. Finally, we briefly discuss some future challenges. Yet, some room for improvement remains especially with regard to the adoption of Good Agricultural Practices. Hence, the FAOWorking-Group for Protected Cultivation in South East Europe wrote a manual, which covers the most important topics and crop technologies. We hope that the recommendations outlined in this manual will affect future governmental policy and serve as guidelines for growers in this region. 
$-16-$ 
PRODUCTION SYSTEMS AND QUALITY OF VEGETABLES \& POTATOES 


\title{
Impact of plant density on capsaicinoid production of high pungent pepper (Capsicum chinense Jacq.) under control house
}

\author{
Suchila Techawongstien ${ }^{1 *}$, Nakarin Jeeatid ${ }^{1}$, Sungcom Techawongstien ${ }^{1}$, Saksit Chanthai ${ }^{2}$ \\ ${ }^{1}$ Khon Kaen University, Faculty of Agriculture, Department of Horticulture, Khon Kaen \\ 40002, Thailand \\ * e-mail: suctec@kku.ac.th \\ ${ }^{2}$ Khon Kaen University, Faculty of Science, Department of Chemistry, Khon Kaen 40002, \\ Thailand
}

Keywords: capsaicin, dihydrocapsaicin, pungency, plant spacing

Due to the climate change, control house should be adopted in modern agriculture to ensure maximum fruit yield per unit area. Therefore, to maximized capsaicinoid yield per unit area, two hot pepper cultivars which belong to Capsicum chinense Jacq., 'Bhut Jolokia' and 'Akanee Pirote' (F1-hybrid) were grown under control house condition to determine the effect of three plant densities, i.e. low, medium and high (11000, 15000 and 18324 plants per ha, respectively) on their yield, pungency, and capsaicinoid yield. 'Akanee Pirote' cultivar showed the highest fruit number per plant (265 fruit) and dry fruit yield per plant (174.96 $\mathrm{g} /$ plant) at low plant density. However, the highest fruit number per area and dry fruit yield per area were obtained in 'Akanee Pirote' (2,963.6 g/plant) at high plant density. Plant density had no effects on the capsaicin, dihydrocapsaicin, and capsaicinoid content. Between cultivars, 'Bhut Jolokia' gave higher capsaicinoid content (1,229,993 SHU) than 'Akanee Pirote' (665,129 SHU). Additionally, the highest capsaicinoid yield was found in 'Akanee Pirote' at high plant density (103.98 g/ha). Therefore, the density of 18324 plants per ha might be the appropriate plant density of high pungency cultivars for capsaicin extraction industries. 


\section{Contamination of aflatoxin in dried chili products during storage in Thailand}

Sungcom Techawongstien*, Suchila Techawongstien

Khon Kaen University, Faculty of Agriculture, Department of Horticulture, Khon Kaen 40002, Thailand

* e-mail: suntec@kku.ac.th

Keywords: KKU\#2 chilli, sodium hypochloride, pungency, capsaicinoids, mycotoxin, Aspergillus flavus

Dried chili fruit and dried chili powder are significantly important spice for Thai cuisine. However, aflatoxin contamination is the major problem of dried chili products in Thailand. The contamination of aflatoxin in dried chili product needs to be investigated in particular during storage. The experiment was laid in Factorial in RCBD design with 2 chili cultivars and 4 concentrations of chemical solution. The experiment was carried out during October 2015 to July 2016. Fresh chili fruits, 'KKU\#2', the improved cultivar of the Plant Breeding Research Center for Sustainable Agriculture KKU, and 'Super Hot', the commercial cultivar of East West Seeds Co., Ltd., were harvested at ripe mature stage. One thousand grams of fresh fruit were soaking in 5 litre of commercial bleach solution, sodium hypochloride $(\mathrm{NaOCl}), 0$ (control treatment), 500, 1,000 and 2,000 mg/L for $10 \mathrm{~min}$, rinsed with running water for $10 \mathrm{~min}$ then soaking in boiling water $\left(100^{\circ} \mathrm{C}\right)$ for $2 \mathrm{~min}$. The treated fruits were sun-dried and oven-dried at $80^{\circ} \mathrm{C}$ thereafter. Dried chili products, either dried fruits or dried powder, were stored in plastic bag at room temperature for 9 months. Aflatoxin and pungency, as well as color of dried products were determined every 3 months. The result showed that chemical solution plus boiling water treatment neither affect on the colour and pungency of the products, nor eliminate the contamination of aflatoxin. Increment of aflatoxin contamination was found during storage in both chili products and especially that the contamination reached beyond safety level (20 ppb) after 3 month of storage. 


\section{Mineral profile of lettuce and green onion}

Zoran Ilić ${ }^{1 *}$, Nikolaos Kapoulas², Athanasios Koukounaras³ ${ }^{3}$ Nataša Mirecki ${ }^{4}$

${ }^{1}$ University of Kosovska Mitrovica, Faculty of Agriculture Pristina-Lesak, Kopaoniska bb, 38219 Lesak, Serbia

*e-mail: zoran.ilic63@gmail.com

${ }^{2}$ Regional Development Agency of Rodopi , 69100 Komotini, Greece

${ }^{3}$ Aristotle of University Thessaloniki, Faculty of Agriculture, Thessaloniki, Greece

${ }^{4}$ University of Monten, Biotechnical Faculty, Podgorica, Montenegro

Keywords: lettuce, minerals, organic production, conventional, growing season

The purpose of this study was to examine the effect of production systems - (organic-ORG or conventional-CONV) and growing season (autumn or spring) of cos lettuce (Lactuca sativa L. var. longifoila cv. 'Parris Island') and green onion (Allium cepa cv. 'Sturon') as intercropping system, have been tested in greenhouse production (plastic tunnels $3.5 \mathrm{~m}$ high, covered by termolux $180 \mu$ ) located in the Sapes, Nort-Eastern Greece during 2015 to 2016. Determinations of $\mathrm{P}, \mathrm{K}, \mathrm{Ca}, \mathrm{Mg}$, $\mathrm{Fe}, \mathrm{Cu}, \mathrm{Mn}$ and $\mathrm{Zn}$ was done by dry ashing at 580 oC for $16-18 \mathrm{~h}$, dissolving the ash in $6 \mathrm{~N} \mathrm{HCl}$ and assaying the solution obtained by inductively coupled plasma-optical emission spectroscopy using a Perkin Elmer Model Optima 5100 DV spectrometer (Shelton, CT). The total N contents of the lettuce leaves were not significantly influenced by the time of production in both CONV and ORG production system. In general, the total $\mathrm{N}$ and $\mathrm{P}$ content of lettuce and green onion in ORG production systems was higher than in the CONV production system. Fall-winter production had highest total $\mathrm{N}$ and $\mathrm{P}$ content compared with the spring production times in both production system. The total $\mathrm{K}, \mathrm{Ca}$ and $\mathrm{Mg}$ contents of the green onion grown under ORG production systems was higher in comparation with CONV production. The results showed that $\mathrm{K}$ contents of green onion obtained higher value from fall-winter than in spring-summer production times. $\mathrm{Ca}$ and $\mathrm{Mg}$ accumulated more in spring-summer production times. $\mathrm{Zn}$ are common constituents of animal feed supplements and a possible explanation for the higher concentrations of $\mathrm{Zn}$ in the organic samples (lettuce and green onion) is that the application of manures, more typical of organic cultivation, may act as an additional source of $\mathrm{Zn}$ to the soil and the plants. Lettuce plant in both production system obtained higher content of $\mathrm{K}, \mathrm{B}, \mathrm{Zn}$ and Fe compared to onion. The general order of the mineral content in both plant is $\mathrm{K}>\mathrm{Ca}>\mathrm{Mg}>\mathrm{Fe}>\mathrm{Mn}>\mathrm{B}>\mathrm{Zn}>\mathrm{Cu}$. ORG grown green onion at both production time had higher content of all macro and micro elements (except $\mathrm{Cu}$ ) than the CONV grown ones. The higher copper concentrations found for the CONV green onion and lettuce could be due to residual of copper-based fungicides to help control of blight. Lettuce from CONV systems contains more $\mathrm{Ca}, \mathrm{Mg}, \mathrm{Mn}$, Fe, Cu compared to ORG production. Mineral bio-availability and especially plant-uptake is strongly dependent on the form of the mineral on entering the soil, the physico-chemical properties of the soil, production systems, growing season and crop type. 


\title{
The effect of farming system and variety on the yield, morphometric characteristics and chemical composition of carrot (Daucus carota L.)
}

\author{
Nina Kacjan Maršić ${ }^{1 *}$, Nataša Šink ${ }^{2}$, Maja Mikulič Petkovšek ${ }^{1}$ \\ ${ }^{1}$ University of Ljubljana, Biotechnical Faculty, Jamnikarjeva 101, 1110 Ljubljana, Slovenia \\ * e-mail: nina.kacjan.marsic@bf.uni-lj.si \\ 2Biotechnical Centre Naklo, Strahinj 99, 4202 Naklo, Slovenia
}

Keywords: organic farming system, integrated farming system, carrot (Daucus carota L.), primary metabolites, phenolic acids, carotenoids

Vegetable quality is characterized by the sensory parameters and chemical composition of metabolites which often depends on the genotype, environmental factors and the methods of cultivation. The aim of the study was to evaluate some morphometric characteristics and chemical composition of the yield of three carrot varieties grown in organic and integrated farming system, and on unfertilized control plots. The carrot yield from organic system was higher with all tested varieties compared to the yield from the integrated system, but the differences between them were not statistically significant. Farming system significantly influenced some morphological traits of carrot plants: the height and the weight of the above part plants as well as the characteristics of the carrot roots (mass, length, xylem and floem diameter). Among the metabolites, carrots roots from the organic farming system had significantly higher total organic acids and vitamin $\mathrm{C}$ content at all tested varieties compared to the integrated system and the control plots. Of the organic acids, malic, pyruvic, citric and fumaric acid were detected and all of them were influenced significantly by the varieties. Of the secondary metabolites, the chlorogenic acids was detected as the major phenolic compound, ferulic acid derivative was the second prevailing, followed by 5-pcoumaroylquinic acid and 5-feruloylquinic acid as the minor. Total phenolic acids concentration was higher in organically cultivated carrots than in the integrated system, but the differences were not statistically significant. Farming system and genotype significantly influenced also the content of carotenoids, which resulted in significantly higher $\alpha$ - and $\beta$ carotene content in the roots from the organic and integrated systems, but the differences between them were not statistically significant. Among varieties the higher carotenoids content was detected in the roots of 'Rodelika' and 'Rolanka' compared to the roots of 'Fanal'. 


\section{Summer production of lettuce under shading conditions}

Zoran Ilić ${ }^{*}$, Lidija Milenković1, Ljiljana Stanojević ${ }^{2}$, Aleksandra Dimitrijevićc ${ }^{3}$, Dragan

Cvetković $^{2}$,̌arko Kavresan ${ }^{4}$, Jasna Mastilović ${ }^{4}$

${ }^{1}$ University of Kosovska Mitrovica, Faculty of Agriculture Pristina-Lesak, Kopaoniska bb, 38219 Lesak, Serbia

* e-mail:zoran.ilic63@gmail.com

${ }^{2}$ University of Niš, Faculty of Technology, Leskovac, Serbia

${ }^{3}$ University of Belgrade, Faculty of Agriculture, Nemanjina 6, 11080 Zemun, Serbia

${ }^{4}$ Institute of Food Technology, University of Novi Sad, 21000 Novi Sad, Serbia

Keywords: colour shade nets, lettuce, summer production, yield, physiological disorders, quality

Production of cool-season vegetables like lettuce during the hot summer months represents a challenge to market growers. The objectives of this study were to evaluate the potential of using different coloured nets (pearl, blue, red and black) with shade index (50\%) compare with open field lettuce (Lactuca sativa L.'Tizian') production, during warm-season, (with high solar radiation 950-1000 Wm-2 and photosynthetic photonflux density of 1800-2010 $\mu \mathrm{mol}$ $\mathrm{m}-2 \mathrm{~s}-1$ ) under Serbia climate conditions. Lettuce grown covered by coloured shade-nets had a higher yield, bolting ratedecreased, but no significantrelative to the open field. Leaf area indices (LAI) ranged from 1.3 in open field crop (control) to maximum LAI values of 3.1 in plants under pearl nets. Photosynthetic pigments in lettuce leaf increased under low light conditions. The highest content of chlorophyll b (1.355 mg g-1) and carotenoids (2.918 mg g-1) was observed in lettuce under the pearl nets. Colour shade-nets improved the leaves structural parameters and texture become soft-buttery. Lettuce from open field characterized by hard crisp leaf texture. Shading reduced the physiological disorders (tip burn, rib discoloration, bolting) and leaf bitterness thus increased the marketable lettuce production by about $15 \%$ compared to non-shading conditions. Lettuce grown under black $(54.23 \mu \mathrm{g}$ g-1) or pearl $(50.59 \mu \mathrm{g}$ g- 1$)$ shade-net had significantly more b-carotene than plants

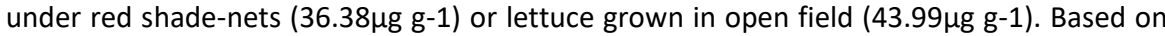
our results, summer production of lettuce would not be recommended at open fields or net house in south Serbia, although the potential of net house by coloured nets deserves further studies, special pearl nets with the introduction of adequate cultivars for summer production. 


\section{Accumulation of capsinoids and capsaicinoids in three Capsicum species during fruit growth}

Tanyarat Tarinta $^{1 *}$, Suchila Techawongstien ${ }^{1}$, Kamol Lertrat $^{1}$, Saksit Chanthai ${ }^{1}$, Eiji Nawata ${ }^{2}$

${ }^{1}$ Khon Kaen University, Faculty of Agriculture, Khon Kaen 40002, Thailand

* e-mail: tanyarattainta@gmail.com

${ }^{2}$ Kyoto University, Graduate School of Agriculture, Kitashirakawa, Sakyoku, Kyoto 606-

8502, Japan

Keywords: fruit development, pepper, non-pungency

Capsinoids is the new emerging phytochemical substance in chili fruits, with similar structure to capsaicinoids. But, less pungency and more palatable in taste than capsaicinoids. Capsiate and dihydrocapsiate are the main components for capsinoids, where capsiate plays the major role for suppress body fat accumulation. Beside cultivars and environmental conditions, capsaicinoids and capsinoids accumulation depend on the fruit growth stages. Therefore, this experiment was conducted to find out the appropriate harvest time of fruit growth in different Capsicum cultivars. The field experiment was conducted in factorial in randomized completely block design ( $3 \times 5$ Factorial in RCBD) with three replications (10 plants per replication) at the research farm, Khon Kaen University during June to November 2016. Three Capsicum cultivars, i.e. KKU-P31146 (Capsicum annuum), KKU-P62268 (C. frutescens)and KKU-P13049 ( $C$. chinense)were designed as factor $A$, and five periods of fruit growth, i.e. 10, 20, 30, 40 and 50 days after anthesis (DAA) were designed as factor $B$. Interaction between factor $A$ and $B$ was found for capsiate, dihydrocapsiate and sum of capsiate and dihydrocapsiate. The maximum content for capsiate accumulation was found in KKU-P31146 (872.2 $\mathrm{\mu g} / \mathrm{g}$ DW) at $30 \mathrm{DAA}$, while the maximum content for capsaicin accumulation was found in KKU-P62268 $(6566.9 \mu \mathrm{g} / \mathrm{g} \mathrm{DW})$ at 40 DAA. This means that different cultivars give different phytochemical contents at different stages of fruit growth. To improve the high capsiate and capsaicin cultivars with good agronomic traits, KKU-P31146 and KKU-P62268 should be used as a good sources in breeding program. 


\title{
Pesticide residues in vegetables on Slovene farms and market
}

\author{
Kristina Urbanč, Martina Robačer, Franc Bavec, Tjaša Vukmanič, Martina Bavec* \\ University of Maribor, Faculty of Agriculture and Life Sciences, Pivola 10, 2311 Hoče, \\ Slovenia \\ *e-mail: martina.bavec@um.si
}

Keywords: vegetable, pesticides residue, integrated farming, organic farming

Country of origin, method of agricultural production and the presence of pesticide residues are important criteria buying food, especially in case of fresh vegetables and fruits.

For the period 2011 to 2015 content and quantity of pesticide residues in vegetables depending on the method of production were analysed in samples from integrated and organic production on Slovene farms from data base of two certification bodies and compared to the situation on the general market of Republic Slovenia based on results of official national monitoring in the same period. The results show that the presence of pesticide residues in vegetables depends on the method of production. Vegetables produced within the scheme of quality organic production in Slovenia are not contaminated with any pesticide. In 17.3\% of samples (out of 75 in years 2011 to 2015) from Slovene integrated production were found pesticide residues, but in comparison with the samples of the general market (2,159 in years 2011 to 2015$)$ where $35.1 \%$ of samples have residues, integrated production of vegetables have higher share of samples without residues or below detection level $(82.7 \%$ of the samples compared to $64.9 \%$ samples on the market). Five the most frequent pesticides residues in the vegetables from the market were boscalid, propamocarb, dithiocarbamates, imidacloprid, azoxystrobin, difenoconazol. Slovene vegetables from integrated production have twice less residues compared to vegetables on the market. Slovenia's self-sufficiency in fresh vegetables is low (50\%) and in the future, we need to pay attention to reduce dependence on imports and increase the volume of local production, encourage farmer's participation in quality schemes, provide short supply chains and raise awareness among population about the importance of consuming locally grown organic vegetables to improve quality of their life. 


\title{
Quantification of volatile compounds in "aromatic" and "non-aromatic" Italian strawberry populations by means of solid phase microextraction (SPME) and gas chromatography-mass spectrometry (GC-MS)
}

\author{
Federico Ferioli ${ }^{1 *}$, Elisa Giambanelli ${ }^{1}$, Filippo D'Antuono ${ }^{1}$, Gianluca Baruzzi ${ }^{2}$, Maria Luigia \\ Maltoni ${ }^{2}$ \\ ${ }^{1}$ University of Bologna, Department of Agroenvironmental Science and Technology, P.zza \\ Goidanich 60, 47521 Cesena, Italy \\ * e-mail: federico.ferioli@unibo.it \\ ${ }^{2}$ Council for Agricultural Research, Fruit Research Unit of Forlì, Via La Canapona 1 bis, \\ 47121 Forlì, Italy
}

Keywords: strawberries, volatile compounds fruit aroma, solid phase microextraction (SPME), gas chromatography-mass spectrometry (GC-MS), discriminant analysis

The volatile compounds responsible for strawberry aroma have been receiving an increasing attention as primary determinants of fruit sensory quality. A complex mixture of hundreds of volatile compounds, some of which are generated during chewing and many of them odour-active even at low concentrations, can be detected in strawberry fruits. The present research considered seven Italian strawberry varieties or advanced breeding lines, classified as "aromatic" or "non-aromatic" only on the basis of their parentals and collected on four harvest dates. The volatile compounds were extracted from a fine puree by solid phase microextraction (SPME) and analysed by means of a gas chromatography-mass spectrometry (GC-MS) system. Eighty-seven volatiles were identified, 75 of which in amounts over the limit of quantification. The average total volatile amount was not different between "aromatic" and "non-aromatic" accessions. An average increasing trend was detected, as a function of harvest time. Nevertheless, the effect of genotype was prevailing in both cases, with strong and significant interactions with factors "type" and "harvest time". Esters, aldehydes, carboxylic acids and lactones were the major chemical classes, accounting on average for $0.106,0.380,0.315$ and $0.173 \mu \mathrm{g} \mathrm{\mu g}^{-1}$ of volatiles, respectively. None of the individual components clearly distinguished the "aromatic" from the "non-aromatic" group, as a whole. A discriminant analysis was therefore carried out and led to a very clear and univocal discrimination between the two groups, with no interference of any other experimental factors and their interactions. Although the derived function cannot be clearly identified, 23 analytical variables that included several major and minor odour-active volatile compounds were retained in its calculation. 


\title{
Evaluation of cysteine sulfoxides and volatile compounds in local garlic (Allium sativum L.) and elephant garlic (Allium ampeloprasum L.) populations from northern and central Italy
}

\author{
Federico Ferioli*, Elisa Giambanelli, Filippo D'Antuono
}

University of Bologna, Department of Agroenvironmental Science and Technology, P.zza Goidanich 60, 47521 Cesena, Italy

* e-mail: federico.ferioli@unibo.it

Keywords: garlic (Allium sativum L.), elephant garlic (Allium ampeloprasum L.), cysteine sulfoxides, volatile compounds, local populations

The popularity of garlic (Allium sativum L.) and other Allium species depends on their characteristic flavour and putative health-promoting properties, both determined by sulfurcontaining cysteine sulfoxides and their volatile derivatives. Diverse local garlic populations are present in many areas of Italy and still poorly characterised for the total content and composition of their sensorially and biologically active compounds. In the present investigation, fresh garlic cloves from eight garlic and four elephant garlic (Allium ampeloprasum L.) populations cultivated in northern and central Italy were analysed for their cysteine sulfoxide and volatile compound profile. Garlic types were further classified into "red" and "white" groups, according to clove skin colour. Elephant garlic showed an average significantly lower content of cysteine sulfoxides (14306 $\mathrm{mg} \mathrm{kg}^{-1} \mathrm{~d} . \mathrm{m}$.), than both white (27257 mg kg-1 d.m.) and red garlic (26294 mg kg-1 d.m.). Compositional differences were also assessed, with a significantly higher relative amount of sulfoxides methiin and isoalliin in elephant garlic, in comparison to the two garlic types. The volatile fraction was extracted by means of a simultaneous distillation-extraction procedure; thirty-three compounds were identified and quantified by GC-MS. The highest volatile total amount was observed on average in red garlic (2095 mg kg-1 d.m.), followed by white (1829 $\mathrm{mg} \mathrm{kg}^{-1} \mathrm{~d} . \mathrm{m}$.) and elephant garlic (1383 $\mathrm{mg} \mathrm{kg}^{-1} \mathrm{~d} . \mathrm{m}$.). An expected high correlation $(r=0.86, p<0.001)$ was verified between total volatile compounds and their precursors. The volatile profile of elephant garlic mainly differed from white and red garlic for its lower diallyl disulfide and higher allyl methyl trisulfide relative amounts. Discriminant analysis of analytical data clearly separated the three garlic types, whereas principal component analysis allowed a further discrimination of garlic populations within the same type, confirming between-group differences as the main source of analytical variation. 


\title{
Geographical authentification of potato using multi-elemental fingerprint and stable isotope ratio analysis
}

\author{
Anja Mahne Opatič ${ }^{1 *}$, Marijan Nečemer ${ }^{1}$, Bojan Budič ${ }^{2}$, Sonja Lojen $^{1}$ \\ 1Jozef Stefan Institute, Jamova 39, 1000 Ljubljana, Slovenia \\ * e-mail: anja.mahne00@gmail.com \\ ${ }^{2}$ National Institute of Chemistry, Hajdrihova 19, Ljubljana, Slovenia
}

Keywords: geographical origin, potato, stable isotopes, elements

Slovenia, the country in South-Eastern Europe, covers only a small territory of $20273 \mathrm{~km}^{2}$. It is situated between the Alps, the Dinaric Mountains, the Pannonian Basin and the Mediterranean Sea. Considering its geographical position, Slovenia is known for its diverse geological, climatological and biological characteristics and thus very interesting for investigating the influence of geographical factors. In present study we have investigated the suitability of stable isotope ratios of light elements $(\mathrm{C}, \mathrm{N}, \mathrm{O}, \mathrm{S})$ and multi-elemental fingerprint ( $\mathrm{Na}, \mathrm{Mg}, \mathrm{K}, \mathrm{Ca}, \mathrm{Cl}, \mathrm{S}, \mathrm{P}, \mathrm{Mn}, \mathrm{Fe}, \mathrm{Ni}, \mathrm{Cu}, \mathrm{Mo}, \mathrm{Zn}, \mathrm{Br}, \mathrm{Rb}, \mathrm{Sr}, \mathrm{Sc}, \mathrm{Nb}, \mathrm{La}, \mathrm{Pr}, \mathrm{Nd}, \mathrm{Dy}, \mathrm{Er}$, $\mathrm{Y}, \mathrm{Ce}$ ) in combination with supervised pattern recognition statistical analysis, namely multivariate discriminant analysis (DA) for characterizing and classifying organically grown potato (Solanum tuberosum L.) according to its geographical origin into four geographical macro-regions (Alpine, Dinaric, Pannonian, Mediterranean). Results of multivariate DA show that potato samples are successfully separated into four groups, input as a priori, according their macro-region origin. Cross validation test of the proposed model shows that $100.0 \%$ of samples were correctly classified into four groups. The first discriminant function (F1) explains $74.22 \%$ of total variance, while the second discrimination function (F2) explains $15.87 \%$. The distinction among potato samples is clearly demonstrated along F1 axis by $\mathrm{Pr}$, $\mathrm{Nd}$ and $\delta 13 \mathrm{C}$ and along $\mathrm{F} 2$ axis by $\mathrm{Nd}$, Pr and $\mathrm{Y}$, respectively. Based on the data obtained, traceability models can be created for potential identification and classification of unknown samples in terms of their geographical provenance. 


\section{Quality changes of fresh and then microwaved minimally processed faba seeds}

Elena Collado, Tammila Venzke-Klug, Francisco Artés-Hernández, Encarna Aguayo, Francisco Artés*, Juan A. Fernández, Perla A. Gómez

Polytechnic University of Cartagena, Paseo Alfonso XIII, 48, 30203 Murcia Cartagena, Spain * e-mail: fr.artes@upct.es

Keywords: Vicia faba, UV-C, sensory quality, microbial, tannins.

Faba beans (Vicia faba L.) are one of the most common grain legumes, rich in proteins, carbohydrates, antioxidants, fiber, vitamins and minerals. Therefore, the production of minimally processed immature faba seeds would be an alternative to promote its consumption. In addition, that product can be then microwaved, if packaged in an appropriate package. In this study, the effects of sanitation with $\mathrm{NaOCl}(150 \mathrm{ppm}, \mathrm{pH} 6.5)$ or alternatively UV-C light $\left(3 \mathrm{~kJ} \mathrm{~m}^{-2}\right)$ during storage $(10 \mathrm{~d}, 4 \mathrm{o} C)$ on fresh and then microwaved (700 W, $1 \mathrm{~min}$ ) faba seeds were analyzed. Here, the evolution of sensory attributes (overall quality, taste, aroma, visual appearance, texture, browning, dehydration, and loss of brightness) and tannins, a group of antinutritional compounds that might adversely affect the consumption of legumes, are presented. The microbiological quality of the fresh seeds was also evaluated. Seeds treated with UV-C maintained their sensory attributes above the limit of acceptability after 10 days, while those treated with $\mathrm{NaOCl}$ were acceptable until day 7. After 10 days reductions of 1 log CFU for mesophilic aerobes, 0.5 log CFU for psicrophilic and $1.5 \mathrm{log}$ CFU for enterobacteria were achieved for the UV-C treatment respect to $\mathrm{NaOCl}$. Tannins decreased during storage, regardless of the type of treatment. They also decreased after microwaved, with a reduction of around $35 \%$ in relation to the fresh product at the beginning of storage. More research is needed to study the effect of these treatments on other quality parameters. 


\section{GAP for reducing wastage and increasing profitability on vegetable production}

Silvana Nicola ${ }^{1 *}$, Giuseppe Pignata

${ }^{1}$ University of Turin, Department of Agriculture, Forestry and Food Sciences, Leonardo Da Vinci 44, 10095 Grugliasco, Torino, Italy

* e-mail: silvana.nicola@unito.it

2Proteo International S.r.L., Corso IV Novembre, 13, 12073 Ceva CN, Italy

Enhancing vegetable profitability implies cultivation of standardized high-quality produce, implementation of advanced technologies for competitive production and optimization of resources. Small stakeholder farms require innovative strategies to enter new markets and extend the impact of local and niche productions, while achieving sustainability. Food loss, waste and wastage refer to human edible material that is discarded, lost, degraded or consumed by pests at any point in the food supply chain. Food wastage accounts for onethird of world food production; it occurs to varying degrees at all stages of the food supply chain. More than 60 percent of the total wastage of fruit, vegetables, roots, tubers and bulbs takes place during harvesting and consumption. Food wastage involves not only wastage of input and agricultural land area, but also missed opportunities. To reduce food wastage in the food supply chain - by recycling and re-using plant residues, among other approaches is both smart and sustainable. To enhance the profitability of vegetable small stakeholder farms, it is necessary to achieve standardized high-quality production while optimizing the resources. Vegetable quality and shelf-life are affected by pre-harvest, harvest and post-harvest conditions; consequently, to achieve profitability and competitiveness, action is required at the various stages of the food supply chain, including processing, storage, transport and distribution. Some production and marketing strategies can be adopted by small stakeholder farmers to increase profitability. Furthermore, good practices can be adopted to minimize losses in protected cultivation systems and to reduce losses and waste during post-harvest and throughout the food supply chain. 
$-30-$ 
ORGANIC VEGETABLES \& POTATOES PRODUCTION 


\section{Growing media in organic seedling production}

Yüksel Tüzel1* , Golgen Oztekin ${ }^{1}$, Ismail Hakki Tuzel², Hale Duyar ${ }^{3}$

${ }^{1}$ Ege University, Agriculture Faculty, Department of Horticulture, 35100 Bornova Izmir, Turkey

* e-mail: yuksel.tuzel@ege.edu.tr

${ }^{2}$ Ege University, Faculty of Agriculture, Department of Farm Structures Irrigation, 35100 Bornova-Izmir, Turkey

${ }^{3}$ Ege University, Bayindir Vocational School, Bayindir, Izmir, Turkey

Keywords: peat, vermicompost, compost, seedling quality

Vegetable seedlings are produced in specialized commercial nurseries. Peat is the most common growing medium used in seedling production. In organic agriculture, organic seeds and plant material should be used according to the EU Regulation No 834/2007. However, there is no restriction in the use of peat as the growing media in the Regulation although there is a comment on peat as a limited natural resource and restriction of its use with the approach of sustainability of organic agriculture. In fact, Bio Suisse Standards recommends restricting the use of peat for the cultivation of planting material no more than $70 \%$ peat. During the last two decade many researches have been conducted on the use different wastes or by-products or compost or vermicompost alone or as a part of a mixture as peat substitute. This review aims to bring the researches on peat alternatives in organic seedling production and their effects on different vegetable crops. 
Impact of soil cover and manure application on soil moisture, mineral nitrogen and lettuce (Lactuca sativa L. subsp. secalina) yield in organic farming

Maja Manojlović ${ }^{1 *}$, Ranko Čabilovski ${ }^{1}$, Klara Marijanušić ${ }^{1}$, Dragan Kovacevići ${ }^{1}$ Martina Bavec $^{2}$

${ }^{1}$ University of Novi Sad, Faculty of Agriculture, Trg Dositeja Obradovića 8, 21000 Novi Sad, Serbia

* e-mail: maja.manojlovic@polj.uns.ac.rs

${ }^{2}$ University of Maribor, Faculty of Agriculture and Life Sciences, Pivola 10, 2311 Hoče, Slovenia

Keywords: hoeing, agrotextile cover, straw mulch, manure

In order to access soil cover management and manure effects on soil moisture, nitrogen dynamics and lettuce yield in organic farming, a two-year field experiment was established on certified organic farm in Kisač (Vojvodina, Serbia). The experiment had 2-factorial splitplot completely randomized design, with manure as one factor and soil cover treatments as a second factor. Manure was applied on the half of the experimental field, as a whole-plot factor, while soil cover management included four treatments: control without cover (C1); control without cover with hoeing (C2); agro-textile cover (A); and straw mulch (S). The results showed that soil cover and manure managements had an important role in organic lettuce production. Soil hoeing and soil cover treatments ( $A$ and S) affected the soil moisture. Manure application increased soil nitrate concentration, the lettuce yield and nitrate concentration in lettuce. The highest lettuce fresh mass yield was obtained by $A$ and then $S$, while $\mathrm{C} 2$ did not positively affect the yield probably due to negative effect on soil moisture. Although impact of soil cover treatments on soil $\mathrm{N}$ dynamics and nitrate concentration in lettuce were not consistent in the examined years, nitrate concentration in fresh mass of lettuce on all treatments were below limit according to the EU regulation. The lettuce yield was higher with manure application and it was decreasing in order $\mathrm{A}>\mathrm{S}>\mathrm{C} 2>\mathrm{C} 1$. 


\section{Trace elements in soils and vegetables on organic farms in Serbia}

Maja Manojlović*, Ranko Čabilovski, Klara Marijanušić, Dragan Kovacević

University of Novi Sad, Faculty of Agriculture, Trg Dositeja Obradovića 8, 21000 Novi Sad, Serbia

* e-mail: maja.manojlovic@polj.uns.ac.rs

Keywords: heavy metals, plant, soil, food safety

Conventional agricultural production is characterized by intensification and high input of fertilizers and pesticides, which can cause accumulation of potentially toxic trace elements (TEs), both, in soil and plants. Although the risk of TEs accumulation in soil / plants is smaller in organic farming compared to conventional, monitoring of these elements is important and has benefits. The aim of the research was to assess the concentrations of cadmium (Cd), lead $(\mathrm{Pb})$, nickel $(\mathrm{Ni})$, chrome $(\mathrm{Cr})$, copper $(\mathrm{Cu})$, and zinc $(\mathrm{Zn})$ in soil and edible parts of vegetables at three representative organic farms in Serbia, located at different soil types. Three groups of vegetables (leafy, fruiting and root and tuber vegetables) were sampled from each farm. Accompanying soil samples $(0-30 \mathrm{~cm}$ depth) were taken in the same time as vegetable samples. The results of investigation have shown that total TEs concentrations in soils were under maximum allowed values in organic farming (Official Gazette of Republic of Serbia, No. 51/2002). Also, the concentration of TEs in fresh matter of edible parts of vegetables was notably under permissible levels (EC No 333/2007). On the other hand, high variability of TEs concentrations in soil and plant samples, not only between the farms/soil types, but also within the groups of vegetables on the same farm, was found. The highest concentration of all analyzed TEs was found in leafy vegetables and the lowest in fruiting vegetables at all three farms. Except in the case of root and tuber vegetables, soil type did not significantly influence the TEs concentration in vegetables. However, concentrations of $\mathrm{Ni}$ and $\mathrm{Cr}$ in root and tuber vegetables grown on clay loam soil were significantly higher than in the same group of vegetables grown on loam and sandy loam soil. 


\section{SoilVeg - Improving soil conservation and resource use in organic cropping systems for vegetable production through introduction and management of Agro-ecological Service Crops}

Martina Bavec ${ }^{1 *}$, Martina Robačer ${ }^{1}$, Franc Bavec ${ }^{1}$, Tjaša Vukmanič ${ }^{1}$, Manfred Jakop ${ }^{1}$, Urška Lisec $^{1}$, Silva Grobelnik Mlakar ${ }^{1}$, Stefano Canali²

${ }^{1}$ University of Maribor, Faculty of Agriculture and Life Sciences, Pivola 10, 2311 Hoče, Slovenia

*e-mail: martina.bavec@um.si

${ }^{2}$ Council for Agricultural Research (CREA), Rome, Italy

Keywords: Agro-ecological Service Crops, organic vegetable production, roller crimper

SoilVeg is an innovative European research project under Core Organic Plus coordinated by CREA Italy. In three 3 years, 9 European countries and 14 partner institutions will be working together with the aim to study the better manage-ment of Agro-ecological Service Crops (ASC). ASC represent a powerful tool for organic farmers. They are able to positively influence the agro-ecosystem, promoting the whole soil-plant system equilibrium in space and time, having impact on soil fertility and on occurrence of weeds, diseases and pests. If appropriately managed, ASC can contribute to reduce nutrient losses from the agroecosystem, to increase soil $\mathrm{C}$ sink potential and to improve system energy use efficiency. To avoid competition with the subsequent cash crops, the growth of the interposed ASC is terminated in advance of the cash crop planting. The traditional technique used to terminate the ASC is incorporation as green manure into the soil by tillage. Since tillage is an energy and labour consuming and soil disturbing operation, the use of no/reduced tillage techniques, as the rolling crimping technology that terminates by flattening the ASC, has received increasing interest. In the case of Slovenia barley and crimson clover are used as ASC and cauliflower and cabbage as main crops and in field experiment tested hypothesis if the use of the roller crimping technology for ASC termination is able to: (i) maintain yield of the cash crops and vegetable products quality, (ii) reduce soil disturbance and enhance soil quality, improving internal system use of nutritive elements, (iii) reduce fossil fuel energy consumption, (iv) create a suppressive environment for pests, diseases and weeds. 


\section{Evaluation of carrot cultivars for irrigated organic farming}

Johannes Balas ${ }^{1 *}$, Peter Cepuder ${ }^{2}$, Rita Kappert ${ }^{1}$, Reinhard Nolz² , Sieglinde Pollan ${ }^{3}$, Jürgen Renner ${ }^{4}$

${ }^{1}$ University of Natural Resources and Life Sciences Vienna, Department of Crop Sciences, Gregor Mendel Strasse 33, 1180 Vienna, Austria

*e-mail: johannes.balas@boku.ac.at

${ }^{2}$ University of Natural Resources and Life Sciences Vienna, Department of WaterAtmosphere-Environment, Muthgasse 18, 1190 Vienna, Austria

${ }^{3}$ Research Institute of Organic Agriculture, FIBL Austria, Doblhoffgasse 7101010 Vienna, ${ }^{4}$ Himbeerium, Neustiftbachstrasse 13, 7532 Litzelsdorf, Austria

Keywords: on field vegetable production, carrot, Daucus, irrigation, Marchfeld, organic growing, open pollinated cultivars, semi-humid conditions

Five open pollinated cultivars and a dominating F1-hybrid in field-production of carrots (Daucus carota L.) were cultivated in a three years on-farm field-trial (organic farm Biohof Adamah, Markgrafneusiedl) in north-eastern Austrian dry-subhumid region Marchfeld (pannonic climate) under 3 differing irrigation-regimes: local standard (control) and two reduced-supply strategies: reduced (RED) and severely reduced (STR). According to regular production carrots were sown in two rows on raised beds. Water supply was controlled by an irrigation computer (Galcon) by reducing the flow rate and intervals. Experimental design was in 3 blocks each for the graduated factor irrigation. Within blocks (factor cultivar) 3 replicates were arranged randomly. Additional amount of water was calculated and added to natural precipitation. Objectives were to evaluate agronomic performance (marketable yield, rooting, plant-health), effects on sensory quality and physiological based quality traits (bioactive and osmotic effective compounds) of the open-pollinated cultivars (Nantaise 2 types: 'Milan', 'Mö 14 RFE 402','Fynn', 'Rotin', 'Beate') compared to 'F1 Maestro'. In the course of the trial severe drought-stress never occurred, light and middle did. Significant effects of cultivar and graduated water supply were detected on agronomic and biochemical traits. 'F1 Maestro' performed best agronomically, 'Milan' and 'Beate' might be suitable alternatives. 


\title{
Heavy metal contents in organic baby-food-carrots
}

\author{
Amal Aryan ${ }^{1}$, Markus Puschenreiter $^{2}$, Rita Kappert ${ }^{1}$, Johannes Balas ${ }^{1 *}$ \\ ${ }^{1}$ University of Natural Resources and Life Sciences Vienna, Department of Crop Sciences, \\ Gregor Mendel Strasse 33, 1180 Vienna, Austria \\ * e-mail: johannes.balas@boku.ac.at \\ 2University of Natural Resources and Life Sciences Vienna, Institute of Soil Research, Peter \\ Jordan Strasse 82, 1190 Vienna, Austria
}

Keywords: field-grown vegetables, fresh-food vegetables, baby-food-standard, crop-quality management

Crop-quality requirements led to this research. To assure baby-food-quality standard in plant-production by controlling uptake of lead, cadmium and mercury in field vegetables: Carrot (Daucus carota L.), onions (Allium cepa) and potatoes (Solanum tuberosum) as staple food. This is especially valid for fresh vegetables as industrially processed batches. Samples, taken within the quality management chain, have been compared to soil samples exactly from the same field. Analysis of soil samples has been done by ICP-MS after aqua regia digestion; crops' digestion in acid digestion. The general soil parameters were analyzed by the Austrian Agency for Health and Food Safety (AGES). A strict resources canon left only soil-born pollution as reason for some light heavy-metal load occasionally exceeding maximum levels. Impact on the contents refers to regional sources from bedrock, so the hypothesis, and under certain weather conditions leads to excess of baby-food-limits. Differences among species and cultivars exhibit differing levels of uptake. As it was found, that production was optimized, the key was to strictly hold to soil $\mathrm{pH}$ and the corresponding dates of clay and organic matter. Further, carrot cultivars from the Marchfeld region, showed to have significantly different uptake; some cultivars can be recommended for reduced risk in production. 


\title{
Biostimulants affect quality and yield of tomato fruits from open-field production
}

\author{
Else Herzog, Anna Keutgen, Johannes Balas* \\ University of Natural Resources and Life Sciences Vienna, Department of Crop Sciences, \\ Gregor Mendel Strasse 33, 1180 Vienna, Austria \\ * e-mail: johannes.balas@boku.ac.at
}

Keywords: Lycopersicon, biostimulants, organic vegetable production, antioxidant compounds contents, lycopene, carotene

The two commercialized bio-stimulants (plant strengthening agents) 'Amino Vital' (Biofa) and 'Equisetum plus' (Biofa) were applied weekly on the two traditional cultivars of tomato ('beef tomatoes', Lycopersicon esculentum L.) 'German Gold' and 'Olena Ukraninian'. Both agents are registered for organic vegetable production (infoXgen) and have shown to be effective. They were applied regularly by spraying. 'German Gold' delivers yellow and 'Olena Ukrainian' red tomato-fruits. The trial was arranged unprotected in the fiel, randomly in two rows, three replicates per treatment, $1 \times 1$ meter spacing, in total 45 plants per cultivar in the warm-dry eastern county Burgenland, Austria. Plants were treated according to good practice in open-field production of tomato, fertilized and irrigated (drop system). Fruit-set, number of harvested fruits, fresh-weights, total harvest and occurrence of pests and diseases on the plants were monitored. Contents of ascorbic acid, Lycopene, and Carotene were determined at the lab of the Institute of Botany (Dept. of Integrative Biology and Biodiversity Research). The results displayed differences in several parameters between the used biostimulants. Equisetum-plus application exhibited higher resistance, more regular growth and fruits showed less rots. The content of Carotene appeared to be higher. Aminovital seems to promote fruit-rots, therefore it should only hit leaves. 


\title{
Drip application of a biopolymer-based biostimulant enhances root growth and nutrient uptake of processing tomato
}

\author{
Giuseppe Colla ${ }^{1}$, Mariateresa Cardarelli ${ }^{2}$, Walter Stefanoni ${ }^{1}$, Antonio Fiorillo ${ }^{1}$, Roberto \\ Mariotti $^{3}$, Marios C. Kyriacou 4 , Youssef Rouphael ${ }^{5 *}$
}
${ }^{1}$ Tuscia University, Department of Agricultural and Forestry, Via Santa Maria in Gradi, 4, 01100 Viterbo, Italy
${ }^{2}$ Council for Agricultural Research (CREA), Rome, Italy
${ }^{3}$ Regional Agency for Development and Innovation of Agriculture Lazio, Via Rodolfo
Lanciani, 38, 00162 Roma, Italy
${ }^{4}$ Agricultural Research Institute Cyprus, Department of Vegetable Crops, Nicosia, Cyprus, Cyprus
${ }^{5}$ University of Naples Federico II, Department of Agricultural Sciences, Via Università 100, 80055 Portici, Napoli, Italy
* e-mail: youssef.rouphael@unina.it

Keywords: chlorophyll fluorescence, fertilization levels, fruit quality, Solanum lycopersicum L., SPAD index.

A well-developed root system is pivotal for the success of horticultural crops. In processing tomato, the most intensive root growth takes place during the first growing period and decreases over time due to the limitation of photosynthates resulting from the strong sink demand for reproductive growth. To appropriate supply of water and nutrients during the reproductive period, optimal root growth at early vegetative stage is necessary. However, root growth is often restricted by genetic, cultural factors, and adverse environmental conditions. The application of plant biostimulants, especially under adverse environmental conditions, can help to promote root growth and to guarantee optimal shoot growth and productivity. An innovative natural biopolymer-based biostimulant (Quick-Link, Italpollina S.p.A., Rivoli Veronese, Italy) for boosting root growth and improving availability of plant nutrients was tested in two trials on processing tomato. In the first trial, carried out under greenhouse conditions, tomato plants were transplanted in pots filled with a sandy soil and irrigated two days later with a solution containing the biostimulant at three concentrations $(0,3$ or $6 \mathrm{~L} / \mathrm{ha})$. After twelve days from transplanting, tomato plants treated with biostimulant, especially at the rate of $6 \mathrm{~L} / \mathrm{ha}$, exhibited a higher dry biomass of leaves, stems and roots than control plants while SPAD index and chlorophyll fluorescence (Fv/Fm) of leaves were not significantly affected by treatments. In the second trial, carried under field conditions, treatments were defined by a factorial combination of two fertilization levels (standard and half-ratof mineral fertilizers) and two biostimulant concentrations ( 0 and 6 L/ha). Biostimulant applications increased marketable yield under reduced fertilization level. Fruit quality parameters were only affected by fertilization level with an increase of soluble solids content obtained under reduced rate of mineral fertilizers. 
$-40-$ 
SHORT SUPPLY CHAINS AND OTHER CONCEPTS OF VEGETABLES \& POTATOES MARIKETING 


\title{
Estimation of the vegetable production on allotment gardens in Ljubljana and London
}

\author{
Gregor Volk, Matjaž Glavan, Marina Pintar, Rozalija Cvejić* \\ University of Ljubljana, Biotechnical Faculty, Jamnikarjeva 101, 1000 Ljubljana, Slovenia \\ * e-mail: rozalija.cvejic@bf.uni-lj.si
}

Keywords: urban gardening, economic production potential

Urban gardening has become an important civic activity. Individual and allotment gardens are an attractive form of land use because of their ability to satisfy the needs of modern day citizen; providing fresh and healthy vegetables of controlled origin, supporting employment, education and recreation. Ljubljana and London's lively gardening activities have been analyzed. Through mapping of digital ortophoto images both capital cities current extent of allotment gardens and their economic potential were estimated along with economic eligibility of vegetable production. Results showed that cities strongly differed in number of citizens per hectare of allotment gardens (Ljubljana 1809 citizens/hectare, London 9550 citizens/hectare) and because of different economic conditions also in economic production potential. In Ljubljana gross margin is $2.42 \mathrm{EUR} / \mathrm{m}^{2}$ per year whereas in London its corresponding value is $2.89 \mathrm{EUR} / \mathrm{m}^{2}$ per year. 


\section{Profit efficiency estimation of tomato farms in Kosovo}

Iliriana Miftari*, Muje Gjonbalaj, Arben Mehmeti, Skender Kaçiu

University of Prishtina, Faculty of Agriculture and Veterinary, Bill Clinton Str., 10000

Pristina, Kosovo

* e-mail:

Keywords: tomato, efficiency, DEA, Kosovo

The main objective of this paper is to estimate profit efficiency of the tomato farms in Kosovo. A non-parametric method Data Envelopment Analysis (DEA) is used to estimate frontier production function. The efficiency scores were obtained using the profit of the tomato production as an output and the costs for saplings, fertilizers, pesticides, marketing, labor, and machinery as inputs. Truncated regression analysis is performed in the secondstage to examine how other farm characteristics such as size, age, experience correlates and explains the profit efficiency variation at farm level. The estimated results showed that on average tomato producers was profit inefficient. This implies that tomato farmers could further reduce quantities of the inputs used and minimize total costs, without worsening the current level of profit. Calculated bias-corrected efficiency scores showed that there is even more potential for improvement in tomato farm profit efficiency. 


\section{Perspective tomato landraces for fresh consumption in the Republic of Macedonia}

Gordana Popsimonova*, Rukije Agić, Zvezda Bogevska, Maragrita Davitkovska, Goce Georgievski

University Ss Cyril and Methodius, Faculty of Agricultural Sciences and Food, Blvd. Aleksandar Makedonski bb, Skopje, 1000, Macedonia

* e-mail: gpopsimonova@yahoo.com

Keywords: tomato, landraces, morphological traits, fruit quality

Following long pepper, tomato is most widely cultivated vegetable in the Republic of Macedonia. It is mainly grown under tunnels and in glasshouses. Considerable portion of the production is intended for export during April, May and June, whereas the local markets are supplied with imports for the rest of the year. A survey has been carried out at the beginning of 2016 aiming to determine consumer preferences for fresh tomato among 50 fresh markets and distributors. It was concluded that consumers prefer to buy local landraces over hybrids. Landrace with apple shaped tomato fruit (Yabuchar) is favorite one for the buyers. In order to in reach the offer of the local tomato producers, 10 Yabucahar-type tomato landraces, collected from different villages and producers during 2006 have been tested for their productive and qualitative traits. Field trials were carried out in the villages of Drachevo and Lisiche, both in vicinity of the capital, Skopje. The landraces were grown in open field conditions following standard agricultural practices for this type of tomato. The characterization of the examined landraces was made by IPGR descriptor for tomato (Lycopersiocon esculentum Mill.). Although all these landraces appear under the same name, significant distinctiveness has been recorded regarding morphological traits such as flower morphology, shape and size of the fruits, pericarp thickness, cracking and green zone of the fruits and mass of the fruits, as well as in the content of sugars. Main drawback for wider production of these landraces is generally short shelf live (1-5 days) that might be improved in further breeding programs. 


\section{Evolution of the potato (Solanum tuberosum L.) market in Argentina (Ex aecquo)}

Ana María Castagnino ${ }^{1 *}$, Karina E. Díaz ${ }^{1}$, Andrea Guisolis ${ }^{1}$, Oscar Liverotti², José Fernández Lozano $^{1}$, Mario Peralta ${ }^{3}$, William John Rogers ${ }^{4}$

${ }^{1}$ National University of Central Buenos Aires, Faculty of Agronomy, República de Italia 780, Azul 7300, Argentina

* e-mail: amcastagnino@gmail.com

${ }^{2}$ Pontifical Catholic University of Argentina, Av. Alicia Moreau de Justo 1300, C1107AAZ, Buenos Aires, Argentina

${ }^{3}$ University of Belgrano, Faculty of Agricultural Sciences, Zabala 1837, Buenos Aires, Argentina

${ }^{4}$ Laboratory of Functional Biology and Biotechnology, Azul 7300, Argentina

Keywords: provinces, varieties, prices, commercial volumes

Potato is the main horticultural crop commercialised in Argentina; along with just a handful of other vegetables, namely tomato, onion, squash and carrot, it represents $70 \%$ of total vegetable commercialisation and consumption in the country. The aim of the current work is to analyse the evolution of the potato market in Argentina, based upon the volume received by the Buenos Aires Central Market. For this end, the following aspects were assessed for the period 1999-2016: the per cent variation in the incoming volume and the tendency of the total incoming volumes (TV); and, in 2016, the volume per month and per variety (VM and VV), province of origin and average price evolution over the year (EP). From the comparative analysis between the early years and the end of the study, an increase of $19 \%$ was observed, mainly in the months of May (20\%), February (13\%), January (12\%), October (10\%), April (7\%) and July (6\%). The mean TV commercialised over 1999 to 2016 was 333254 t, with a mean VM of $27774 /$ month. The following months exceeded this mean: November (29509a), August (29235a), October (29200a), July (28997ab), June (28553ab), December (28117ab) and May (27970ab); while in 2016, the mean VM 27772, where the following exceeded the mean: October: 32789a, May: 30286ab and August: $28715 a b$. Potatoes are grown in twelve provinces: Buenos Aires (75.86\%), Córdoba (12.07\%), Tucumán (7\%), San Luis (2.02\%), Mendoza (1.97\%), Jujuy (0.55\%) and Santa Fe $(0.34 \%)$, with the remaining $2 \%$ in San Juan, Rio Negro, Catamarca, Corrientes and Santa Cruz. The varieties under commercialisation are: Spunta (95\%), Innovator (0.27\%), Daisy (0.15\%), Asterix $(0.10 \%)$, Kennebec $(0.034 \%)$, Atlantic $(0.022 \%)$, Ballenera $(0.06 \%)$ and unidentified $(3.92 \%)$. For EP, the average monthly price was $0.27 \mathrm{US} \$ / \mathrm{kg}$, and higher than average prices were observed in July 0.35 , September 0.34 , June 0.322 , August 0.31 , October 0.29 and December $0.28 \mathrm{US} \$ / \mathrm{kg}$, respectively. These results indicate an annual increase of $1 \%$, and the need to expand the production and consumption of varieties of higher nutritional quality and increase the production in those provinces that, although possessing favourable agroclimatic conditions, show low market participation. 
$-46-$ 
PROTECTED CULTIVATION AND GAP OF GREENHOUSE PRODUCTION ON SMALL FARMS 


\title{
GAP recommendations for improving sustainability on small-scale farm greenhouse vegetable production
}

\author{
Martina Bavec*, Martina Robačer, Franc Bavec, Tjaša Vukmanič, Denis Stajnko \\ University of Maribor, Faculty of Agriculture and Life Sciences, Pivola 10, 2311 Hoče \\ Maribor, Slovenia \\ *e-mail: martina.bavec@um.si
}

Keywords: sustainability, greenhouse, vegetables, small-scale farms, ecological footprint

Sustainability is a central issue in protected cultivation of vegetables, as greenhouse production considerably contributes to environmental pressures, such as greenhouse gas emission, nitrate pollution and biodiversity erosion. Decreasing pressures on environment is becoming more important and could be achieved by: (i) using new and alternative production methods and adopt innovative approaches to reduce water and energy consumption, increase efficiency, reduce use of chemicals and lower greenhouse gas emissions; (ii) introducing organic farming production methods in greenhouse vegetable production to reduce environmental impact and to give consumer quality through higher nutritional value, taste and health; (iii) considering various possibilities for energy saving, including passive means without the application of external energy; (iv) applying dark mulches to absorb light radiation and enhance soil warmth; (v) using renewable energy sources; (vi) optimizing water use to maximize water-use efficiency taking care about the quantity and quality of water available; (vii) promoting local and regional production; (viii) establishing short supply chains and alternative marketing opportunities for small farms and (ix) increasing the use efficiency of all external inputs. Using new tools for evaluating sustainability like ecological footprint calculations and the ecological efficiency index could reveal the differences between production systems e.g. organic, integrated and conventional, soil and soilless cultivation in greenhouses, and take into account the distance from production to consumption. 


\section{Potential decrease of ecological impact in greenhouse production of tomato by introducing renewable energy sources}

Denis Stajnko*, Martina Bavec, Miran Lakota

University of Maribor, Faculty of Agriculture and Life Sciences, Pivola 10, 2311 Hoče Maribor, Slovenia

* e-mail: denis.stajnko@um.si

Keywords: tomato, heating systems, ecological footprint, Sustainable Process Index

Since the beginning of intensive vegetable production in greenhouses in the early 1960 s the sum of all activities connected with indoor production have profoundly influenced the ecosystem. Nowadays, the tomato (Solanum lycopersicum L.) production for fresh consumption is widely spread all over the world and also in Slovenia, despite its high temperature demands and requirements for installation of additional heating. For this reason, estimating of global environmental impact is essential. In our study the Sustainable Process Index (SPI) was used for estimating ecological footprint, $\mathrm{CO}_{2}$ emissions and Global Warming Potential (GWP) of different heating systems used by local producers. SPIonWeb ${ }^{\circledR}$ software was implemented for estimating the potential decrease of all impacts by introducing the alternative heating systems - geothermal energy and wooden chips. It was proved that fossil fuels might be successfully replaced by wooden chips in the PE tunnel, and by geothermal energy in the glasshouses, respectively. On that way, the ecological footprint might be reduced by $61.88 \%$ in PE production and up to $90 \%$ in glasshouse. 


\title{
Improving greenhouse production of French bean, kohlrabi and kale by GAP implementation
}

\author{
Božidar Benko* \\ University of Zagreb, Faculty of Agriculture, Department of Vegetable Crops, \\ Svetosimunska 25, Zagreb 10000, Croatia \\ *e-mail: bbenko@agr.hr
}

Keywords: Phaseolus vulgaris L. ssp. vulgaris, Brassica oleracea L. var. gongylodes, Brassica oleracea L. var. acephala, seed inoculation, mulching, fertigation

Due to short growing period, French bean and kohlrabi have great potential for growing in different types of greenhouses as previous crop in early spring or as second crop in autumn. Kale is suitable for winter and early spring production in unheated greenhouses because of its tolerance to low temperatures. Despite to their suitability, these vegetables are rarely grown in greenhouses in South-East Europe. To achieve high and quality yield, small-scale greenhouse producers should apply some practices during the growing period. Kohlrabi and kale seedlings for winter-spring production should be grown in heated greenhouse, and for summer-autumn production should be grown in well ventilated and shaded greenhouse due to lower temperature requirements of these species. It is also recommended to grow French bean from seedlings for an early spring production and to use the French bean seed inoculated with Rhizobium bacteria to increase nitrogen fixation by root. Nutrients supply should be based on soil analysis and crop requirements. Black polyethylene mulch has to be applied to ensure optimal soil temperature during early spring production. For summerautumn production of kohlrabi and kale white mulch should be used to avoid high soil temperatures. Drip irrigation system placed under the mulch foil and used for irrigation and fertigation according to plant development stages, physical characteristics of the soil and greenhouse climatic conditions will result with optimal plant growth and development, without physiological disorders. Plant protection measures should be in accordance with Integrated Pest Management principles and recommendations, which combines a number of measures and processes with the aim to reduce the use of pesticides. Application of mentioned practices, especially in greenhouses heated with renewable energy sources will result with increased sustainability, yield and quality, and extended marked supply period. Consequently, producers will become more competitive in the fresh vegetable markets. 


\title{
GAP recommendations for permanent and temporary protection system - early potato production
}

\author{
Žarko llin ${ }^{1 *}$, Boris Adamovići ${ }^{1}$ Sonja Ilin², Dragan Žnidarčič ${ }^{3}$ \\ ${ }^{1}$ University of Novi Sad-Faculty of Agriculture, Trg Dositeja Obradoviča 8, 21000 Novi Sad, \\ Serbia \\ *e-mail: ilin@polj.uns.ac.rs \\ 2Institute of Field and Vegetable Crops, Maksima Gorkog Street 30, 21000 Novi Sad, Serbia \\ ${ }^{3}$ University of Ljubljana, Biotechnical Faculty, Jamnikarjeva 101, 1000 Ljubljana, Slovenia
}

Keywords: early potato, permanent protection system, temporary protection system, small-scale farms

Harvest area of potatoes in South-eastern Europe is about 580,000 ha with a production of about $11,000,000 \mathrm{t}$. It is estimated that $20-25 \%$ of all harvested areas is used for early potatoes. It is suitable for growing on small family-operated commercial farms. Early potato reaches the market 20 to 25 days earlier by using specific growing technology. Temporary protected area includes the production on mulched land with plastic film and direct covering of plants with agro-textil, directly coverage of the plants with the agro-textil and in low plastic tunnels and permanent protected area (high tunnel) includes the production without heating or cooling, with or without direct coverage of plants with agro-textil. Preconditions for high, stable and quality production of early potato are: (i) choice of very early maturing cultivars with a high yield potential, good adaptability and stability; (ii) equally sprouted and certified planting material (without viruses and ecologically degeneration); (iii) check sprouting seed potatoes, removal of damaged or diseased tubers, especially those with weak, elongated and hairy sprouts that are usually infected by viruses; (iv) fertilizing with organic fertilizers manufactured and managed on farms. Alternatively it is generally recommended to use industrially-manufactured pelleted or granulated bio-organic fertilizers; (v) planting very early and early cultivars at $60-70 \mathrm{~cm} \times 23-25 \mathrm{~cm}$ and medium early at $60-70 \mathrm{~cm} \times 27-30 \mathrm{~cm}$ with a planting depth of 6-10 cm; (vi) lower limit of optimal soil moisture for successful early potato farming is $70-80 \%$ of field water capacity. The necessary amount of water for successful early potato farming is $260-280 \mathrm{~mm}$; (vii) harvest before they are completely mature, marketed immediately after their harvesting. Storage temperature should be $4{ }^{\circ} \mathrm{C}$. Inadequate storing conditions cause quality deterioration within a few days; (viii) permanent protected area is the most expensive, but the safest system for earliest production - high plastic tunnel without additional heating and cooling. Temporary protected area on mulched soil with or without additional agro-textile contributions mostly uniform large young tubers, but yields are moderate. The technologically easiest alternative is to use agro-textile cover; (ix) early potatoes ensure continuity in the supply of consumer until you arrive early potatoes from conventional production from the open fields. Early potato production in greenhouses is safe for consumption since no pesticides are used during farming. 


\section{Early greenhouse production of male genotypes of green asparagus (Asparagus officinalis var. altilis L.) in their seventh production year in the Province of Buenos Aires, Argentina}

Ana María Castagnino ${ }^{1 *}$, Melanie Tobío ${ }^{2}$, Victoria Ruarte ${ }^{2}$, Karina E. Díaz ${ }^{1}$, María Belén Rosini $^{1}$, María Belén Tarantino ${ }^{1}$, William John Rogers ${ }^{3}$

${ }^{1}$ National University of Central Buenos Aires, Faculty of Agronomy, República de Italia 780, Azul 7300, Argentina

* e-mail: amcastagnino@gmail.com

${ }^{2}$ University of Belgrano, Faculty of Agricultural Sciences, Zabala 1837, Buenos Aires, Argentina

${ }^{3}$ Laboratory of Functional Biology and Biotechnology, Azul 7300, Argentina

Keywords: turions, calibres, quality, productivity

Asparagus comprises an interesting productive option, given growing global demand and the opportunity the crop offers for early seasonal production, as well as its cultivation in the greenhouse. In order to evaluate the behaviour, in their seventh production year, of the Italian genotypes Italo, Zeno, Eros, Ercole, H-668, Marte and Giove, compared with the North American genotype UC-157 as control, a greenhouse trial was initiated on 15/11/2006 by means of seedlings transplanted at a spacing of $1 \mathrm{~m} \times 0.3 \mathrm{~m}$. Thirty-five harvests were performed between $21 / 08 / 2013$ and 16/10/2013. The characters studied were: total and commercial production of the different hybrids (TFP and CFP), total and commercial number of turions ha-1 (TTN and CTN) and calibre distribution (CD): Jumbo (J), Extra-Large (XL), Large $(\mathrm{L})$, Medium (M), Small (S) and Asparagin (A) were studied. Analysis of variance was performed and means were compared using the LSD test $(P \leq 0.05)$. For TFP, the cultivars Italo: 25800(a), Zeno:15900 and Giove:12400(b) stood out from the rest, followed by UC157: 7400; Ercole: 7000 and Eros: 6800(c); H-668: 5100(cd) and Marte: 3100(d), whereas for CFP, Italo: 13400(a) stood alone, followed by Zeno: 7200 and Giove: 6400(b); UC-157: 4000; Ercole: 3100 and Eros: 3300(cd); H-668: 1900(d) and Marte: 1700(d). For TTN, Italo:1155000(a) again stood out, followed by Zeno: 557515(b); Giove: 542500(bc); H-668: 457485 and Eros: 447510(bcd); Ercole: 402500(cd); UC-157: 347515; Marte: 194985(e); for CTN, Italo: 822500 (a) similarly outperformed the rest, followed by Giove: 367500; Zeno: 325010(b), UC-157: 227500(c), Eros: 207515(cd), H-668: 172515(cd), Marte: 120015(d). For DC, J, L, M and S Italo(a) again showed superior performance, whereas for XL and $A$ there was homogeneous calibre production. It can therefore be concluded that the cultivar Italo was the best option amongst the hybrids tested. 


\section{Seedling production}

Astrit Balliu1*, Nina Kacjan Maršić ${ }^{2}$, Nazim Gruda³

${ }^{1}$ Agricultural University of Tirana, Faculty of Agriculture, Kodër Kamëz, SH1, Tirana 1000, Albania

* e-mail: aballiu@ubt.edu.al

2University of Ljubljana, Biotechnical Faculty, Jamnikarjeva ulica 101, 1000 Ljubljana

${ }^{3}$ University of Bonn, Faculty of Agriculture, Meckenheimer Allee 174 D-53115 Bonn,

Germany

Keywords: substrate, seed, temperature regime, fertigation, hardening, grafting

The production of vegetable seedlings for transplanting is an extremely important operation. If farmers do not use high quality, healthy and vigorous seedlings the full potential yield potential cannot be achieved. Though still are farmers producing the seedlings by themselves, separation of transplant production from the final crop production is a recent worldwide trend. Production of high quality transplants is highly desirable in greenhouse crop production. Though there are not well distinct standards, high quality transplants are generally defined as those with: no infections of diseases or pests; ability to survive in unfavorable environments after transplanting; good morphology suitable for planting; well developed root system (or higher root to shoot ratio); no visual defect such as chlorosis (yellowing) or nechrosis (dead tissue). Achieving disease-free and pest-free status is the primary quality characteristics necessary for greenhouse transplants. Vegetable seedlings might be either non grafted or grafted. The latest is a unique horticultural technology used to: overcome soil-borne diseases and pests and to add vigour to plants under various environmental stress conditions; increase soil-borne disease and pest resistance/tolerance; increase tolerance to abiotic stresses (e.g. soil temperature, drought or salt stress); and increase plant vigour and yields. Grafting can also improve fruit quality (e.g. increasing firmness), although negative effects (e.g. altered flavour, reduced sugar content) are sometimes reported. 


\title{
Training of soil grown cherry tomato in the open field and in the tunnel
}

\author{
Kristina Ugrinović*, Mojca Škof \\ Agricultural Institute of Slovenia, Hacquetova 17, Ljubljana, Slovenia \\ *e-mail: kristina.ugrinovic@kis.si
}

Keywords: Solanum lycopersicum, number of stems, yield dynamics, variety, open field, protected area

When grown in the soil, indeterminate tomato in Slovenia is traditionally trained to one stem. Two stems training is occasionally practiced for soil grown grafted plants, while it is a prevailing training system for hydroponically grown plants. The trials with two varieties (Sweet Million and Tomatoberry) of cherry tomato were set up in the open field (location Lucija, submediterranean climate) and in unheated plastic tunnel (location Jablje, temperate continental climate) to test two training systems for ungrafted soil grown plants. Two-stems training (2S), conducted as primary stem plus secondary stem from the first strong auxiliary shoot on the primary stem, was compared with traditional one-stem training (1S). The planting density was adjusted to reach the same stem density per surface area - for $2 S$ training the number of transplants was reduced by halves as compared to $1 \mathrm{~S}$ training. The development of plants, the amount of yield and the dynamics of fruit ripening were monitored. Harvesting begun at about the same time on both locations, but it lasted only about 2 month in the open field and about 3.5 month under the tunnel. The final yields in the open field were only about one third of those achieved under the tunnel, while the early yields in the open field were about two thirds of those from the tunnel. On both locations, the $1 \mathrm{~S}$ plants of both varieties produced only about half as many fruits as $2 \mathrm{~S}$ plants and, secondary stems of $2 \mathrm{~S}$ plants produced less fruits than primary stems. Final yield per surface area did not significantly differ among the both training systems in neither of locations; anyhow the yield of first harvests of $2 S$ plants was significantly lower than that of $1 S$ plants on both locations and for both varieties. The differences between the two varieties were significant only in the tunnel where Sweet Million in total yielded more than Tomatoberry, but the yields of the first harvests of Tomatoberry were higher than those of Sweet Million. 


\section{Production systems in SEE greenhouses}

Gordana Popsimonova ${ }^{*}$, Božidar Benko², Ljutvia Karić3 ${ }^{3}$ Nazim Gruda ${ }^{4}$

${ }^{1}$ University Ss Cyril and Methodius, Faculty of Agricultural Sciences and Food, Blvd.

Aleksandar Makedonski bb, Skopje, 1000, Macedonia

* e-mail: gpopsimonova@yahoo.com

2University of Zagreb, Faculty of Agriculture, Department of Vegetable Crops,

Svetosimunska 25, Zagreb 10000, Croatia

${ }^{3}$ University of Sarajevo, Hrasnička cesta 15, 71210 llidža, Sarajevo, Bosnia and Herzegovina

${ }^{4}$ University of Bonn, Faculty of Agriculture, Meckenheimer Allee 174 D-53115 Bonn,

Germany

Keywords: soil-less cultivation, organic production, integrated crop management

South Eastern European (SEE) greenhouses vary in technological advancement, individual size and legislative environment. This paper is an attempt to provide advices on common issues that would be easily accessible and acceptable by growers in the whole region. It describes greenhouse production systems - integrated production in the soil or in soilless culture systems and organic crop production compared with conventional cultivation. Specific cultivation practices and various options are explained for growers, depending on the technology used and in accordance with the climatic and economic conditions. For soil cultivation, the emphasis is placed on soil testing, fertilization planning and diseases monitoring, as well as mulching and crop rotation. Organic production additionally requires use of certified organic reproductive materials, as well as certified organic plant protection products and fertilizers. To acquire best results from soil-less cultivation growers should adapt the irrigation strategy to the physical properties of the growing media and consider sustainability and environmental protection. Closed systems are more environmentally friendly than open systems. Growers are advised to keep records of all inputs and operations, regardless the production system. Besides helping the crop production planning and inspections, this is an excellent basis to quantify the various parameters influencing the production price. Investment costs and a template table for calculation of variable costs are included in order to provide farmers with a tool to make an economic assessment. 


\section{Screenhouses as a cropping system alternative to open field cultivations}

Evangelini Kitta ${ }^{*}$, Nikolaos Katsoulas ${ }^{2}$, Constantinos Kittas ${ }^{2}$

${ }^{1}$ Centre for Research and Technology Hellas, Dimitriados 95, 38333 Volos, Greece

* e-mail: eva.kitta@gmail.com

2University of Thessaly, Department of Agriculture Crop Production and Rural Environment, Fytokou St, 38446, New Ionia, Magnisia, Greece

Keywords: screen; insect proof; under cover; shading; microclimate

Hi-tech greenhouses are capable of providing the optimal conditions for year-round production; however, they constitute the most expensive option, in terms of capital, running costs and energy consumption. Screenhouses covered by shading or insect proof screens are becoming popular among growers in arid and semiarid regions like the Mediterranean area, due to the environmental, economic and agronomic benefits they offer. In order to study the effect of screens on screenhouse and crop microclimate and on crop production, experiments were carried out during two years in three screenhouses cultivated with a sweet pepper crop and covered by different screens and the results were compared with an open field crop. The first screenhouse was covered with an insect proof screen with shading intensity of about $20 \%$, the second one with an insect proof screen with shading intensity of about $35 \%$ and the third one with a shading screen with shading intensity of about $35 \%$. The light quality characteristics observed under screens were related to the optical properties of the screens. It was found that net-covering had a positive effect on plant physiology by preventing a down-regulation of photosynthesis during periods of high radiation. Furthermore, the presence of the screen material decreased the air velocity inside the screenhouse and along with the changes in solar radiation under screens affected crop sensible and latent heat exchange. Finally, the yield and quality of pepper fruits was higher under screenhouse conditions than in open field. 


\title{
Adapt2Change: The semi-closed greenhouse
}

\author{
Nikolaos Katsoulas*, Constantinos Kittas
}

University of Thessaly, Department of Agriculture Crop Production and Rural Environment, Fytokou St, 38446, New Ionia, Magnisia, Greece

* e-mail: nkatsoul@uth.gr

Keywords: renewable energy; cooling; heating; dehumidification; water recycling

Adapt2Change is a project funded in the frame of LIFE+ projects (LIFE09 ENV/GR/000296). The objectives of the project were to minimize fresh water use for agricultural production and introduce water collection and recycling methods in a closed greenhouse system, demonstrate how shallow geothermal energy may be used in water recycling process and introduce renewable energy use in the agricultural sector. In the framework of this project a prototype greenhouse was designed to operate as semi-closed, constructed and tested in Greece and Cyprus. A heat pump system and heat exchangers were installed in the greenhouse to be used for heating, cooling and dehumidification. The heat pump were connected with drillings for heat exchange with underground water. During periods that the greenhouse needs cooling, the greenhouse air is cooled and dehumidified the same time through the heat exchangers. The vapour collected during the cooling mode is recycled and used for irrigation. The heat exchangers are cooled via the heat pumps. However, since the installed power was only $140 \mathrm{~W} \mathrm{~m}^{-2}$, it was not sufficient for greenhouse cooling during periods with high heat load and thus the greenhouse vents were opened to reduce cooling needs. During periods were the greenhouse needs heating, the system was used for both heating and dehumidification. The greenhouse air was first cooled below the dew point temperature for dehumidification purposes and then heated again before entering the greenhouse. The heat gained during the dehumidification process was released again in the greenhouse during the heat process. The installed heat power of $140 \mathrm{~W} \mathrm{~m}^{-2}$ was enough to fully cover the greenhouse heating needs. The system was tested for three cultivation periods and compared to a conventional greenhouse with cultivation in the soil. It was found that the use of the prototype greenhouse could result to a $70 \%$ water saving, a $60 \%$ of energy saving, an increase of production and an excellent quality of vegetables eliminating the needs for use of products for crop fungi control. 


\section{Technologies and Techniques for Sustainable Greenhouse production in Slovenia}

\section{Constantinos Kittas*, Nikolaos Katsoulas}

University of Thessaly, Department of Agriculture Crop Production and Rural Environment, Fytokou St, 38446, New Ionia, Magnisia, Greece

* e-mail: ckittas@uth.gr

Keywords: greenhouse design; climate control; cover materials; water management; energy saving

A high quality production of vegetables and ornamentals under cover with less energy, water, fertilizers and pesticides and homogeneous environment in the enclosure, call for a better design and management of greenhouse climate control. Therefore, the different systems of climate control (heating, ventilation, cooling) are firstly presented, analysed and discussed. Simultaneously, we simply refer how the substantial progresses in Computer Fluid Dynamics (CFD) modelling can be used for the 3D characterization of the flow field, heat and mass transfer aiming in better design and management of greenhouses climate control equipment. In addition, the substantial technological advances in physical plant protection tools used to avoid chemical inputs in greenhouse ecosystem are presented and especially insect proof screens and photoselective cover materials. Furthermore, since, recent studies about the crop-climate relationships induced by the new energy saving techniques indicate that the influences of high inside air confinement, as in closed or semi closed greenhouses, on inside air humidity and $\mathrm{CO}_{2}$ content are very important, their consequences are analysed in terms of greenhouse water consumption. 
IRRIGATION AND PLANT-WATER RELATIONS

$-59-$ 


\title{
Spinach production in cocopeat: Effects of plant density and the number of emitters on plant growth and nitrate concentration
}

\author{
Rui Machado*, Isabel Alves-Pereira, Rui Ferreira \\ University of Évora, Institute of Agrarian and Environmental Environmental Sciences, 7000 \\ Evora Codex, Mitra, Portugal \\ * e-mail: rmam@uevora.pt
}

Keywords: Spinacia oleracea, soilless culture systems, cocopeat, yield, nitrate

Currently, the interest in the use of coir dust (or cocopeat) as a growing medium has increased. The aim of this research was to evaluate the effects of plant density and the number of emitters per Styrofoam box on plant growth, nitrate $\left(\mathrm{NO}_{3}{ }^{-}\right)$concentration and antioxidant activity in spinach (Spinacia oleracea L. cv. Manatee) cultivated in cocopeat. The experiment was carried out with four treatments, including two plant densities (160 and 280 plants $/ \mathrm{m}^{2}$ ) and two number of emitters per Styrofoam box ( 4 and 8 emitters). The crop was irrigated and fertigated daily with a complete nutrient solution, in which $\mathrm{NO}_{3}{ }^{-} / \mathrm{NH}_{4}{ }^{+}$ratio decreased through the crop cycle. Shoot dry weight was not affected by plant density or emitter number. However, the yield $\left(\mathrm{kg} \mathrm{m}^{-2}\right)$ increased significantly with plant density and with the number of the emitters by Styrofoam box. The yield in treatment 280 plants $/ \mathrm{m}^{2}$ and 8 emitters reached $5.4 \mathrm{~kg} \mathrm{~m}^{-2}$. Leaf-blade and petiole $\mathrm{NO}_{3}{ }^{-}$concentration was not affected by plant density, number of emitters and the interaction between treatments. Leafblade and petiole $\mathrm{NO}_{3}{ }^{-}$concentration was low, ranged from 0.49 to 0.56 and 0.94 to 0.96 $\mathrm{NO}_{3}^{-} \mathrm{mg} \mathrm{g}^{-1}$ fresh weight, respectively. These results indicate that cocopeat is a very suitable growing medium for spinach production. 


\section{Impact of different rhizobial strains and reduced $\mathbf{N}$ supply on growth and biological $\mathrm{N}_{2}$-fixation in cowpea grown hydroponically}

Georgia Ntatsi*, Christina Vrontani, Maria Vlachou, Eleni Rizopoulou, Christos Fotiadis, Andreas Ropokis, Anastasia Tampakaki, Dimitrios Savvas

Agricultural University of Athens, Laboratory of Vegetable Crops, lera Odos 75, 11855

Athens, Greece

* e-mail: ntatsi@aua.gr

Keywords: legume, nitrogen, strains, hydroponics, Vigna unguiculata, Ensifer spp.

One of the strategies contributing to a more sustainable crop production in greenhouses is the reduction of nitrogen input without compromising yield. To this end, relevant rhizobial strains capable of biologically fixing atmospheric nitrogen are used to inoculate legume plants like beans grown in greenhouses. In soilless culture, inoculation of legumes with rhizobia can considerably reduce the input of inorganic nitrogen to the nutrient solutions. However, the practical application of this approach encounters some difficulties. On the one hand, the supply of plant available nitrogen is important at the early growth stage when the rhizobia are still not functional in terms of $\mathrm{N}_{2}$-fixation. On the other hand, inorganic nitrogen and especially nitrate $\mathrm{N}$ inhibits rhizobia colonization. To cope with these two contrasting issues, a fine tuning of the $\mathrm{N}$ supply is needed, when legumes grown in soilless culture are inoculated with relevant rhizobial strains. In the present study, two different indigenous rhizobial strains, Bradyrhizobium spp. and Ensifer spp., and a mixture of them were used to inoculate cowpea (Vigna unguiculata subsp. unguiculata (L.) Walp) grown in perlite and supplied with different $\mathrm{N}$ levels to test their inoculation and $\mathrm{N}$-fixation ability. Plants were supplied with either full-N (total-N $11.2 \mathrm{mM}$ ) or $60 \%$ of full-N until the flowering stage. Afterwards, the $\mathrm{N}$ supply was either reduced to $30 \%$ or fully starved until the end of the cultivation period. BNF was quantified at the early pod filling stage using the $15 \mathrm{~N}$ natural abundance method. Biomass, yield and nutrient uptake were also estimated. The results showed that applying different rates of inorganic $\mathrm{N}$ before and after the formation of N2fixing nodules could be considered an effective strategy to reduce $\mathrm{N}$ fertilizer supply in hydroponic cowpea crops without compromising yield. 


\section{Production of Valeriana officinalis roots in different soil structure in East Albania}

Shkelqim Karaj ${ }^{1}$, Nazim Gruda2* ${ }^{2 *}$ Matthias Buscher ${ }^{3}$, Joachim Müller ${ }^{1}$

${ }^{1}$ University of Hohenheim, Hohenheim, Germany; shkelqim_karaj@uni-hohenheim.de (coauthor)

2University of Bonn, Faculty of Agriculture, Meckenheimer Allee 174 D-53115 Bonn, Germany

* e-mail: nazim.gruda@uni-bonn.de

${ }^{3}$ Agro-MAP, Tirana, Albania

Keywords: valerian, medicinal aromatic plants, MAP, plant production

Valerian (Valeriana officinalis L.) is a perennial crop, whose roots and rhizomes are most commonly used as herbal raw materials. Selection of soil type for valerian cultivation is very essential for plant production. The production of valerian roots in three different soil types (heavy clay soil, medium loam and light sandy soil) and three different altitudes (600, 800 and 1000 m.a.s.I.) was evaluated in region of Prrenjas, East Albania. Plant growth data sets were collected form nursery to plant maturity stage. All experimental fields were treated with same agricultural technology. The yield was measured and the harvest labor intensity at different soil types was evaluated. Large differences were observed in root formation at different soil types. Heavy soils were characterized by small root formation with thick main roots and very low rhizome development. Whereas medium and light soils large roots with high rhizome formation. Harvest was more labor intensive in heavy soils than medium and light, respectively. Light and sandy soils reach in potassium are very suitable for optimal growth. There was not detected any effect of altitude in plant growth for the tested area. More research is needed for determining oil composition and product quality of valerian plants produced in Albania as medicinal and aromatic plant. 


\section{Deficit irrigation and its potential for yield and potato quality in humid climates}

Rozalija Cvejić1* ${ }^{*}$, Vesna Zupanc ${ }^{1}$, Blaž Germšek², Peter Dolničar², Marina Pintar ${ }^{1}$

${ }^{1}$ University of Ljubljana, Biotechnical Faculty, Jamnikarjeva 101, 1000 Ljubljana, Slovenia

* e-mail: rozalija.cvejic@bf.uni-lj.si

${ }^{2}$ Agricultural Institute of Slovenia, Hacquetova 17, Ljubljana, Slovenia

Keywords: deficit irrigation, potato

Potatoes are variably sensitive to water deficit. There are several studies in which the influence of controlled deficit irrigation has been studied on potato crop cultivated in arid and semi-arid zones, using drip irrigation. Several factors have been identified as important, namely growth stage, extent of water deficit, nutrient regime and irrigation strategy (such as partial root drying). Depending on the growth stage on which the water deficit was imposed variation in yield quantity and quality was recorded. Irrigated water increased yields not only by increasing tuber number, but also by increasing the mean weight of the tubers. In the presented study, factors influencing potential for deficit irrigation in potatoes crop production in humid climate for Slovenia were evaluated. Feasibility study considered standard potatoes growing practices and tillage as well as irrigation technique availability and know-how. 


\title{
Configuration of basil quality and aroma profile in response to cultivar, cut number and salinity source
}

\author{
Youssef Rouphael ${ }^{1 *}$, Marios C. Kyriacou ${ }^{2}$, Giuseppe Colla ${ }^{3}$, Annalia Civitillo ${ }^{1}$, Maria \\ Giordano $^{1}$, Antonello Paduano ${ }^{1}$, Raffaele Sacchi ${ }^{1}$, Stefania De Pascale ${ }^{1}$ \\ ${ }^{1}$ University of Naples Federico II, Department of Agricultural Sciences, Via Università 100, \\ 80055 Portici, Napoli, Italy \\ * e-mail: youssef.rouphael@unina.it \\ ${ }^{2}$ Agricultural Research Institute Cyprus, Department of Vegetable Crops, Nicosia, Cyprus, \\ Cyprus \\ ${ }^{3}$ Tuscia University, Department of Agricultural and Forestry, Via Santa Maria in Gradi, 4, \\ 01100 Viterbo, Italy
}

Keywords: aroma volatile composition, phenols, mineral composition, nutrient solution management, vitamin C, nitrate.

Basil (Ocimum basilicum L.) is one of the most common aromatic herbs cultivated all over the world. It is widely used for its aromatic and culinary purposes. Consumer demand for fresh basil has been rising and many farmers of leafy vegetables have oriented their production schemes to include basil. The management of mineral nutrition is a key preharvest factor determining the yield and quality of leafy vegetables. In this perspective, hydroponics represents an important tool, since it provides the possibility of regulating secondary metabolism, implicated in the production of aromatic volatiles, by proper control of the nutrient solution composition. Another cultivation practice that may affect the quality of leafy vegetables and herbs is the number of cuts. Leafy vegetables are cut several times ( 2 or 3 ) during the growing cycle, leading to physiological changes that affect the plant and obviously the obtained product. The aim of this research was to assess in a multi-factorial approach the effects of the number of cuts and nutrient solutions enriched with both $\mathrm{NaCl}$ and $\mathrm{CaCl}_{2}$ at two different iso-osmotic concentration levels (non-salt control, low $\mathrm{NaCl}+$ $\mathrm{CaCl}_{2}$, low $\mathrm{NaCl}$, high $\mathrm{NaCl}+\mathrm{CaCl}_{2}$, and high $\mathrm{NaCl}$ ) on yield, mineral composition, nitrate content, bioactive compounds and aroma composition of green and purple basil cultivars. Low and high $\mathrm{NaCl}$ concentrations in the nutrient solution as well as high $\mathrm{NaCl}+\mathrm{CaCl}_{2}$ reduced yield, while similar values were recorded between low $\mathrm{NaCl}+\mathrm{CaCl}_{2}$ and control treatments. Green cultivar exhibited higher yield, whereas the purple one was characterized by high levels of antioxidant activity, Vitamin $\mathrm{C}$ and total phenols contents. The second cut influenced positively the mineral composition ( $\mathrm{K}$ and $\mathrm{Ca}$ ) and nutritional quality and negatively the content of nitrates of both cultivars. The total number of volatile compounds detected through SPME/ GC-MS analysis were 86, of which 48 terpenes and 38 other compounds (aldehydes, alcohols and esters). Particularly, eucalyptol and $\beta$-linalol increased significantly under low $\mathrm{NaCl}$, High $\mathrm{NaCl}+\mathrm{CaCl}_{2}$ and high $\mathrm{NaCl}$. Overall, the application of low concentration of $\mathrm{NaCl}+\mathrm{CaCl}_{2}$ in the nutrient solution produced basil leaves with high bioactive content without compromising yield. 


\section{Arbuscular mychorrizae fungi (AMF) improves stand establishment and enhances root morphology parameters of pea (Pisum sativum L.) plants under suboptimal temperature conditions}

Astrit Balliu*, Glenda Sallaku

Agricultural University of Tirana, Faculty of Agriculture, Horticultural Department, Kodër Kamëz, SH1, Tirana 1000, Albania

*e-mail: aballiu@ubt.edu.al

Keywords: root length, root surface area, root morphology, relative growth rate

The study aimed to investigate the effects of commercially available AMF inoculate (Glomus sp. mixture) on the growth and root morphology of field pea (Pissum sativum L.) plants under suboptimal temperatures during and immediately after germination. Inoculated (AMF+) and non-inoculated (AMF-) pea plants were subjected to two levels of environment temperatures. For that purpose, an equal number of seeds sown in foam trays filled with vermiculate were put in two different growth chambers and kept in there till the 22nd day after sowing. The germination rooms were settled to constant air temperatures of respectively $10^{\circ} \mathrm{C}$ and $15^{\circ} \mathrm{C}$ and in both the relative humidity were maintained at $90 \%$, PPFD $180 \mu \mathrm{mol} \mathrm{m} \mathrm{m}^{-2} \mathrm{~s}^{-1}$ with a photoperiod of $12 \mathrm{~h}$. Several times during the growing cycle, in randomly selected plants the morphology of root system was analyzed and the dry matter of roots and the above ground biomass were individually measured. The growth and the morphology of root system were highly influenced by environment temperature. Consequently, total root length, root projected area, root surface area and root volume of plants grown under suboptimal environmental temperatures were significantly smaller compared with plants grown in optimum environment temperature. However, the inoculation of AM fungi in the growing substrate enhanced root system and plant growth rates and significantly improved root morphology parameters. Therefore, the artificial inoculation of AM fungi could be considered as an effective alternative to improve growth of pea plants under suboptimal temperature conditions. 


\section{The uptake of selenium and iodine in chicory (Cichorium intybus L.) after foliar spraying}

Ana Kroflič ${ }^{1 *}$, Nina Kacjan Maršić ${ }^{2}$, Ana Jerše ${ }^{1}$, Mateja Germ², Helena Šircelj² ${ }^{2}$ Vekoslava Stibilj ${ }^{1}$

${ }^{1}$ Jozef Stefan Institute, Jamova cesta 39, 1000 Ljubljana

* e-mail: ana.kroflic@ijs.si

2University of Ljubljana, Biotechnical Faculty, Jamnikarjeva 101, SI 111 Ljubljana, Slovenia

Keywords: selenium, iodine, foliar spraying, chicory

Selenium (Se) and iodine (I) are known as essential elements in humans and animals. However, their essentiality for plants is not confirmed yet. The main reason for insufficient intake of both elements is low content of bioavailable Se and I forms in soil. Consequently, the uptake of plants and further transfer along the food chain is low. Interactions between Se (as selenite and selenate) and I (as iodate and iodide) uptake by chicory (Cichorium intybus L.) and their effect on selected morphological and physiological characteristics were studied. Seedlings were transplanted on the field and at the beginning of head formatting, chicory leaves were foliar sprayed with the following solutions: Milli-Q water (control), Se(IV), Se(VI), $\mathrm{I}(-\mathrm{I}), \mathrm{I}(\mathrm{V}), \mathrm{Se}(\mathrm{IV})+\mathrm{I}(-\mathrm{I}), \mathrm{Se}(\mathrm{IV})+\mathrm{I}(\mathrm{V}), \mathrm{Se}(\mathrm{VI})+\mathrm{I}(-\mathrm{I})$ and $\mathrm{Se}(\mathrm{VI})+\mathrm{I}(\mathrm{V})$. Concentrations of Se and I were $10 \mathrm{mg} / \mathrm{L}$ and $1000 \mathrm{mg} / \mathrm{L}$, respectively. Chicory heads were sampled, lyophilized, milled and stored at $-20^{\circ} \mathrm{C}$ until analysis.

Different treatments did not significantly affect yield (30 - 38 t/ha) and mass ( $970-1200 \mathrm{~g})$ of chicory heads. Se content was enhances up to 8-fold in comparison with control plants containing $26 \mathrm{ng} \mathrm{Se/g} \mathrm{DW.} \mathrm{Chicory} \mathrm{was} \mathrm{enriched} \mathrm{with} \mathrm{I} \mathrm{up} \mathrm{to} 730 \mathrm{ng} / \mathrm{g}$ DW, while I content in control plants was 7-times lower. lodine in spraying solution had different effect on Se uptake by chicory and vice versa. Plants, treated with I(V) had lower amount of chlorophyll a, carotenoids and anthocyanins comparing to control. On the other hand, respiratory potential was higher in comparison with control indicating possible presence of stress in I(V) treated plants. However, potential photochemical efficiency of photosystem II was similar in control and treated groups and close to theoretical maximum (0.83), showing that plants were in good condition. 


\section{Differences in the mode of salt tolerance between self-rooted and grafted tomato cultivars and their impact on modeling $\mathrm{NaCl}$ accumulation in a closed hydroponic system}

Dimitrios Savvas*, Konstantinos Tsopelopoulos, Stavroula Filopoulou, Christos Vourdas, Manolis Chatzigiakoumis, Panagiotis Panagi, Nikolaos Fanourakis, Andreas Ropokis, Georgia Ntatsi

Agricultural University of Athens, Laboratory of Vegetable Production, lera Odos 75, 11855 Athens, Greece

* e-mail: dsavvas@aua.gr

Keywords: salinity, hydroponics, soilless culture, grafting, Solanum lycopersicum L.

The irrigation water in Mediterranean countries is frequently characterized by high $\mathrm{Na}^{+}$and $\mathrm{Cl}^{-}$concentrations. If this water is used to prepare nutrient solution (NS) for vegetable crops grown in closed hydroponic systems, a gradual accumulation of these ions in the recycled NS is observed, which may reach harmful levels for plant growth and yield. To avoid an undesirable increase of the salt concentration in the root zone of the plants, the recycled NS should be regularly discharged, thereby lowering the benefits of recycling. To address this problem, proper automated management of the recycling process by using mass-balanced models may reduce the frequency of drainage solution discharge. In the present study, a model previously developed to simulate the course of $\mathrm{Na}^{+}$and $\mathrm{Cl}^{-}$accumulation in closed hydroponic systems, as a function of plant water consumption, was further evaluated using different tomato genotypes and rootstock/scion combinations. For this reason, a greenhouse experiment was conducted with four different tomato (Solanum lycopersicum) cultivars, namely 'Lobello', 'Formula', 'Merillia', and 'Belladonna'. Moreover, to test whether grafting elite cultivars modifies the course of $\mathrm{Na}+$ and $\mathrm{Cl}$ - accumulation in closed hydroponic systems, the tomato cultivars 'Merillia' and 'Belladonna' were grafted onto the rootstock Armstrong (S. lycopersicum L.XS. habrochaites). All plants were grown in recirculating nutrient solution with three replicates per treatment and nine plants per replication. The $\mathrm{NaCl}$ concentration in the NS introduced to the closed system to compensate for nutrient and water uptake by plants was either 0.6 or $5 \mathrm{mM}$. In the present paper, the relationship between $\mathrm{Na}^{+}$or $\mathrm{Cl}^{-}$exclusion efficiency and yield performance is presented and discussed. Furthermore, the differences in the $\mathrm{Na}^{+}$and $\mathrm{Cl}^{-}$exclusion efficiency between the tested root and rootstock/scion genotypes were related to commensurate differences in the rates of $\mathrm{Na}+$ and $\mathrm{Cl}$ - accumulation. The need to apply different calibration constants for cultivars with strong genotypic differences in $\mathrm{Na}^{+}$and $\mathrm{Cl}^{-}$exclusion efficiency when using models to predict the rate of salt accumulation in closed hydroponic systems is discussed. 


\section{Response of potatoes to fertilizer application and nutrient use efficiency in Bulgaria}

Ivan Manolov ${ }^{1 *}$, Nidal Shaban², Sergey Bistrichanov², Margarita Nikolova², Boyan Stalev ${ }^{1}$, Anton Yordanov ${ }^{1}$

${ }^{1}$ Agricultural University - Plovdiv, Department of Agrochemistry and Soil Science, Mendeleev 12, 4000 Plovdiv, Bulgaria

* e-mail: manolovig@yahoo.com

${ }^{2}$ University of Forestry, Kliment Ohridski Street 10, Sofia 1756, Bulgaria

Keywords: potato, omission effects of nutrients, nutrient use efficiency

In the frame of the large extensive research project titled "Best agricultural practices for sustainable crop nutrition in Bulgaria" supported by the International Plant Nutrition Institute (IPNI) the response of potatoes to nutrient fertilization was studied. The potatoes trials were carried out on two locations in the two most suitable regions for potato growing in the country (Smolyan and Merdanya). The experiment was designed on the base of omission plots (control, N, P, K, NP, NK, PK, NPK, NPKMg). The paper presents the effects of fertilization on the yield, and the effects of nutrient omission (N, P and K) from the triple fertilizer combination on the yield. Nutrient use efficiency (NUE) indicators - Partial Factor Productivity (PFP) and Agronomic Efficiency (AE), were calculated. The results showed that potatoes' response was quite different in the two locations. On both sites the main limiting nutrient was nitrogen followed by potassium. The NUE indicators outline significant specificity of the trials sites - at almost equal PFP both location show rather different AE for the three nutrients. Agronomic efficiency at Merdanya where the soil was more fertile was lower than in Smolyan for the three nutrients. High AE for magnesium was obtained in Smolyan because of low exchangeable Mg contentin the soil. The nutrient omission effects also differ on the two locations. In Smolyan highest omission effect has nitrogen - almost $50 \%$ of the nutrient effect. In Merdanya because of higher yield level, potassium has the same omission effect as nitrogen and reaches $75 \%$. The results at both sites suggest that fertilizer recommendations for potatoes should account for the specificity of the site in question. 


\title{
Soil water management for vegetables in greenhouse conditions
}

\author{
Harun Kaman ${ }^{1 *}$, Ömer Özbek² \\ ${ }^{1}$ University of Akdeniz-Faculty of Agriculture, Dumlupinar Bulvari, 07985 Antalya, Turkey \\ ${ }^{2}$ Bati Akdeniz Agricultural Research Institut, Antalya, Turkey \\ * e-mail: hkaman@akdeniz.edu.tr
}

Keywords: drip irrigation, vegetable, soil water, PR2

Irrigation, especially in arid and semi-arid climatic conditions, is extremely important for the plants growing in the field and/or greenhouses because it is a well-known fact that a significant increase in productivity can be obtained through irrigation. Despite the fact that the water resources in the world have not changed, the rapid growth in population and industrialization have brought about the necessity for reducing the water spared for irrigation purposes. However, excessive use of irrigation water for crop production leads to the waste of good quality water which is of good quality especially with regards to natural contents. In addition, excessive water use raises groundwater level, leading to the problems such as salinity and precipitation. The problems identified above are important risk factors for sustainable agriculture. For the sake of the mentioned reasons, the water content in the plant root region must be correctly determined for a sustainable crop production. Thus, irrigation water can be applied at the right time and as much as needed for the plant. In this research, it is aimed to determine and monitor the water content in the plant root zone. Irrigation applications were conducted by drip irrigation method. The three different irrigation water levels (T1, T2 and T3) were used in the monitoring of the water content in the plant root zone in the study. As a result of the research, it was found that there are some differences in the water content in the plant root zone under T1, T2 and T3 treatments. As a result, it has been determined that it is very important to determine and monitor the water content in the plant root zone before and after irrigation in vegetable growing under greenhouse conditions. 


\title{
Effect of water reduction rate on vegetables
}

\author{
Ömer Özbek ${ }^{1}$, Harun Kaman²* \\ ${ }^{1}$ Bati Akdeniz Agricultural Research Institut, Antalya, Turkey \\ ${ }^{2}$ University of Akdeniz-Faculty of Agriculture, Dumlupinar Bulvari, 07985 Antalya, Turkey \\ * e-mail: $\underline{\text { hkaman@akdeniz.edu.tr }}$
}

Keywords: drip irrigation, eggplant, fruit weight, soil water

Some causes such as population increase and urbanization put pressure on reducing the amount of water used in agriculture. For this reason, it is very important to apply and develop the techniques that save irrigation water by the least reducing the loss of productivity in crop production. In this study, some parameters were measured and handled during the growing season when the need for water was fully met and when deficit water irrigation was applied. The research was carried out in a greenhouse in Antalya, a province of Turkey, where Mediterranean climate conditions are dominant. In the study, three different irrigation water levels were applied by drip irrigation method as $100 \%, 75 \%$ and $50 \%$. In the study, traditional deficit and partial root drying applications were compared with the control treatment. As a result of the research, it was concluded that water reduction rates and irrigation application techniques were effective on the eggplant vegetation. The relationship between the number of fruits harvested and the average fruit weight varied considerably from treatment to treatment. The regression coefficient for average fruit weight and the amount of irrigation water used varied between 0.94 and 0.03 for the treatments. The regression coefficients for the irrigation water and number of fruits harvested varied between 0.94 and 0.42 . It was also found out that the number of leaves per irrigation treatment changed between 79 and 39 during the periods when plants experienced maximum development. 


\title{
Effect of deficit irrigation and soil water content on tomato yield in the peruvian semi-arid coastline
}

\author{
Ximena Reynafarje ${ }^{1 *}$, Eddie Schrevens ${ }^{2}$, Diego Grados ${ }^{1}$, Andres Casas $^{1}$ \\ ${ }^{1}$ National Agrarian University - La Molina, Avenida La Molina, Lima 15024, Peru \\ * e-mail: xreynafarje@gmail.com \\ 2University of Leuven, Department of Biosystems, Oude Markt 13, 3000 Leuven, Belgium
}

Keywords: deficit irrigation, soil water content, TDR, tomato.

Tomato national production is concentrated in the semi-arid coastal areas (65\%) (MINAGRI, 2014). Average annual rainfall in this region is $40 \mathrm{~mm}$. Therefore, agriculture depends exclusively on irrigation water from the rivers. In previous research, we observed average water use exceeds $200 \%$ of FAO crop evapotranspiration (ETc), reducing water and fertilizers use efficiency. An experiment with a drip irrigation system, where four deficit irrigation treatments were applied based on ETc (30,60, 90 and 120\%) was installed for a low-density planting $\left(7500 \mathrm{pl} \mathrm{ha}^{-1}\right)$. The soil in the experimental site is a loam with a depth of $70 \mathrm{~cm}$ and the following characteristics: saturation (SAT) $43 \%$, field capacity (FC) $27 \%$ and wilting point (WP) $13 \%$. Soil volumetric water content at four depths $(10,20,30 \& 45 \mathrm{~cm})$ was measured using a time domain reflectometry system (TDR). Observed soil water content (WC) on average was kept between FC and SAT for $120 \%$, and FC and WP for 60 and $90 \%$. The case for the lowest treatment (30\%) resulted in a relatively higher WC possibly due to low rooting volume and shoot biomass. Coverage was measured on the weekly basis resulting on a maximum coverage of $80 \%, 60 \%, 50 \%$ and $40 \%$ for the treatments $120 \%, 90 \%, 60 \%$ and $30 \%$ of ETc respectively.Tomato production was significantly affected by irrigation treatments. The highest yield was obtained with $120 \%$ of ETc $\left(50.23 \mathrm{t} \mathrm{ha}^{-1}\right)$, with significant differences between this and deficit irrigation (90, 60 \& 30\% ETc) yielding 25.98, 18.3 and $16.6 \mathrm{t} \mathrm{ha}^{-1}$ respectively, being below the national average yield $\left(35 \mathrm{t} \mathrm{ha}^{-1}\right)$, however we were able with the $120 \%$ treatment to get a $15 \mathrm{t} \mathrm{ha}^{-1}$ additional yield reducing the average water use in at least $80 \%$. In further research, we will use processed based mechanistic modelling to simulate the water transport dynamics under fertigation. 
$-72-$ 
GENETIC RESOURCES AND BREEDING 


\title{
General combining ability analysis of sex expression, fruit and seed characteristics in melon (Cucumis melo L.)
}

\author{
Zdenka Girek ${ }^{1 *}$, Slaven Prodanović ${ }^{2}$, Suzana Pavlović ${ }^{1}$, Slađan Adžić ${ }^{1}$, Mladen Đorđević ${ }^{1}$ \\ Jelena Damnjanović ${ }^{1}$, Bogoljub Zečević ${ }^{1}$ \\ ${ }^{1}$ Institute for Vegetable Crops, Karadjordjeva 71, Smederevska Palanka, Serbia \\ * e-mail: zdnkgirek@yahoo.com \\ 2University of Belgrade, Faculty of Agriculture, Nemanjina 6, Belgrade, Serbia
}

Keywords: andromonoecious, combiner, flowering, genotype, monoecious

Melon is the most diverse species of the genus Cucumis, which is characterized by a rich diversity of shape, color and size of the fruit. This study has been conducted in order to select melon genotypes that will be used as starting material in melon breeding programs. Determination of general combining ability (GCA) is important for facilitating the selection of parents from which it is possible to get good commercial hybrids. Four monoecious genotypes (Sesame, ED-3, ED-4, Pobeditel) and 5 andromonoecious genotypes (Chinese muskmelon, Anannas, Fiata, Honey dew, A2-3lb) have been crossed (partial diallel design without reciprocal crosses) and used in the experiment. Andromonoecious lines were used only as pollen donors. The experiment was conducted during two vegetative seasons (2010 and 2011) in the experimental plots of the Institute for Vegetable Crops in Smederevska Palanka, Serbia (latitude $44^{\circ} 21^{\prime} 24.79^{\prime \prime} \mathrm{N}$, longitude $20^{\circ} 56^{\prime} 55.70^{\prime \prime} \mathrm{E}$, altitude $103 \mathrm{~m}$ ). Fourteen melon characteristics were analyzed of which five related to flowering and sex expression, seven fruit, and two seed characteristics. According to the results, best general combiner for all five characteristics of sex expression was monoecious cultivar Sesame. In addition, great general combiner was A2-3lb, line that is characterized with extra small sized fruits. The best general combiner for the most observed fruit characteristics was cultivar Pobeditel, while the poorest combiner was genotype ED-3. If the aim of melon breeding will be to create hybrids with large fruit length, width, and weight - cultivar Pobeditel should be used. In this study, this cultivar has the largest, positive value of GCA, which is significant at the 0.01 level. The opposite, if the aim will be to create smaller melon hybrids with small fruit length, width and weight than genotype ED-3 should be used, which had the lowest value of GCA for this characteristics. Best general combiner for seeds weight and number of seeds is also cultivar Pobeditel. 


\section{Cytogenetic study of onion (Allium cepa L.) by physical mapping of ESTs}

Dmitry Romanov*, Mikhail Divashuk, Ilya Kirov, Ludmila Khrustaleva

Russian State Agrarian University, Center of Molecular Biotechnology, 127550 Moscow, Russian Federation

* e-mail: akabos1987@gmail.com

Keywords: Allium cepa L., Tyramide-FISH, chromosome, EST, cytogenetic marker

Onion (Allium cepa L.) is an important part of human nutrition. Chemical compounds of bulbs and green leaves includes an abundance of useful substances that prevent many diseases (Insani et al., 2016). Onion genome is still poorly studied due to its large size, high duplication level and heterozygosity (Scholten et al., 2016). Physical mapping of genes is of great practical importance for the onion breeding. To develop DNA probes for in situ hybridization we used EST clones from two onion EST libraries: from Native Plants, Inc., Salt Lake City, Utah (prefix API) and from Plant Research International, Wageningen, The Netherlands (prefix PRI). The insert size of EST-clones was from $500 \mathrm{bp}$ to $3000 \mathrm{bp}$. Tyramide-FISH technique was used to increase the detection sensitivity of the small target DNA sequences (Khrustaleva and Kik, 2001). Tyramide-FISH mapping of the EST clones revealed hybridization signals on different onion chromosomes at specific positions. It allows to distinguish individual chromosomes and to use these EST clones as cytogenetic markers. We demonstrated the efficacy of chromosomal in situ mapping of ESTs for the extremely large onion genome. We were able to visualize relatively small target DNA sequences on compacted onion metaphase chromosomes. The results of this work may assist sequencing of the onion genome. The reported study was supported partly by RFBR (research project № 16-04-01747 A), and partly by the Grants Council (under RF President) for State Aid of Young Scientists (research project № MK-6066.2016.11). 


\title{
Phenotypic responses of putative resistance chili cultivars infected by PepLCV with viruliferous whitefly transmission
}

\author{
Yanisa Sangsotkaew*, Suchila Techawongstien \\ Khon Kaen University, Faculty of Agriculture, Khon Kaen 40002, Thailand \\ * e-mail: yannisa.san@gmail.com
}

Keywords: pepper, begomovirus, PYLCV (Pepper yellow leaf curl virus-Thailand), Bemisia tabaci, disease resistance, breeding

Yellow leaf curl disease caused by begomovirus is well recognized as a major limiting factor of chili pepper productions worldwide. Breeding for virus resistance is an alternative efficient disease management strategy. Although, there has been an attempt to improve resistant varieties for this disease, various difficulties including scarcity of resistant source and confusion of virus strains are common problems for screening virus resistance in chili cultivar. Therefore, this study aims to identify the aggressive begomovirus strain infecting chili in Thailand by using DNA analysis and to evaluate putative resistance chili cultivars caused by PYLCV with whitefly transmission. The results showed that nucleotide sequences of CP gene was closely related to Pepper yellow leaf curl virus-Thailand (PYLCV) with the sequences identity ranging from 97-98\%. In addition, it was found that disease reaction to PYLCV of cultivars 103 and 107 were highly resistant with coefficient of infection (CI) 2 and 5 , respectively, while cultivar 102 was resistant $(\mathrm{Cl}=10)$, and cultivars 101 and 108 were moderately resistant $(\mathrm{Cl}=20$ and 15 , respectively). Therefore, those five potential cultivars might be used as sources of resistance for improving chili variety with good horticultural traits and resistance to PYLCV in breeding program. 


\title{
Investigation on mung bean yield and quality related to diffrent cultuivation systems
}

\author{
Creola Brezeanu ${ }^{1}$, Petre Marian Brezeanu2*, Teodor Robu¹, Silvica Ambarus ${ }^{2}$ \\ ${ }^{1}$ University of Agricultural Sciences and Veterinary Medicine Iaşi, Faculty of Agriculture, \\ Aleea Mihail Sadoveanu nr. 3, Iasi, 700490, Romania \\ ${ }^{2}$ Vegetable Research and Development Station Bacau Calea Birladului Street, No. 220, \\ 600388 Bacau Romania \\ * e-mail: brezeanumarian@yahoo.com
}

Keywords: Vigna radiata, organic, conventional, potential use

The aim of the study was to assess the obtained yield accrued by mung bean species, which can be use for culinary, medicinal or even for animal feed. Our interest was to investigate two different cultivation systems, ecologic (organic) and conventional, in order to detect species suitability for ecological performance. In our study we used as biological material, mung bean species, which represents a valuable crop thanks to its multiple benefits at different levels and also to its large potential use in food and feed industry (high protein content), agriculture practices - as green manure because of nitrogen content, organic agriculture because of strong resistance to pathogen attack. The average of mung bean conventional yields $\left(2.3 \mathrm{t} \mathrm{ha}^{-1}\right)$ was higher than the ecological yield $\left(1.7 \mathrm{t} \mathrm{ha}^{-1}\right)$, although the difference is not statistically significant. This fact can be explained by the application of chemical treatments (fertilizers and pesticides) allowed in conventional system. In conventional system the level of yields can be affected due to excessive use of chemicals, represented by fertilizers and pesticides, proving less sustainability of cultural system. The result of research demonstrates the benefits of ecological system at different levels as: decreasing of environmental degradation, sustainability of the agriculture and safety of ecological products consumers. The results of the TLC investigation reveal that the mung bean species can be considered a food-drug hybrid thanks to its chemical composition. 


\title{
Studies on documentation, evaluation and use of Cucurbita moschata Duchesne genetic resources
}

\author{
Petre Marian Brezeanu ${ }^{1 *}$, Creola Brezeanu${ }^{2}$, Silvica Ambarus ${ }^{1}$, Tina Oana Cristea ${ }^{1}$, Maria \\ Calin ${ }^{1}$
}

${ }^{1}$ Vegetable Research and Development Station Bacau Calea Birladului Street, No. 220, 600388 Bacau, Romania

* e-mail: ; brezeanumarian@yahoo.com

${ }^{2}$ University of Agricultural Sciences and Veterinary Medicine laşi, Faculty of Agriculture, Aleea Mihail Sadoveanu nr. 3, Iasi, 700490, Romania

Keywords: investigation, biodiversity, quality, suitability,

Cucurbita moschata Duchesne is a seasonal crop known for its edible fruits and seeds, used as food and feed source and also for its medicinal potential. The objective of the present study was to investigate morphological and physiological features of ten $C$. moschata Duchesne genotypes, collected form Romanian areal. The main objective of investigation was to identify promising germplasm, having superior plant and fruit characteristics and significant yield potential. In this purpose, there were accomplished investigations on following characteristics: fruit diameter, fruit length, skin thickness, flesh thickness, length of seed cavity, fruit weight, yield, content of total dry mater, mineral content, total soluble solids, titratable acidity, content of carotene and ascorbic acid. We can conclude that the investigated genotypes of $C$. moschata are characterized by a wide variability in constituents as well in morphological features, and represent a valuable starting material for breeding works. Physical, physicochemical and chemical characteristics showed a great variability: skin thickness $(0.5-1.3 \mathrm{~mm})$, fruit weight $(2.9-5.2 \mathrm{~kg})$, yield $(40-72 \mathrm{t} / \mathrm{ha})$, content of total dry mater (93.4 - 96.7\%), titratable acidity (0.18-0.83\%), content of $\beta$-carotene $(1.3$ - 5.8 $\mathrm{mg} / 100 \mathrm{~g}$ ) and ascorbic acid (4.13 $-6.52 \mathrm{mg} / 100 \mathrm{~g})$. Because of its rich content in total soluble solids, carotene and ascorbic acid $C$. moschata represent a healthy and functional vegetable. 


\section{Agronomical traits of different cultivars of oil seed pumpkins (Cucurbita pepo L. group Pepo) and some nutritional characteristics of seeds, oil cakes and pumpkin oils}

Lovro Sinkovič*, Janko Verbič, Aleš Kolmanič

Agricultural Institute of Slovenia, Hacquetova 17, Ljubljana, Slovenia

* e-mail: lovro.sinkovic@kis.si

Keywords: Cucurbita pepo, oil cake, pumpkin oil, total fat content, total protein content, fatty acids

North-eastern Slovenian region has the long tradition of cultivation of oil seed pumpkins (Cucurbita pepo L., Cucurbitaceae) and processing the seeds into pumpkin oil. The pumpkin oil is a food specialty of the country, which has been approved by the Commission of the European Union as a 'protected geographic name'. Oil seed pumpkins are cultivated as a main crop and have an integral part of crop rotation. Slovenian oil seed pumpkins were cultivated on nearly 5000 ha in 2015 . The aim of the present study was to investigate some agronomical traits of different cultivars and nutritional characteristics of seeds, oil cakes and pumpkin oils. Five oil seed pumpkin cultivars were studied: two varieties ('Slovenska golica', 'Gleisdorfer Ölkürbis') and three hybrids ('GL Maximal', 'GL Rustical', 'GL Opal'). Plant development of the varieties was differing from the development of the hybrids. Varieties were observed to have 'vine' type and hybrids more 'bush' type growth characteristics. Seed yield of hybrids was higher compared to seed yield of varieties. The highest seed yield was seen for the hybrid ' $G L O$ Opal' ( $501 \mathrm{~kg} \mathrm{ha}^{-1} \mathrm{dry}$ weight; DW). Total fat content in seeds ranged from $471 \mathrm{~g} \mathrm{~kg}^{-1} \mathrm{DM}$ to $498 \mathrm{~g} \mathrm{~kg}^{-1} \mathrm{DM}$ and total protein content from $383 \mathrm{~g} \mathrm{~kg}^{-1} \mathrm{DM}$ to $395 \mathrm{~g}$ $\mathrm{kg}^{-1} \mathrm{DM}$. Oil yield during processing phase of pumpkin seeds varied from $39.7 \%$ to $41.5 \%$. The fatty acid analysis was determined by the extraction of fatty acid methyl esters and analysis by means of gas chromatography. The analysis revealed the contents of the C14:0, C16:0, C16:1, C18:0, C18:1, C18:2, C18:3, C20:0, C20:1, C22:0, C22:1, C24:0 and C24:1 fatty acids. The highest relative content in pumpkin oil was presented by linoleic acid (46\%), followed by oleic (34\%) and stearic acid (12\%). Differences in fatty acid composition were observed among the varieties and hybrids. Varieties had slightly higher content of oleic acid and lower content of linoleic acid compared to hybrids. Total fat content in oil cakes (after oil processing) ranged from $79 \mathrm{~g} \mathrm{~kg}^{-1} \mathrm{DM}$ to $103 \mathrm{~g} \mathrm{~kg}^{-1} \mathrm{DM}$ and total protein content from $653 \mathrm{~g} \mathrm{~kg}^{-1} \mathrm{DM}$ to $689 \mathrm{~g} \mathrm{~kg}^{-1} \mathrm{DM}$. 


\section{The assessment of Albanian pea and faba bean genotypes based on principal component analyses for yield and protein content}

Astrit Balliu*, Thoma Nasto, Glenda Sallaku

Agricultural University of Tirana, Faculty of Agriculture, Kodër Kamëz, SH1, Tirana 1000, Albania

*e-mail: aballiu@ubt.edu.al

Keywords: PCA, eigen values, eigen vectors

An experiment was carried out to assess genetic diversity of several pea and faba bean landraces by principal component analysis (PCA) for yield and protein content during 2015 and 2016 years. For that purpose, 17 field pea (Pissum sativum L.) and 11 faba bean (Vicia faba L.) locally grown genotypes were characterized in two successive years (2016 and 2017), according to UPOV descriptors in the experimental premises of Agricultural University of Tirana, in Albania. The principal component analyses revealed that two first principal components with eigen value higher than one (PC1 and PC2) contributed $80.5 \%$ of the total variability in faba bean, whilst three first principal components (PC1, PC2 and PC3) contributed $84.2 \%$ of the total variability in field pea. The first PC-s had positive association with plant length, number of pods per plant, number of seeds per plant and dry weight of 100 seeds. In both crops, the first respective principal component (PC1) had high positive component loading for all variables except for protein concentration. 


\title{
Breeding prospective of common bean (Phaseolus vulgaris L.) for Central and South-Eastern European production area
}

\author{
Barbara Pipan*, Peter Dolničar, Jelka Šuštar-Vozlič, Vladimir Meglič \\ Agricultural Institute of Slovenia, Hacquetova 17, Ljubljana, Slovenia \\ * e-mail: barbara.pipan@kis.si
}

Keywords: breeding, dry bean, snap bean, hand cross pollination, new varieties

Common bean (Phaseolus vulgaris L.) is one of the most important legumes for human consumption. For Slovenian production area, common bean is known as a vegetable with increasing level of agronomic interest. In the past, four different varieties of common bean were developed at the Agricultural institute of Slovenia using individual selection procedure from autochthonous populations. In the last decade, we started with directed cross pollinations of dry bean and recently snap bean. Generally, breeding of snap beans is tending to develop new early varieties of "maslenec" type. This ideotype is flowering before naturally high temperatures occur and induce flower shedding, is resistant to diseases, particularly viral infections and bean blight, and forms the yellow, long and flat stringless pods. Dry bean breeding strategy is oriented towards developing high-yielding varieties, resistant to viral infections and bean blight and tolerant to abiotic (drought) stress. In 2016, we obtained 328 pods with 1377 F1 seeds in total, using hand cross pollination. The acquired F1 seeds represent highly perspective genetic material for further selection, resulting from 40 parental dry bean and 26 snap bean combinations, originating from Slovenian and European germplasm. Therefore, the advantage for development of varieties with desired characteristics for cultivation in Central and South-Eastern European production area that are favorably accepted by producers and consumers, lies in the use of adapted germplasm. 


\section{Effects of genotypes, plant density and $\mathrm{N}$ rates on yield and quality of spinach}

Youssef Rouphael*, Maria Giordano, Valerio Cirillo, Christophe El-Nakhel, Emma Colonna, Roberto Maiello, Stefania De Pascale

University of Naples Federico II, Department of Agricultural Sciences, Via Università 100, 80055 Portici, Napoli, Italy

* e-mail: youssef.rouphael@unina.it

Keywords: genetic variation, mineral composition, nitrate, Spinacia oleracea L., vitamin C

Nitrate is the principal source of $\mathrm{N}$ for most higher plants. Particularly leafy vegetables, require large quantities of nitrate fertilizer to attain maximal yields. Vegetable farmers have increased application of $\mathrm{N}$ fertilizers, without considering the response of different species/genotypes to $\mathrm{N}$ application causing an excessive and inappropriate use of chemical $\mathrm{N}$ fertilizers leading to an accumulation of these compounds in the edible products. The crop yield and quality as well as nitrate accumulation in leafy vegetables depends upon many preharvest factors such as genetic materials, agronomic and environmental factors. Three greenhouse experiments were carried out in order to evaluate the effects of preharvest factors (cultivars, plant density and $\mathrm{N}$ dose) on yield and quality of processing spinach (Spinacia oleracea L.). In the first trial four spinach cultivars were compared in terms of yield and quality attributes. The marketable yield of the four cultivars tested was in the following order: Tasman = Kookaburra > Platypus = Regiment, whereas an opposite trend was observed for the leaf dry matter content. No significant differences among cultivars were observed for the $\beta$-carotene, vitamin $C$ and nitrate contents. In the second trial, treatments were defined by four plant densities (800000, 1000000, 1200000, 1500000 seeds/ha). The lowest marketable yield was observed under the lowest plant density, whereas no significant difference was recorded between the other treatments. The highest leaf dry matter content, $\mathrm{K}, \mathrm{Ca}$ and $\mathrm{Mg}$ contents were recorded at 1000000 seeds/ha, whereas the lowest nitrate content was observed under both 1000000 and 1200000 seeds/ha treatments. In the third experiment we evaluated the effects of four $\mathrm{N}$ fertilizer doses $(0,75,150$ and $225 \mathrm{~kg} / \mathrm{ha})$ on crop performance. Marketable yield increased quadratically with increasing $\mathrm{N}$ application with the highest values recorded at both 150 and $225 \mathrm{~kg} / \mathrm{ha}$ indicating a luxury consumption of the nutrient at $225 \mathrm{~kg} / \mathrm{ha}$. The highest leaf dry matter content was recorded at both 0 and $75 \mathrm{~kg} / \mathrm{ha}$. Finally, the highest $\mathrm{K}, \mathrm{Ca}, \mathrm{Mg}$ and nitrate contents were observed at $225 \mathrm{~kg} / \mathrm{ha}$ of N. 


\title{
Agronomic traits of savoy cabbage varieties in autumn production
}

\author{
Mojca Škof, Kristina Ugrinović*
}

Agricultural Institute of Slovenia, Hacquetova 17, Ljubljana, Slovenia

* e-mail: kristina.ugrinovic@kis.si

Keywords: Brassica oleracea var. sabauda, yield, head parameters, plant parameters, rayonisation of production, cultivar

In Slovenia, savoy cabbage is predominantly produced as a winter vegetable in Primorska region which is characterised with a submediterranean climate. With the aim to examine the possibilities of savoy cabbage production in autumn period, field trials with six hybrid varieties were set in three different production regions in 2015 and 2016. Primorska region with submediterranean climate was represented with the location Šempeter pri Gorici in both years, Central Slovenia with humid temperate continental climate with the location Jablje near Ljubljana in both years, and Eastern Slovenia with subpanonic climate with location Ptuj in 2015 and location Ivanci in 2016. Earliness of varieties and their yields were recorded as were the plant and head morphological characteristics. Generally, on all trial locations, 2016 was more favourable for savoy cabbage than 2015. In both years, the highest yields were achieved on location Šempeter pri Gorici (trial average in 201523.26 t/ha and $33.63 \mathrm{t} / \mathrm{ha}$ in 2016), on other locations the trial averages were about two thirds of those achieved in Šempeter pri Gorici. Considering the varieties, early to medium early Capriccio was usually among the highest yielding varieties, while late to very late Sabrosa was usually among the varieties with the lowest yields. Very early to early variety Sonho turned out as a very sensitive to growing conditions and timing of harvest. In optimal conditions the variety can give high yields, but needs to be harvested on time due to poor field standing ability and proneness to cracking. Other three varieties, i.e. early to medium early Miletta and medium to late Firnesa and Caserta, in most cases, gave average yields. 


\title{
Comparison of selected traits of sweet fennel (Foeniculum vulgare var. dulce
} Alef.) cultivars

\author{
Ana Slatnar*, Marko Sraka \\ University of Ljubljana, Biotechnical Faculty, Jamnikarjeva 101, SI 111 Ljubljana, Slovenia \\ * e-mail: ana.slatnar@bf.uni-lj.si
}

Keywords: cultivar comparison, yield, quality, total soluble solids

Sweet fennel (Foeniculum vulgare Mill. var. dulce Alef..) is a aromatic plant belonging to the Apiaceae family. It is cultivated and also widespread in many parts of Mediterranean and Middle East countries such as Italy, Turkey and Iran. It is a common vegetable in Europe but used less in other parts of the world. The study was conducted in a completely randomized block design with three replications. The experimental treatments included 8 different cultivars (two hybrids and six varieties). The study was performed to evaluate variations between cultivars in most important traits (number of lateral shoots, height, width, and weight of the bulbs, yield and total soluble solids). The study showed great variability among the tested cultivars. The highest average bulb weight was in hybrid 'Teseo F1' (715.9 g) and the lowest average bulb weight was in variety 'Romanesco' (450.4 g). This trait has the greatest impact on final yield. Surprisingly, in contrast to our expectations, hybrids were not the best at this trait. 


\title{
Fertility restoration and breeding of garlic: recent advances
}

\author{
Rina Kamenetsky*, Einat Shemesh Mayer \\ Institute of Plant Sciences, Agricultural Research Organization, The Volcani Center, Rishon \\ LeZion, 7528809, Israel \\ * e-mail: vhrkamen@volcani.agri.gov.il
}

Keywords: garlic, breeding, seed propagation

The cultivated garlic (Allium sativum L.) is sterile, does not produce flowers and seeds and is propagated only vegetatively. Lack of sexual reproduction prohibits genetic studies and conventional breeding of this important crop. Recent restoration of flowering and fertility in the landraces from Central Asia and increasing variation by seed propagation has opened new avenues in physiological and genetic studies. Our research reveals that florogenesis and sexual reproduction of garlic are prone to environmental interruption at several stages, from flower induction to seed maturation. Initiation and differentiation of the inflorescence and elongation of the flower stalk are regulated by the environment, but the phase-specific photoperiod and temperature effects are not universal within the species. The competition for resources by the simultaneously developing bulb and inflorescence differentially determines the fate of the floral induction, stalk elongation and inflorescence development. The temporal and spatial expression of the homologues of flowering key-genes FT and LFY is strongly associated with the development of the reproductive organs. In addition, we have established modern molecular tools and created a large comprehensive transcriptome catalogue, which enables the investigation of the molecular and genetic mechanisms of the flowering and fertility processes, as well as accelerating the breeding process by molecular markers technics. At present, we are focusing on the potential physiological barriers that interrupt the normal development of the flower with the consequent male/female sterility. These new insights broaden our basic understanding of flower biology in general, and that of garlic in particular, and will provide additional tools for conventional and molecular breeding systems for this crop. New variation within the seedling populations, now available for breeding, will permit the development of new and better cultivars adapted to a variety of climates and to different production conditions. 
$-86-$ 


\section{POTATO}

$-87-$ 


\section{Breeding new potato varieties suitable for Balkan region at Agricultural Institute of Slovenia}

\section{Peter Dolničar*}

Agricultural Institute of Slovenia, Hacquetova 17, Ljubljana, Slovenia

* e-mail: peter.dolnicar@kis.si

Keywords: potato, resistance breeding, PVY, late blight

Potato production has a long tradition in Balkan countries. The arrival of the crop in the region dates back in the 18th century. As soon as it was widely accepted for the human consumption, it abolished the hunger in the region. Potato production systems in Balkan countries still differs a lot from western countries with developed potato industry today. Production is dispersed, with just some larger farmers and majority of very small potato growers or even more crops produced on small gardens. While the large farmers have modern technology with high quality yields, the small growers don't invest much in potato crop. Their seed exchange rate is low (sometimes even every seventh year), nutrition is not adequate, and plant protection against important diseases such as late blight is very poor or none at all. This situation is very similar in all countries of former Yugoslavia. For all those markets very different types of varieties are needed that can facilitate the producers needs. Large farmers pay much more attention on quality aspects of single purpose varieties, while small potato growers prefer robust multipurpose varieties. This and the low seed price is the reason why many old varieties such as Desiree or Jaerla still represent a significant portion of potato production. Most of the new potato varieties are very special single purpose varieties. Due to high virus infection pressure breeding for extreme resistance to PVY was an obvious choice of the new breeding programme which started at Agricultural Institute of Slovenia in 1993. The main focus of the programme is breeding of varieties adapted to Slovenian (and Balkan) growing conditions and customers demands. Mass selection against potato virus $Y$ is performed after artificial inoculation at the seedling stage, followed by selection for important qualitative and quantitative traits in subsequent 10 field generations. Healthy plant material is transferred in in vitro conditions for multiplication before registration trials starts. Resistances against potato virus $Y$ (Rysto), potato leafroll virus, potato wart and against yellow potato cyst nematodes were introduced into new Slovenian varieties. For late blight major R genes were introduced form species Solanum demissum, $S$. bulbocastanum and $\mathrm{R}$ genes of Sarpo variety group. 10 new varieties were released o far. They have high yielding potential, excellent quality performance, high resistance level. Two late blight resistant varieties KIS Kokra and KIS Savinja, suitable for small growers, were released so far. KIS Sora and KIS Mura are high yielding main crop varieties for pre pack, mainly for professional farmers. KIS Krka is a main crop variety tolerant to drought and heat stress. KIS Vipava is an early purple skin and white flash variety with very long dormancy. Both are suitable for small growers. The very early variety KIS Slavnik is a promising new yellow flesh multipurpose variety suitable for both, large and the smallest growers. 


\title{
Colletotrichum coccodes ' the covert enemy of potatoes?
}

\author{
Karina Eva Hauer*, Maria Müller
}

University of Graz, Institute of Plant Sciences, Schubertstrasse 51, 8010 Styria Graz, Austria

* e-mail: karina.hauer@edu.uni-graz.at

Keywords: fungus, Colletotrichum coccodes, potatoes, Solanum tuberosum, pathogen, tuber, yield

The harmful fungus' influence on plant health (leaf and stem health, tuber development and weight, normal or premature senescence symptoms) and crop yield (qualitative and quantitative) of potatoes, respectively is investigated in open land as well as in climate chambers. There the black dot pathogen shows among other things for example soil and tuber borne infections partly due to climate change increasing relevance in Austria during the last few years depending on the weather conditions of the particular year and the prevalent soil conditions. Generally, warm weather with sufficient amount of precipitation and well-drained, permeable soil are with regard of the phytopathogenic fungus beneficial for potato plants, whereas very high or too less precipitation amounts are weakening the potato plants and hence promote black dot disease. Furthermore $C$. coccodes influences tuber's shelf life and accordingly the secondary parasite (weakness parasite) reduces in interaction with other for potatoes relevant plant pathogens (e.g. silver scurf (Helminthosporium solani)) the merchandise value. This happens due to appearance of characteristic symptoms as for instance black dots on greyish-brown lesions, wrinkled look and increased weight loss. Additionally the possibility of latent infections of tubers especially seed potatoes as well as genetics of Austrian potatoes in internationally comparison, morphology (hyphae, microsclerotia, acervuli, spores), life cycle and physiology (enzymes, influence of phytohormones) of the ascomycete are examined by microbiological (polymerase chain reaction (PCR), sequencing), biochemical and microscopic (light microscope, SEM, TEM) methods. 


\section{Efficiency of foliar applications of potassium sulphate on potato and vegetable production}

\section{Michel Marchand*}

Tessenderlo Chemie, 180 rue du Centre, 62170 Ecuires, France

* e-mail: michel.marchand@tessenderlo.com

Keywords: potassium sulphate, potato, foliar applications

Besides basal dressing and cropping systems using split applications such as fertigation, foliar sprays can also be considered as an effective way to supply nutrients to the plant. It is widely used for micro-elements but less so when it comes to major elements, particularly potassium. Potato is known to have a high requirement for potassium, particularly during tuber initiation and their enlargement. Most vegetables have also high requirements for potassium during fruit growth. Thanks to a new grade of soluble potassium sulphate, specially designed for foliar applications using large modern sprayers, it is now possible to supply potassium during those critical stages. The first objective of the project was to check the effective absorption of sulphate of potash by the leaf. Measures of absorption indicate an effective penetration into the leaf, depending on leaf structure. The second step was to investigate the effect of foliar applications of potassium sulphate on yield and quality as a complement to the basal dressing. This article presents results from different countries and different crops. On potato, treatments are applied from tuber initiation and then every 8 to 10 days, 2 or 3 times at $10 \mathrm{~kg}$ of potassium sulphate per hectare and per application. Depending on cropping conditions and varieties, an increase from 8 to $20 \%$ in yield can be observed. A direct absorption of potassium sulphate through the leaves increases potassium in the plant. Thanks to its role on the transport of elements, a higher potassium content improves plant functioning. According to the small doses of potassium sulphate applied, there is obviously a stimulation effect of plant metabolism, leading to a better assimilation of all nutrients from the roots. Concerning tuber quality, a positive effect is noted on tuber size, dry matter and starch content. 


\section{Do varietal differences in the morphological traits of potato tubers affect histological and physiological traits of the starch granules?}

Takashi Nishizawa ${ }^{*}$, Tuhin Roy², Kazuhiro Nara ${ }^{3}$, Mahfuzar Rahman², Rajesh Chakraborty², Xue $\mathrm{Li}^{4}$, Yoshie Motomura ${ }^{5}$

${ }^{1}$ Yamagata University Faculty of Agriculture, Tsuruoka 997-8555, Japan

* e-mail: nisizawa@tds1.tr.yamagata-u.ac.jp

2Sher-e-Bangla Agricultural University, Department of Agronomy, Sher-e-Bangla Nagar , Dhaka 1207 , Bangladesh

3 Jissen Womens University, Faculty of Human Life Sciences, Hino 191-8883, Japan

${ }^{4}$ Academy of Agricultural Sciences, Chang Chun 130000, China

5Yamagata University, Faculty of Agriculture, Tsuruoka 997-8555, Japan

Keywords: amylose, potato, starch content, starch glanule size

This study was conducted to clarify if varietal differences in the morphological traits of potato tubers affect histological and physiological traits of the starch granules. Seven potato varieties: 'Fata Pakri', 'Jam Alu', 'Romana', 'Tel Pakri', 'Diamant', 'Irish Cobbler', and 'May Queen' were used in the experiment. The shape of tubers in 'Fata Pakri', 'Romana', 'Tel Pakri', 'Diamant', and 'Irish Cobbler' was round, while that of 'Jam Alu' and 'May Queen' was oval. Both the weight and volume of the smallest variety ('Jam Alu') were lower than half of the largest one ('May Queen'). Both the soluble solid and water contents of 'Irish Cobbler' and 'May Queen' were significantly lower than those of the other cultivars. The starch granule length of 'May Queen' was the longest, while there was no significant difference among the other cultivars. Starch granule width of 'May Queen' was also the longest, but the difference among cultivars was not apparent, as shown in the length. The largest starch volume was found in 'May Queen' $\left(17,000 \mu \mathrm{m}^{3}\right)$, and it was more than two times that of 'Diamant' $\left(8,000 \mathrm{\mu m}^{3}\right)$. The volume was also presented as frequency histograms. In 'Diamant' and 'Tel Pakri', more than $70 \%$ of starch was smaller than $10,000 \mu \mathrm{m}^{3}$, while it was only 52\% in 'May Queen'. The starch content of 'Irish Cobbler' and 'May Queen' was significantly higher than that of the other cultivars, while the amylose content did not differ significantly among cultivars. Morphological traits of the tubers were often significantly correlated with physiological traits of the starch granules, while there was almost no significant correlation between the morphological traits of the tubers and histological traits of the starch granules. 


\title{
Exploring biophysical components in rain-fed potato systems in the Peruvian Central Andes
}

\author{
Eddie Schrevens*, Diego Grados, Reindert Heuts \\ University of Leuven, Department of Biosystems, Oude Markt 13, 3000 Leuven, Belgium \\ * e-mail: eddie.schrevens@biw.kuleuven.be
}

Keywords: biophysical resources, potato system, nutrient use efficiency

Rain-fed potato systems play a key role in food security being the most important crop in the Peruvian mixed farming systems. Sustainable use of biophysical resources has not been fully quantified for these agroecosystems. The general objective of this research is the assessment of biophysical resources distribution in rain-fed potato systems in Peruvian Central Andes (Mantaro Valley). Moreover, nutrient balances and indicators of nutrient use efficiencies were calculated. During 2005-2008 and 2010-2015 cropping cycles, 60 potato pilot plots located on a transect of the Valley were investigated at field level. Climate data were recorded at different altitudes in the study zone.

A mean temperature altitudinal gradient was noticed $\left(8.9-11.4^{\circ} \mathrm{C}\right)$. Total annual rainfall was $720-895 \mathrm{~mm}$. The average farm size was $1308 \mathrm{~m}^{2}$. Fertilization doses ranged from 60 to 957 $\mathrm{kg} \mathrm{ha}^{-1}, 4$ to $476 \mathrm{~kg} \mathrm{ha}^{-1}$, and 10 to $932 \mathrm{~kg} \mathrm{ha}^{-1}$ for $\mathrm{N}, \mathrm{P}$ and $\mathrm{K}$ respectively. C inputs (mainly from farmyard manure) rates varied from 0 to $7267 \mathrm{~kg} \mathrm{ha}^{-1}$. Measured biomass fluctuated considerably, depending on sowing date, plant density, fertilization level, weeding frequency and cycle length. The amount of seed used ranged from 598 to $3157 \mathrm{~kg} \mathrm{ha}^{-1}$. A large variability of fresh weight at harvest was found (19 to $38138 \mathrm{~kg} \mathrm{ha}^{-1}$ ). The fresh weight residual biomass removed from the field varied from 106 to $26620 \mathrm{~kg}$ ha-1 while weed biomass between 268 and $20274 \mathrm{~kg} \mathrm{ha}^{-1}$. On average, NPK and C-balances per cycle were positive. Efficiency of nutrient conversion was $664 \mathrm{~kg} \mathrm{DM} \mathrm{kg} \mathrm{N}^{-1}, 726 \mathrm{~kg} \mathrm{DM} \mathrm{kg} \mathrm{P}^{-1}$ and 663 $\mathrm{kg} \mathrm{DM} \mathrm{kg} \mathrm{K}{ }^{-1}$. Potato yield tended to increase with soil $\mathrm{C}$, total $\mathrm{N}$, extractable $\mathrm{P}$ and exchangeable bases content. Labour productivity was $144 \mathrm{~kg}$ tuber manday ${ }^{-1}$ on average. A self-subsistence (organic oriented) and a market agriculture (inorganic and mixed oriented) were defined with a correlational PCA biplot. Based on the biophysical exploration of the pilot plots, relevant quantitative advices related to nutrient distribution and labor management were performed. Further development in systems' simulation is required to tackle technical sustainability challenges in the study zone. 


\title{
Identification of Ulocladium atrum causing potato leaf spot disease in Iran
}

\author{
Mehdi Nasr Esfahani *
}

Isfahan Center for Research of Agricultural Science and Natural Resources, Plant Protection Research Department, Isfahan, Iran

* e-mail: mne2011@gmail.com

Keywords: morphological characteristics, pathogenicity, Solanum tuberosum L., Ulocladium atrum

A leaf spot was observed on potato (Solanum tuberosum L.) affecting $18.60 \%$ of plants growing in the fields in Iran. Symptomatic leaf samples were collected from infected potato plants in main potato-growing regions of Iran, including Hamadan, Fars and Isfahan provinces and isolations were made on PDA medium. They were as tiny, dark colored lesions initially, and turned black, which later extended into irregular patches and eventually may covered whole of the infected leaves. The colonies of the 30 pure cultures on PDA were black with white margins. The pale olivaceous brown to dark conidia were spherical to subspherical, developing in two main patterns forming septa above and below the median septum becoming 3-transseptate, described as 4-celled, which may lay to further septa to produce 8-celled conidia with about 17.3-23.8 $\times 14.3-16.8 \mu \mathrm{m}$. The septate mycelium had a pale olivaceous brown with a smooth in areas and about $5.2 \mu \mathrm{m}$ in diameter. Conidiophores were simple or branched, erect, arising laterally, with about 5.4-8.2 $\mu \mathrm{m}$ wide and up to about $122 \mu \mathrm{m}$ long. Based on the conidial morphology, including variations in conidial shape, size, length/width ratio, color, septation, and ornamentation, all 30 isolates were identified as U. atrum. Single-spore isolates were identified as Ulocladium atrum on the basis of morphological characteristics. Morphological identification was confirmed by sequence analyses of the ITS, gpd and Alt a1 regions. On pathogenicity test, symptoms of the disease were observed in all of the inoculated potato plants, but not in the control plants. These symptoms were similar to those observed on the inoculated potato plants in the infected fields. Symptoms consisted of as a tiny, dark colored lesion, turned black in due course of time, extended into irregular patches, covered whole of the infected occasionally. The pathogen was re-isolated and was found to be identical to the original isolate. These results revealed that $U$. atrum was pathogenic on potato and was the causal agents of the disease causes leaf spot on potato. To our knowledge, this is the first report of leaf spot caused by $U$. atrum outbreaked as a serious disease on potato in Iran. 
-94- 
PLANT PROTECTION

$-95-$ 


\section{Using trap crops to manage plant parasitic nematodes on vegetable crops}

\section{Becky Westerdahl*}

University of California, Department of Entomology and Nematology, Davis, CA 95616, United States of America

* e-mail: bbwesterdahl@ucdavis.edu

Keywords: trap crop, root-knot nematode, carrot

Trap cropping is a nematode management technique that has been tested periodically since the late 1800 's. A susceptible host is planted and larvae of a sedentary parasitic nematode such as root-knot are induced to enter and establish a feeding site. Once this has occurred, and the female begins to mature, she is unable to leave the root. The plants are then destroyed before the life cycle of the nematode can be completed, trapping nematodes within the root. A commercial crop is planted after termination of the trap crop. Field trials on carrots have been conducted using six different traps crops destroyed at various times after planting. Trap crop treatments destroyed either with tillage, or with an herbicide, or with a combination of the two were compared to untreated (dry fallow) and a standard chemical nematicide. In these trials, several treatments yielded marketable carrots or reductions in root-knot nematode populations at harvest that were similar to the chemical standard, and significantly greater than the untreated $(P=0.05)$. By itself, trap cropping is not likely to provide the same level of control as a chemical nematicide, because not all nematodes are induced to enter the roots. However, the potential for loss of registration of chemical nematicides for various environmental reasons is great enough that an IPM approach using two or more techniques in combination that will each provide partial control of the nematode population is warranted. 


\section{Prevention and control of nematodes and soil borne diseases by grafting peppers}

Marian Bogoescu*, Daniela lorga

Academy of Agricultural and Forestry Sciences, Intrarea BInelui, nr.1A, Sector 4, 041935

Bucharest, Romania

* e-mail: bogoescumarian@gmail.com

Keywords: attack frequency, rootstocks, scion, root index, quality, marketable yield

Soil borne pathogens and nematodes are very destructive in vegetables crops and one of the most limiting factors to farmer's income. In field production, crop rotation is important to prevent infestation with diseases and pests. However, this is rarely practiced in greenhouses, which allows soil borne pathogens and pests to accumulate, progressively reducing crop yields. Methyl bromide was the most effective fumigant for controlling nematodes, pathogens and weeds. But, adoption of the Montreal Protocol ended the use of methyl bromide in Romania in 2005. In the last 14 years at Horting Institute has been identified nonchemical alternatives that are suitable in Romania. Grafting cultivars with high quality and productivity on rootstocks that are resistant to the soil pests and diseases is a method known for years ago, but which was improved and quickly spread in the last years. The objective of the researches was to evaluate the performance of the peppers grafting on the some rootstocks in greenhouse conditions. Data obtained in the combinations scion/rootstock were compared with data recorded from peppers not grafted. The incidence and severity of nematodes and soil-borne disease, marketable yield and fruits quality were evaluated. Grafting was found to significantly reduce the incidence of nematodes, soil borne disease respectively increased marketable yield and peppers quality. 


\section{Relation between phosphorus fertilisation and protection of lettuce against Bremia lactucae}

\section{Christiane Raynal-Lacroix*}

The Interprofessional Fruit and Vegetable Technical Center (CTIFL), Lanxade, 24130

Prigonrieux, France

* e-mail: raynal@ctifl.fr

Keywords: phosphorus fertilization, lettuce, Bremia lactucae, artificial inoculation, natural protection, integrated management

Currently, protection against Bremia lactucae is based on preventive and systematic treatments. However, today the challenge is to develop alternative strategies, less dependent on phytopharmaceutical products. One of the factors controlling the plants' defensive status is fertilisation. Phosphorus $(P)$ has emerged as a risk element following a national survey in France taking stock of plant health problems and growing practices. The first data called for more detailed investigations in order to establish the actual effect of $P$ on lettuces' sensitivity to Bremia lactucae, and to determine the P level that reconciles yield requirements and natural protection against this disease. To this purpose, a study was carried out in controlled conditions of $\mathrm{P}$ supply and using artificial inoculation with Bremia lactucae. The lettuce is grown in pots, on sand. The plants, transplanted at the 3/4-leaf stage, are supplied with complete nutrient solutions that differ in $\mathrm{P}$ content: $0.1,0.2,0.35,0.7$ (control), $2.1 \mathrm{me} / \mathrm{L}$. The summary of the research is based on 4 trials conducted in spring and autumn/winter crops. Right from the start of the observations, the disease manifests differently depending on the P fertilising treatment and, subject to the climate, between 15 and 25 days after inoculation. The intensity of the attacks increases with $P$, whose influence is expressed through the mean number of spots and the spot surface per plant. Although the highest $\mathrm{P}$ levels increase lettuces' sensitivity to Bremia lactucae, they have little impact on the production of biomass. Thus a reduction by half of the control P level can entail a $30 \%$ decrease in the number of diseased leaves, without significantly affecting the plants' dry weight. As for the fresh weight, the difference between the two treatments results in the control plants being 3 to 4 days earlier. Furthermore, this study provides the basis for integrated management of a balanced $\mathrm{N}-\mathrm{P}_{2} \mathrm{O}_{5}$ nutrition that benefits the health and yield of the lettuces, i.e. 1-0.28. The optimum rate to achieve this double objective seems to be 25 kg $\mathrm{P}_{2} \mathrm{O}_{5} /$ ha. 


\title{
Physiological races and genetic diversity of Fusarium oxysporum f.sp. melonis in Iran
}

\author{
Mehdi Nasr Esfahani ${ }^{1 *}$, Noushin Shafagh ${ }^{2}$, Mahrokh Falahati Rastegar ${ }^{2}$ \\ ${ }^{1}$ Isfahan Center for Research of Agricultural Science and Natural Resources, Plant Protection Research \\ Department, Isfahan, Iran \\ * e-mail: mne2011@gmail.com \\ ${ }^{2}$ Ferdowsi University, Department of Plant Pathology, School of Agriculture, Mashhad, Iran
}

Keywords: Melon, Fusarium wilt, forma specials, races

Fusariums wilt of melon, Fusarium oxysporum f.sp. melonis is one of the most important diseases, causing tremendous losses in melon growing areas in Iran. Searching for resistant sources needs detail knowledge of the pathogen. Thus, race identification of the pathogen was assessed on various isolates through out of the important melon's growing areas, using differential standard hosts. For collection of F. o. f.sp.melonis, sampling was carried out from melon fields in Northern and Razavi Khorasan provinces ( $35^{\circ} 42^{\prime} 0^{\prime \prime}$ North, $47^{\circ} 16^{\prime} 0^{\prime \prime}$ East) includeding Torbat jaam, Sarakhs, Taibad, Khaaf, Kashmar, Farouj, Torbat heidariye areas. Infected plants were collected randomly on the basis of symptoms such as damping-off, yellowing, wilting and excretory gum from stems. For isolating of the pathogen, potato dextrose agar (PDA) culture medium and for single sporing, water agar (WA) culture medium were used. In order to force the fungus to produce sporodochium, carnation leaf agar (CLA) culture medium was used. For measurement of colony diameter, isolates were cultured on acid free PDA and keep in dark

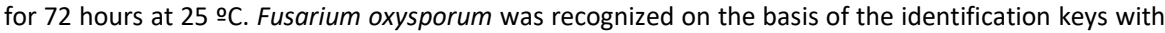
attention to morphological characters. For pathogenicity tests, artificial inoculation was performed under controlled greenhouse condition (temp: $25^{\circ} \mathrm{C}$ at day and $17^{\circ} \mathrm{C}$ at night; photoperiod: $12 \mathrm{~h}$ light/12h dark). The used inoculums was a fungal suspension containing 106 conidia $\mathrm{ml}^{-1}$ collected from 5 days' old PDA cultures of F.o. f.sp. melonis isolates. Standard cv. Charentais T was used in this experiment. The seedling roots were washed with tap water and pruned to about half of their length, inoculated for 7-10 minutes with conidial suspension and then transplanted to pots filled with equal ratio of sand, soil and humus. Recording symptoms were continued every day from first symptom appearance on the plants to the 21 day after inoculation. Symptoms were divided to six groups named as 0 to 5 . Group 0 contained no symptoms, group1: wilting and yellowing in cotyledons, group2: wilting and yellowing in the two first leaves, group3: wilting and yellowing in two first leaves, group 4: wilting and yellowing symptoms in the three or more first leaves and group 5: with damping off symptoms. The results indicated that, eighty percent of the isolates are pathogenic to the melon crops. Distinguished symptoms such as damping-off and vascular wilting were established only on melon plants. In race determination test, all isolates were virulent on susceptible cv. Charentaise T that does not have any resistance gene and on cv. Charentais Fom 1 that has the Fom-1 resistance gene. The other differential hosts did not show any symptoms. In other words, the isolates were only able to overcome Fom 1 resistant gene, therefore indicating the presence of race 1 in the region which is in agreement with others reports. Forma specials proving tests on seedlings of melon, cucumber, watermelon and pea showed typical symptoms of the disease on melon plants, confirming the only forma specials of melon. For the race identification tests, differential hosts were used, out of which, the existence of race one was approved. In race determination test, all isolates were virulent on susceptible cv. Charentaise T that does not have any resistance gene and on cv. Charentais Fom1 that has the Fom-1 resistance gene. 


\section{Treatment guidelines for early blight disease of potato Alternaria solani and $A$. alternata}

\section{Mehdi Nasr Esfahani *}

Isfahan Center for Research of Agricultural Science and Natural Resources, Plant Protection Research Department, Isfahan, Iran

* e-mail: mne2011@gmail.com

Keywords: irrigation, planting type, planting date, resistant and fungicides.

Potato early blight disease, Alternaria solani and A. alternata is of worldwide importance that, now threatens the most potato planting farms epidemically. It is necessary to take managerial measures, based on movements towards sustainable agricultural development being economic, broadly applicable and well accepted by the farmers. In this regard, management programs were conducted in 3 continuous years to examine the effect of planting dates, irrigation types, planting methods, genetic resistance sources and chemicals, dealing by several fungicides in Friedan areas, Esfahan, Iran. The results showed that, all the relevant factors in various treatments for the type of irrigation, sprinkler, drip and furrow systems, cultivation methods, one and two rows, delay in planting date, susceptibility of the cultivars and fungicides to early blight disease, throughout the field had substantial and significant impacts on the reduction of infection percentage, disease severity and scoring scales. Sprinkler and drip irrigations significantly decreased the disease in comparison to furrow one respectively. Double and single row planting had no significant effect. A month and or two weeks delay in planting date had a significant effect on the disease decrease respectively. With respect to resistant and or tolerant varieties, Maradona and Marfona reduced the disease significantly. The low consumption fungicides, Flint at the rate of 200 grams per hectare, were the most effective fungicide to control the potato early blight disease. 
GENERAL AND OTHER TOPICS

$-101-$ 


\title{
The effects of suboptimal environment temperatures during and immediately after germination on the morphology of root system in pea (Pissum sativum L.) plants
}

\author{
Astrit Balliu*, Glenda Sallaku \\ Agricultural University of Tirana, Faculty of Agriculture, Kodër Kamëz, SH1, Tirana 1000, \\ Albania \\ *e-mail: aballiu@ubt.edu.al
}

Keywords: root length, root surface area, root morphology, relative growth rate

Seeds of several pea locally grown genotypes were sown in styrofoam transplant trays filled with vermiculite and afterward were put in two different growth chambers. The temperature of germination rooms was settled at respectively $10{ }^{\circ} \mathrm{C}$ and $15{ }^{\circ} \mathrm{C}$. In both chambers the relative humidity was maintained at $90 \%$, PPFD $180 \mu \mathrm{mol} \mathrm{m}-2 \mathrm{~s}-1$ and the photoperiod $12 \mathrm{~h}$. At DAS 7, 9 and12, ten plant of each treatment were randomly selected, dissected and separated into roots and shoots. The root system was scanned and analyzed and subsequently, all plant organs were dried $\left(65^{\circ} \mathrm{C}, 48 \mathrm{~h}\right)$ and weighted separately. The environment temperature has affected the dry matter accumulation of newly emerged pea plants. Low temperature has significantly reduced the overall plant dry matter, but it has favored a higher proportion of root dry matter versus the total plant matter. However, depend less of environment temperatures root to whole plant ratio was gradually decreased alongside plant growth. The morphology of root system was also highly influenced by the environment temperature. Clearly, under suboptimal environmental temperatures, the root system of pea plants is less branched and total root length, root projected area, root surface area and root volume were significantly smaller compared with plants grown in optimum temperatures. The average root diameter was the only root morphology parameter which was strongly increased under sub optimum temperatures. Significant differences regarding root morphology parameters were also found among different genotypes. 


\title{
The effects of $A M$ fungi and nitrogen fixation bacteria on growth and root morphology parameters of pea (Pissum sativum L.) plants
}

\author{
Astrit Balliu' ${ }^{*}$, Eriola Veselaj ${ }^{2}$, Glenda Sallaku \\ ${ }^{1}$ Agricultural University of Tirana, Faculty of Agriculture, Kodër Kamëz, SH1, Tirana 1000, \\ Albania \\ * e-mail: aballiu@ubt.edu.al \\ ${ }^{2}$ Agriculture Technology Transfer Center, Department of Land Management, Fushe Kruje, \\ Kruja, Albania
}

Keywords: dry matter, root length, root surface area, root volume

The study aimed to investigate the effects of commercially available AMF inoculate (Glomu ssp. mixture) and nitrogen fixation bacteria (Rhizobium leguminosum and Burkholderia spp.), either supplied individually or in combination with each other, on the growth and root morphology parameters of garden pea (Pissum sativum L.) plants. Inoculated and noninoculated pea plants were subjected to two levels of salinity by the addition of sodium chlorate into the tap water $(0$ and $50 \mathrm{mM} \mathrm{NaCl})$. Several times during the growing cycle, in randomly selected plants the morphology of root system was analyzed and the dry matter of roots and the aboveground biomass were individually measured. The raise of salinity has adversely affected the growth of pea plants. The measured growth parameters; root dry matter and shoot dry matter were gradually decreased and almost all root morphology parameters (root length, root projected area, root surface area, root volume) were deteriorated. The presence of AM fungi did not show any positive affects versus control plants regarding root or shoot dry matter, 30 and 60 DAS, either supplied alone, or in combination with nitrogen fixation bacteria. A significant increase of root and shot dry matter due to the presence of nitrogen fixation bacteria was observed until 30 DAS, but not at the latest stage of plant development (60 DAS). The presence of AM fungi has significantly increased root length, root projected area, root surface area and root volume under moderate salinity conditions $(20 \mathrm{mM} \mathrm{NaCl})$, but, except of root volume, that effect was not significant under more severe salinity conditions $(50 \mathrm{mM})$. A significant enhancement effect was also found due to nitrogen fixation bacteria presence regarding root projected area and root surface area. However, no synergy effect was found due to combined application of AM fungi and nitrogen fixation bacteria regarding any of root morphology parameters. 


\title{
Evaluation of the germination rate of tomato seeds with autonomous image processing and artificial neural networks system
}

\author{
Denis Stajnko1*, Črtomir Rozman ${ }^{1}$, Uroš Skrubej \\ ${ }^{1}$ University of Maribor, Faculty of Agriculture and Life Sciences, Pivola 10, 2311 Hoče \\ Maribor, Slovenia \\ * e-mail: denis.stajnko@um.si \\ 2Legendum d.o.o, Lukovica 8a, 3325 Šoštanj
}

Keywords: image processing, artificial neural networks, seeds, tomato

Standard seed tests are designed to evaluate germination rate under controlled conditions by manual counting with specially trained technicians, which is however time-consuming and labour intensive process. Potential enhancement of seed testing methods can be achieved by applying visual techniques to the collection of sample data. This paper describes a computer vision system, based on image acquisition with RGB camera, image processing and machine learning techniques, which was implemented for automatic assessment of germination rate of the tomato seeds (Solanum lycopersicum L.). The entire system was built using the open source applications ImageJ, WEKA and their public Java classes and was linked by a specially developed code, so no expensive commercial software was required. After object detection proceed by Image J, which outcomes eleven object features, artificial neural networks (ANN) were implemented and directly compared to manual counting on a sample of 700 seeds germinated in 28 Petri dishes $(90 \times 98 \times 18 \mathrm{~mm})$. The results indicated that automated system was able to correctly classify $95.44 \%$ of germinated tomato seeds. 


\section{Effect of geographical origin and dimension of corms on saffron production in Basilicata Region (Southern Italy)}

Loriana Cardone $^{1 *}$, Vincenzo Candido ${ }^{1}$, Michele Perniola ${ }^{1}$, Nunzia Cicco $^{2}$, Donato Castronuovo $^{1}$

${ }^{1}$ University of Basilicata, School of Agriculture, Forestry, Food and Environmental Science, Viale dell'Ateneo Lucano, 10, 85100 Potenza, Italy

* e-mail: loriana.cardone@unibas.it

${ }^{2}$ National council of research, Institute of Methodologies for Environmental Analysis, Contrada Loya, 85050 Tito, Potenza, Italy

Keywords: spice, Crocus sativus, flowering, stigma yield, stigma lenght, corms multiplication

Saffron, the dried stigmas of the Crocus sativus L. flowers, is the most expensive spice in the World used mainly as herbal medicine, flavoring agent and food coloring, due to the content of 3 main secondary metabolites: crocin, picrocrocin and safranal. The influence on saffron yield of 3 classes of corm horizontal diameter, $2.0-2.5 \mathrm{~cm}$ (D1), 2.6-3.5 cm (D2) and 3.6-4.5 cm (D3), and 3 geographical corm origins, 'Sardinia' (Italy), 'Abruzzo' (Italy) and 'Kozani' (Greece), was evaluated in this study. For this aim, an experimental field, based on a splitplot design with 3 reps, was conducted in 'Genzano di Lucania' (4050' N, 1608' E, $344 \mathrm{~m}$ a.s.I., Basilicata Region, Southern Italy) during 2015-2016. At harvest time, yield, flower number per $\mathrm{m}^{2}$, stigma length and stigma fresh and dry weight, were detected. Besides, at the end of crop cycle number and dimensions of daughter corms were determined. Results indicated that both yield and stigma length were affected by geographical origin and corm dimension. In particular, the highest stigma yield $\left(8.0 \mathrm{~kg} \mathrm{ha}^{-1}\right)$ was obtained by D3 'Sardinia' corms, followed by 'Abruzzo' and 'Kozani' (7.7 and $4.5 \mathrm{~kg} \mathrm{ha}^{-1}$, respectively). The highest stigma length, $30.2 \mathrm{~mm}$, was obtained by planting D3 'Sardinia' corms, followed by 'Abruzzo' and 'Kozani'. Besides, D3 corms, at the end of crop cycle, generated more daughter corms able to flower (diameter $\geq 2.5 \mathrm{~cm}$ ) than D1 ones. According to this study, there is a positive correlation between corm dimension and yield, stigma length and daughter corm production. In order to achieve higher productivity of saffron, the use of 'D3 $x$ Sardinia' is considered the best option in Basilicata Region environment. 


\section{Effect of nitrogen and potassium fertilizations on carrot seed quality}

\section{Malik Fiaz Huss Ferdosi ${ }^{1 *}$, Sultan Ali $^{2}$}

${ }^{1}$ University of the Punjab, Institute of Agricultural Sciences, 54590 Lahore, Punjab, Pakistan

* e-mail: malikferdosi@yahoo.com

${ }^{2}$ University of Agriculture, Institute of Horticultural Sciences, Punjab Faisalabad, Pakistan

Keywords: carrot, N, K, seed yield, seed quality

This experiment was laid out under field conditions of Faisalabad Pakistan to find the influence of various levels of nitrogen $(\mathrm{N})$ and potash $(\mathrm{K})$ on the seed quality of carrot (Daucus carota L.). There were twelve treatments ( $\mathrm{N}+\mathrm{K}$ doses $\mathrm{Kg} \mathrm{ha}^{-1}$ ) with four replications randomized in forty eight blocks. Seeds obtained from primary and secondary umbels germinate better than tertiary ones. The present study proved that the treatment $\mathrm{T} 3(75 \mathrm{Kg}$ $\mathrm{N} \mathrm{ha}^{-1}+90 \mathrm{Kg} \mathrm{K} \mathrm{ha}^{-1}$ ) was the most effective combination for obtaining not only highest carrot seed yield but also for its good quality. 
AUTHOR INDEX

-107- 
Adamović, B. ............................ 51

Adžić, S................................... 74

Agić, R. ................................. 44

Aguayo, E. .............................. 28

Ali, S. ...................................... 106

Alves-Pereira, I. ...........................60

Ambarus, S........................ 77, 78

Artés, F................................... 28

Artés-Hernández, F. ....................28

Aryan, A. ................................... 37

B

Balas, J. $36,37,38$

Balliu, A. $53,65,80,102,103$

Baruzzi, G $24,35,48$

Bavec, F. $24,33,35,48,49$

Bavec, M. 52

Belén Rosini, $\mathrm{M}$. 52

Belén Tarantino, $\mathrm{M}$. 50,55

Benko, B. 68

Bistrichanov, S. . .44

Bogevska, Z. .97

Bogoescu, M. 77,78

Brezeanu, C. 27

Budič, B. 62

Buscher, M C

Calin, M. 78

Canali, S. 35

Candido, V. 105

Cardarelli, M. 39

Cardone, L. 105

Casas, A.
Castagnino, A. M. 45,52

Castronuovo, D. 105

Cepuder, P. 36

Chakraborty, R 91

Chanthai, S. 18,23

Chatzigiakoumis, M. 67

Cicco, N 105

Cirillo, V. .82

Civitillo, A. . .64

Colla, G. 39,64

Collado, E 28

Colonna, E. .82

Cvejić, R. 42,63

Cvetković, D 22 $\check{C}$

Čabilovski, R. 33,34

D

Damnjanović, J. 74

D'Antuono, F. 25,26

Davitkovska, M. 44

De Pascale, S. 64, 82

Díaz, K. E. 45,52

Dimitrijević, A...........................22

Divashuk, M...............................75

Dolničar, $\mathrm{P}$. $63,81,88$

Duyar, H 32

$\oplus$

Đorđević, M 74 E

El-Nakhel, C. .82 
Falahati Rastegar, M. .99

Fanourakis, N. .67

Ferdosi, M. F. H. 106

Ferioli, F. 25,26

Fernández Lozano, J. .45

Fernández, J. A. 28

Ferreira, R 60

Filopoulou, $\mathrm{S}$. 67

Fiorillo, A. 39

Fotiadis, C 61

G

Georgievski, G. .44

Germ, M. 66

Germšek, B. .63

Giambanelli, E. 25,26

Giordano, M. 64,82

Girek, Z. 74

Gjonbalaj, M 43

Glavan, M. .42

Gómez, J. A .28

Grados, D. 71,92

Grobelnik Mlakar, S .35 Gruda, N. $15,53,55,62$ Guisolis, A. .45 H

Hakki Tuzel, I. ..................................32

Hauer, K. E.................................. 89

Herzog, E. ......................................... 38

Heuts, R.....................................92 I

Ilić, Z. 20,22

Ilin, S 51 Ilin, Ž 51
$J$

Jakop, M. ......................................... 35

Jeeatid, N...................................... 18

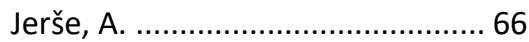

John Rogers, W...................... 45, 52

K

Kaçiu, S. 43

Kacjan Maršić, N. .........14, 21, 53, 66

Kaman, $\mathrm{H}$. 69,70

Kamenetsky, R. 85

Kaniszewski, S 12

Kapoulas, $\mathrm{N}$ 20

Kappert, R. 36,37

Karaj, S. 62

Karić, L. 55

Katsoulas, N $56,57,58$

Kavresan, Ž. 22

Keutgen, $A$ 38

Khrustaleva, L. ................................. 75

Kirov, I............................................ 75

Kitta, E. 56

Kittas, C. $56,57,58$

Kolmanič, A 79

Koukounaras, A. 20

Kovacević, D. 33,34

Kroflič, A. 66

Kyriacou, M. C. 39,64

L

Lakota, M. 49

Lertrat, $\mathrm{K}$. 23

$\mathrm{Li}, \mathrm{X}$. 91

Lisec, U. 35

Liverotti, $\mathrm{O}$. 45 
Lojen, S 14,27

Luigia Maltoni, M. .25

M

Machado, R. 60

Mahne Opatič, A 14,27

Maiello, R

Manojlović, M.

33,34

Manolov, I. 68

Marchand, M. 90

Marian Brezeanu, P. 77,78

Marijanušić, $\mathrm{K}$. 33,34

Mariotti, R 39

Mastilović, J. 22

Matotan, Z. 13

Meglič, V. 81

Mehmeti, A. 43

Miftari, I. 43

Mikulič Petkovšek, M 21

Milenković, L. 22

Mirecki, N 20

Motomura, Y.................................. 91

Müller, J. ......................................... 62

Müller, M. ...................................... 89

$N$

Nara, K. 91

Nasr Esfahani, M 93, 99, 100

Nasto, $\mathrm{T}$. 80

Nawata, E. 23

Nečemer, $M$ 14,27

Nicola, $\mathrm{S}$. 29

Nikolova, M 68

Nishizawa, $T$ 91

Nolz, R. 36

Ntatsi, G.
O

Oana Cristea, T. .............................78

Oztekin, G. 32

$\ddot{O}$

Özbek, Ö. $.69,70$ $P$

Paduano, A. ....................................64

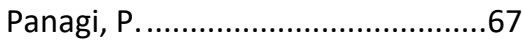

Pavlović, S......................................74

Peralta, M.........................................45

Perniol, M.....................................105

Pignata, G. ......................................29

Pintar, M...............................42, 63

Pipan, B. ........................................ 81

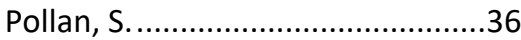

Popsimonova, G. ......................44, 55

Prodanović, S...................................74

Puschenreiter, M..........................37

$R$

Rahman, M.................................91

Raynal-Lacroix, C. ..........................98

Rembialkowska, E..........................12

Renner, J........................................36

Reynafarje, X. ................................71

Rizopoulou, E.................................61

Robačer, M.....................24, 35, 48

Robu, T. ........................................ 77

Romanov, D..................................75

Ropokis, A.............................61, 67

Rouphael, Y. ....................39, 64, 82

Roy, T.........................................91

Rozman, Č...................................104

Ruarte, V.........................................52 
Tobío, M. ....................................... 52

Sacchi, R. .64

Sallaku, G. $65,80,102,103$

Sangsotkaew, Y. .76

Savvas, D. 61,67

Schrevens, E. 71,92

Shaban, N. .68

Shafagh, $N$ .99

Shemesh Mayer, E. ......................... 85

Sinkovič, L....................................... 79

Skrubej, U......................................104

Slatnar, A....................................... 84

Sraka, M. .84

Stajnko, D $48,49,104$

Stalev, B. .68

Stanojević, L. .22

Stefanoni, W. .39

Stibilj, V. .66

$\check{S}$

Šink, N. 21

Šircelj, H. 66

Škof, M. 54,83

Šuštar-Vozlič, J. .81

$T$

Tampakaki, A 61

Tarinta, T. .23

Techawongstien, Suc... 18, 19, 23, 76

Techawongstien, Sun. 18,19

Tsopelopoulos, K. ......................... 67

Tüzel, Y. 32

$U$

Ugrinović, K........................... 54, 83

Urbanč, K. 24

V

Venzke-Klug, T. ............................... 28

Verbič, J. ...................................... 79

Veselaj, E. ...................................... 103

Vidrih, R....................................... 14

Vlachou, M. .................................. 61

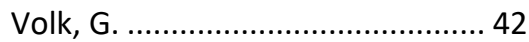

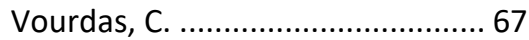

Vrontani, C.................................... 61

Vukmanič, T................... 24, 35, 48

W

Westerdahl, B.............................. 96

Y

Yordanov, A. 68

Z

Zečević, B..................................... 74

Zupanc, V. 63

Ž

Žnidarčič, D. 51 


\section{PAN \\ ORgANIC}

Sonorovno kmetijstwo
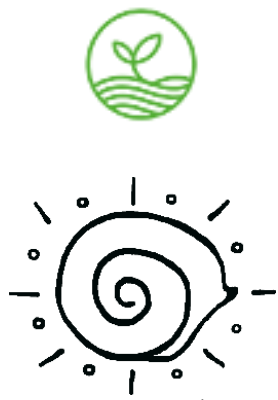

Ekološka kmetija "Zlate misli"
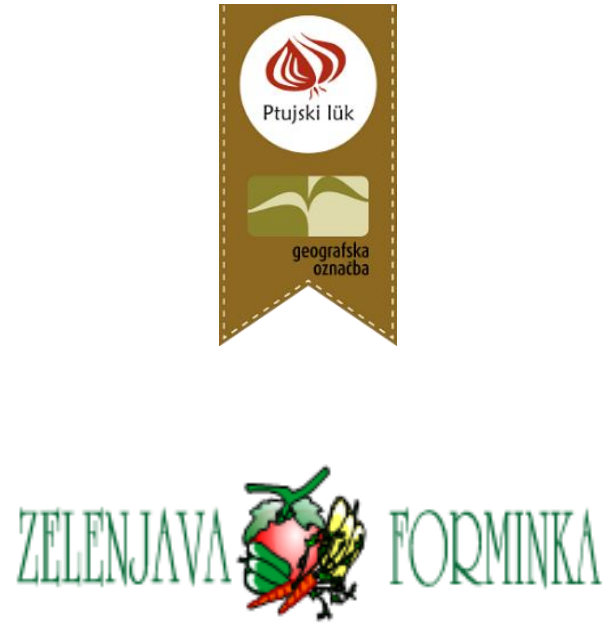

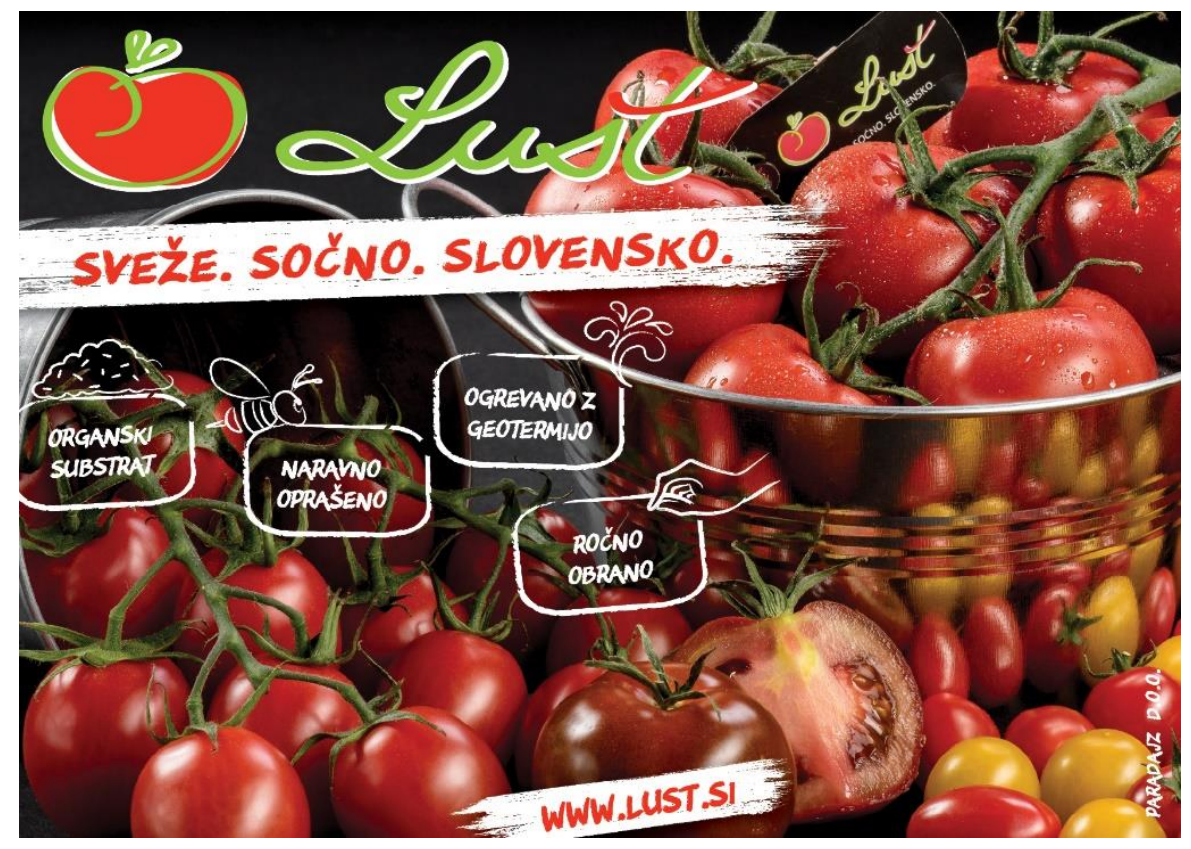




\section{CINIKARNA}

www.cinkarna.si

$$
\begin{gathered}
\text { Cuprablau } \angle 35 \text { JyP } \\
\text { Pepelin WG }
\end{gathered}
$$

\section{FUNGICIDA ZA ZATIRANJE BOLEZNI}

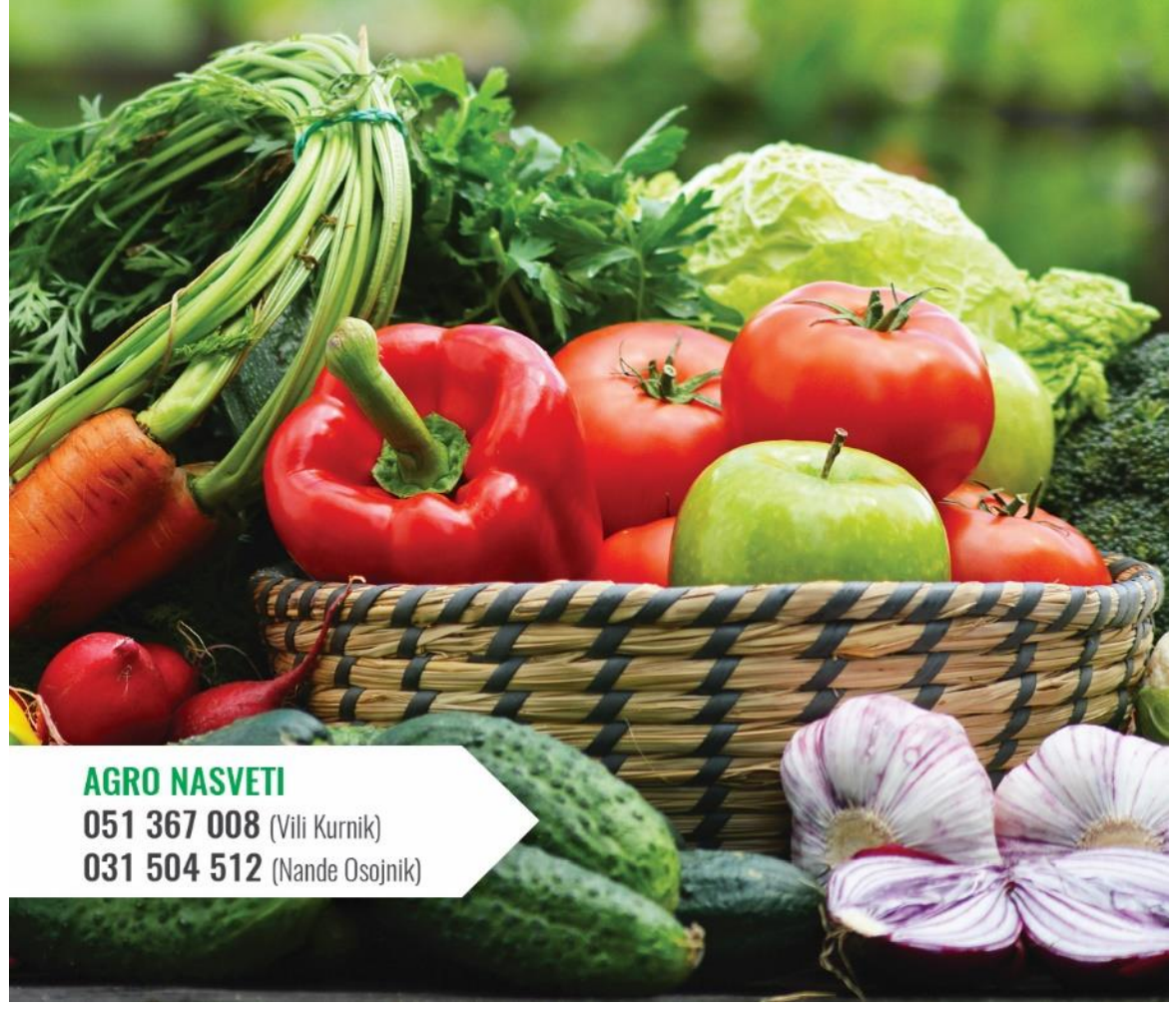




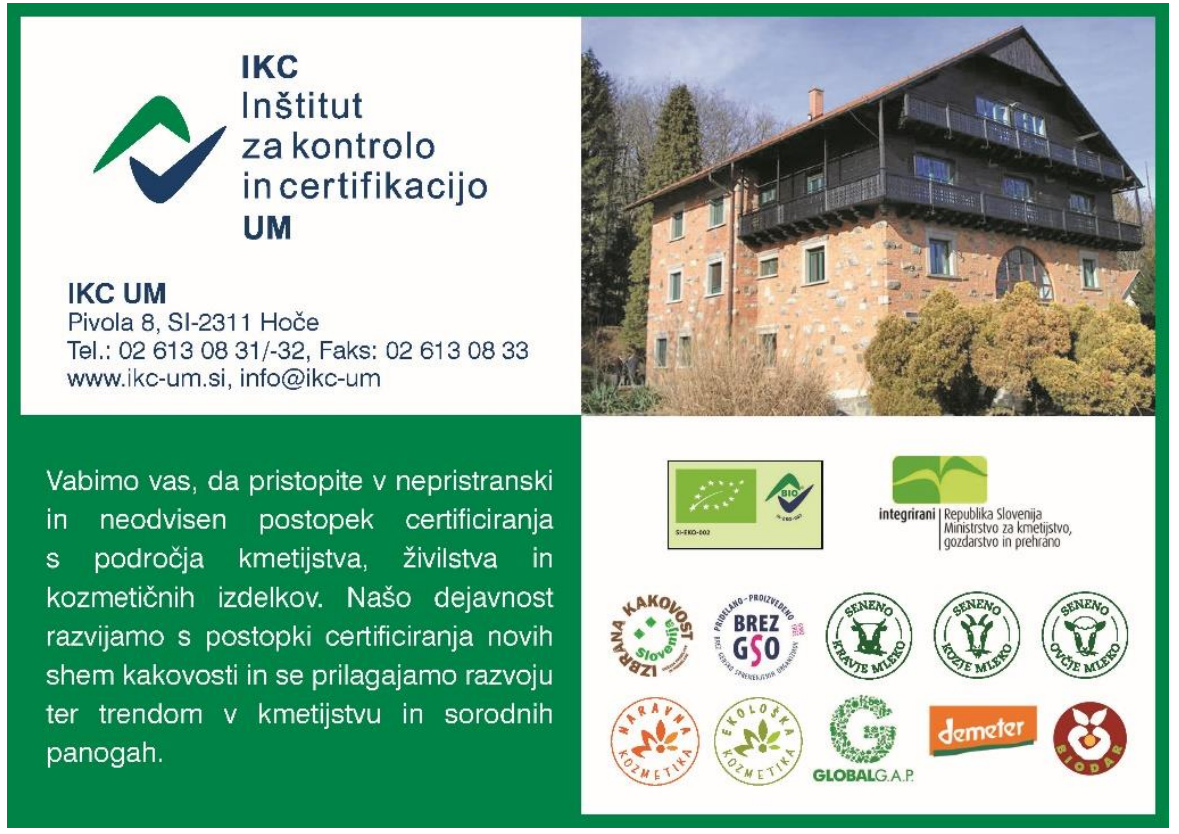

\section{Agro Zavarovalnica $A$}



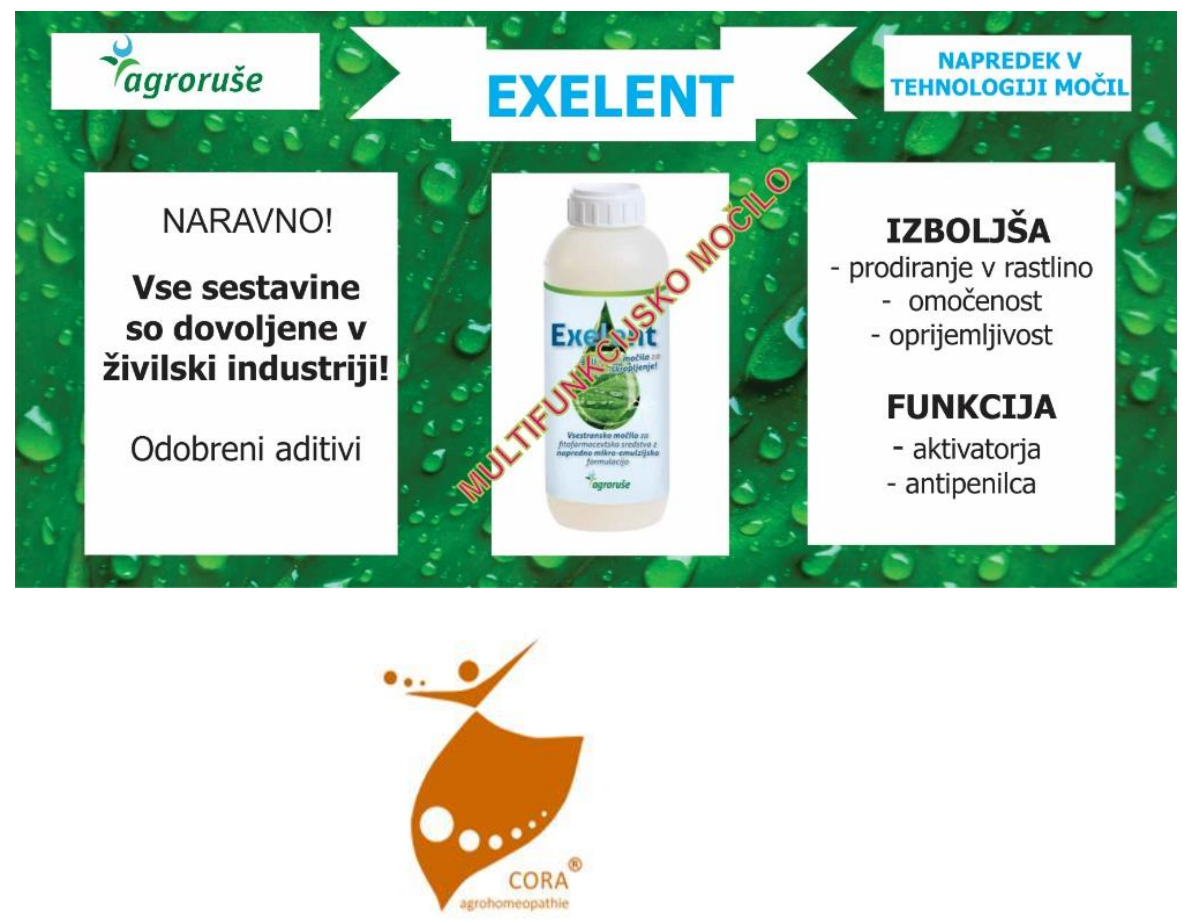

Proizvodi Cora agrohomeopathie ${ }^{\circledR}$ so slovenski, naravni, energizirani, agro-homeodinamični proizvodi za nego in krepitev ravnovesja, odpornosti in vitalnosti rastlin. Nudijo širok nabor visokospecialnih proizvodov, ki so $v$ Sloveniji z že doseženimi dobrimi praksami izkazali odlično učinkovitost, tako v profesionalni - kmetijski in vrtnarski uporabi, kot tudi v vrtičkarstvu. Uporabljajo se razredčeni, v obliki škropiv, pridelki so užitni tudi neposredno po škropljenju (karence ni), pri škropljenju uporaba osebne zaščitne opreme ni potrebna. 61 proizvodov Cora agrohomeopathie ima Potrdilo o skladnosti za uporabo v ekološkem kmetijstvu, med njimi najdete odlične sonaravne rešitve za večino težav $z$ rastlinskimi boleznimi in škodljivci.

Nudi jih podjetje Ph. Agrohom., Agrohomeopatija za rastline in škodljivce, Majda Ortan s.p., Ob Meži 30, Prevalje. Na voljo so po sistemu prodaje po pošti. Pogoji naročanja in nakupa so vam na voljo na spletni strani www.cora-agrohomeopathie.com.

Kontakti za informacije, naročila in svetovanje: email: coraagro@gmail.com, tel.: 070820279 (ing. Majda Ortan). Vabljeni k naročilu! 


\section{MINERAL}

\section{NARAVNA SREDSTVA ZA KREPITEV RASTLIN}

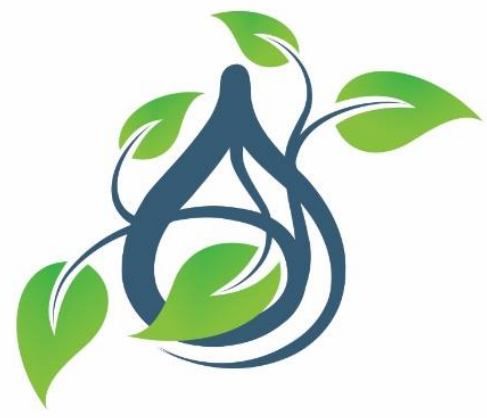

Ni škodljiv za ljudi,

čebele in druge koristne živali.

Ne onesnažuje okolja.

\section{NI KARENCE.}

$\checkmark$ veliki meri zmanjšuje uporabo kemičnih zaščitnih sredstev.

Cenovno ugodno. 

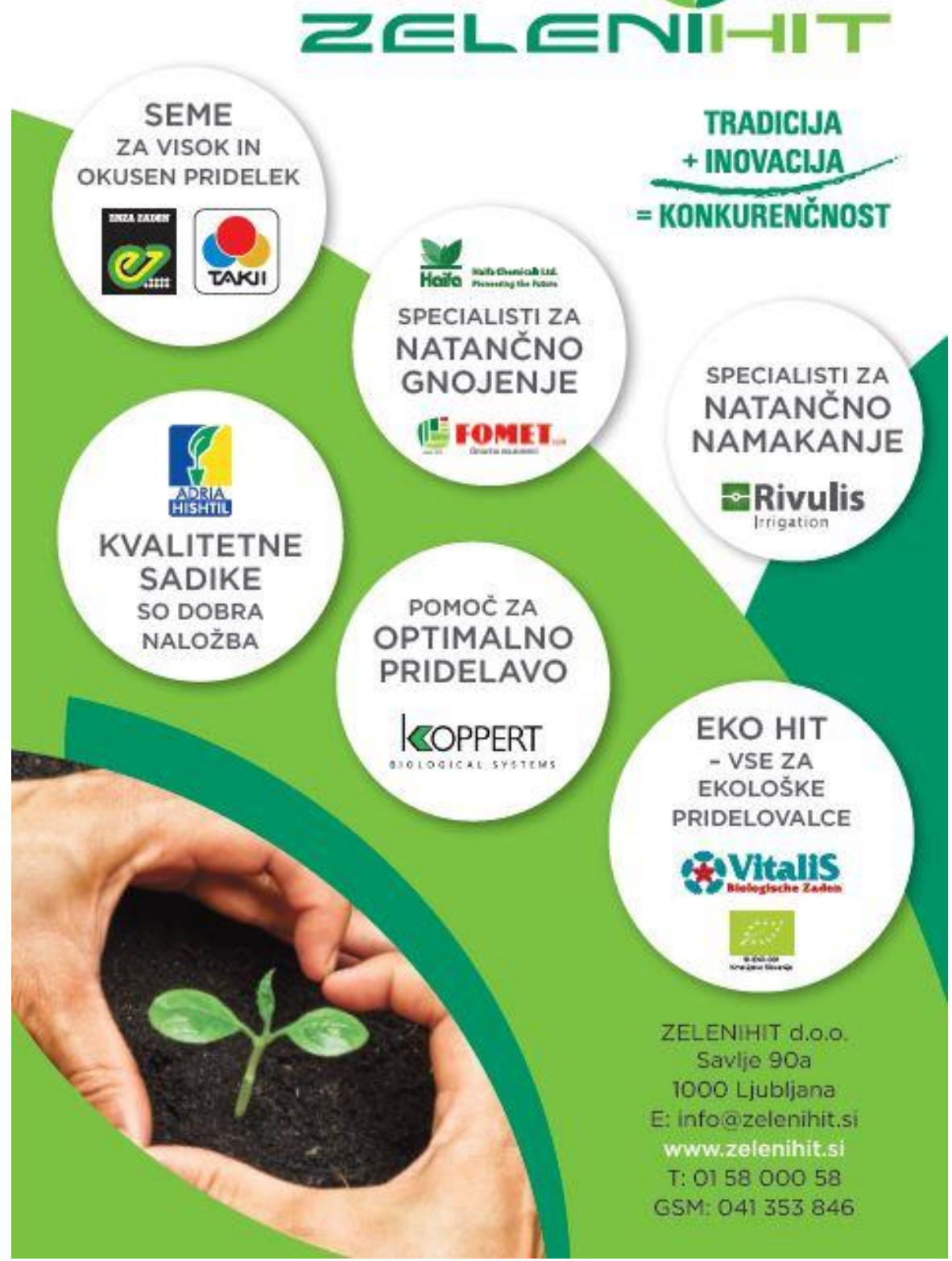


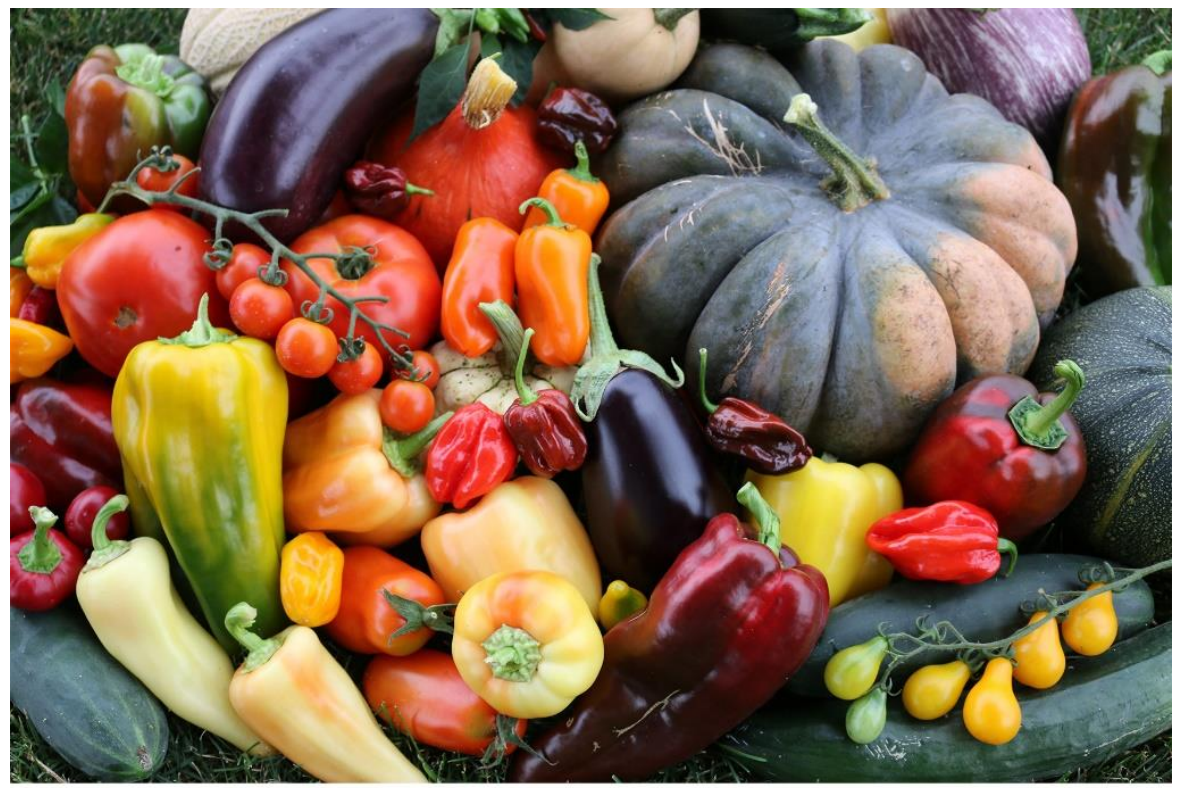

\section{Domače sadike za domači vrt}

Smo družinski proizvodni obrat iz okolice Ljutomera, ki že 25 let proizvajamo sadike zelenjadnic, začimbnic in jagod.

Sadike lahko najdete $v$ bolje založenih vrtnih centrih in trgovinah po vsej Sloveniji.

Celotno ponudbo in sebi najbližjega trgovca najdete na:

www.cornus.si

Pozdrav iz Prlekije.
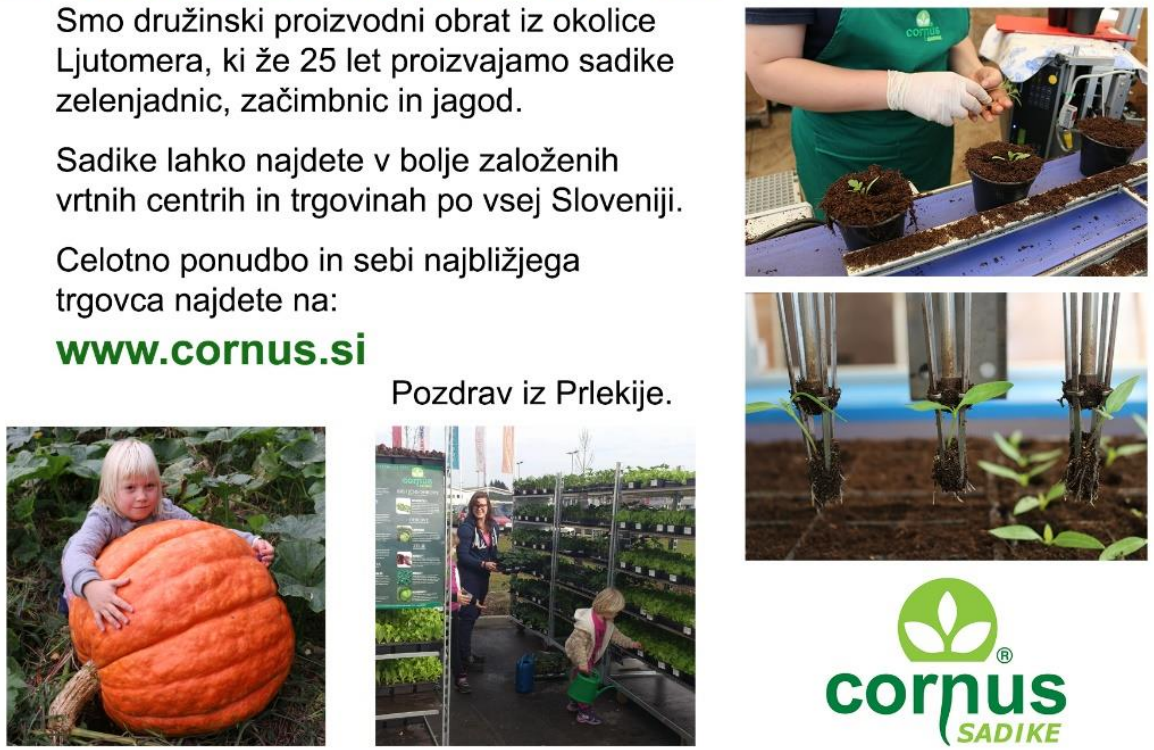